\title{
ipen
}

AUTARQUIA ASSOCIADA À UNIVERSIDADE DE SÃO PAULO

\section{AVALIAÇÃO DO ZINCO PLASMÁTICO NOS PACIENTES IDOSOS NO HOSPITAL REGIONAL DE ARAGUAÍNA, TOCANTINS}

\author{
Luis Fernando D'Albuquerque e Castro
}

\begin{abstract}
Dissertação apresentada como parte dos requisitos para obtenção do Grau de Mestre em Ciências na Área de Tecnologia Nuclear - Materiais

Orientadora:
\end{abstract}

Profa. Dra. Maria Ap. Faustino Pires 
INSTITUTO DE PESQUISAS ENERGÉTICAS E NUCLEARES

Autarquia associada à Universidade de São Paulo

AVALIAÇÃO DO ZINCO PLASMÁTICO NOS PACIENTES IDOSOS NO HOSPITAL REGIONAL DE ARAGUAÍNA, TOCANTINS

Luis Fernando D'Albuquerque e Castro

Dissertação apresentada como parte dos requisitos para obtenção do Grau de Mestre em Ciências na Área de Tecnologia Nuclear- Materiais

Orientadora:

Profa. Dra. Maria Aparecida Faustino Pires

São Paulo

2011 
Dedicatória

Dedico este trabalho à minha família 


\section{AGRADECIMENTOS}

Agradeço em especial à minha orientadora, aos pacientes que colaboraram na pesquisa, aos alunos Eliseu e Fernando pela colaboração no levantamento dos dados e à Valéria pelo companheirismo e força

Agradeço ao Instituto Pesquisas Energéticas e Nucleares, Fundação Medicina Tropical / To, Hospital Regional de Araguaína e Laboratório Analisys por viabilizar o desenvolvimento desta pesquisa 
RESUMO

\section{AVALIAÇÃO DO ZINCO PLAMÁTICO NOS PACIENTES IDOSOS NO HOSPITAL REGIONAL DE ARAGUAINA, TOCANTINS}

\section{Luís Fernando de D'Albuquerque e Castro}

Zinco é um importante micronutriente, participa de várias enzimas e tem papel fundamental na atividade imunológica. Com o objetivo de avaliar a deficiência de zinco nos idosos foi dosado o zinco plasmático em 88 pacientes com mais de 65 anos admitidos na Emergência do Hospital Regional de Araguaina, TO. Foram analisados: raça, gênero, medidas antropométricas, dosagem da hemoglobina, albumina, contagem de linfócitos, dosagem da proteína $C$ reativa e tempo de permanência. Os resultados sugerem que ocorre deficiência de zinco mais acentuada no sexo feminino e que pacientes com deficiência de zinco também apresentam menores valores de índice de massa corpórea (IMC), hemoglobina, albumina e contagem de linfócitos. Não se observou maior incidência de infecção no grupo com deficiência de zinco, porém o grupo apresentou maior tempo de permanência hospitalar.

Palavras-chave: zinco; deficiência de zinco; infecção; desnutrição; imunodeficiência 


\begin{abstract}
EVALUATION OF ZINC IN PLASMA SAMPLES COLLECTED FROM AGED PACIENTS ADMITTED IN THE REGIONAL HOSPITAL OF ARAGUAINA CITY, TOCANTINS
\end{abstract}

\title{
LUÍS FERNANDO DE D'ALBURQUERQUE E CASTRO
}

Zinc is an important micronutrient that plays a role in many enzymatic and immune system activities in human body. Considering this, the goal of this work is to evaluate zinc deficiency in elderly patients. A total of 88 volunteers with more than 65 years old, admitted at ER from Regional Hospital, were monitored and zinc concentration was dosed in their plasma. The sampling volunteers were evaluated according to: race, gender, anthropometric measurements, hemoglobin, albumin, total lymphocyte count, C-reactive protein dosage and length of stay. The results suggest that zinc deficiency is more pronounced in females and patients with zinc deficiency also show lower values of body mass index (BMI), hemoglobin, albumin and lymphocyte count. There was no increased incidence of infection in the group with zinc deficiency, but the group had a longer hospital stay.

Keywords: zinc, zinc deficiency, infection, malnutrition, immunodeficiency. 


\section{SUMÁRIO}

1 INTRODUÇÃO

2 OBJETIVO

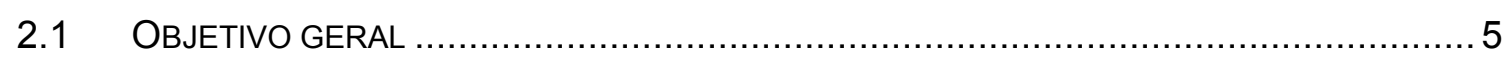

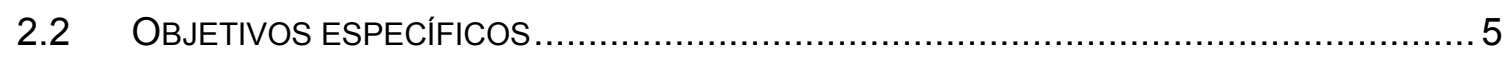

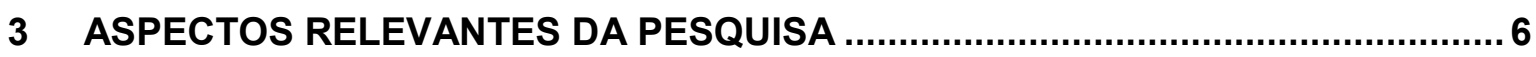

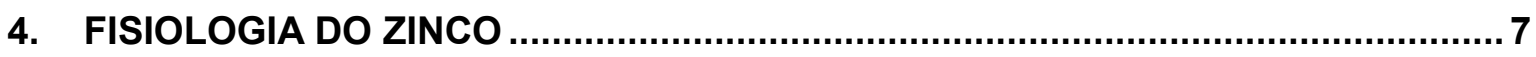

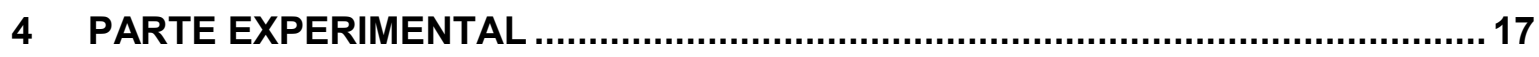

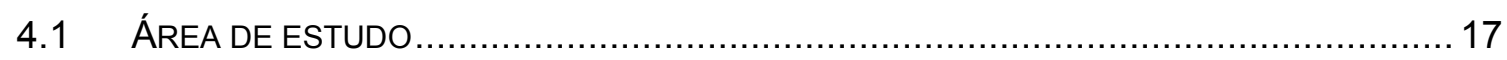

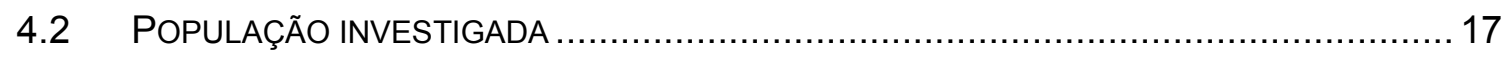

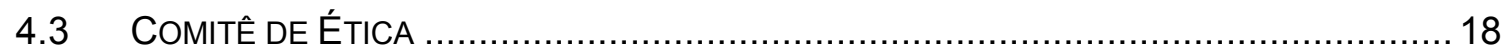

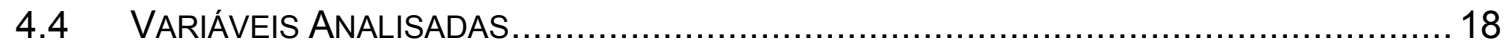

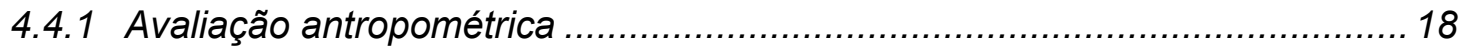

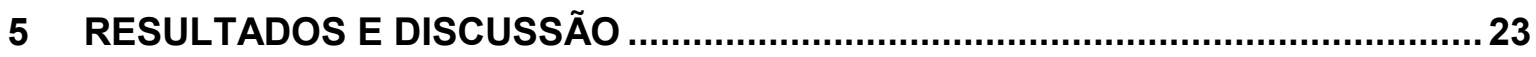

6 CONCLUSÃO

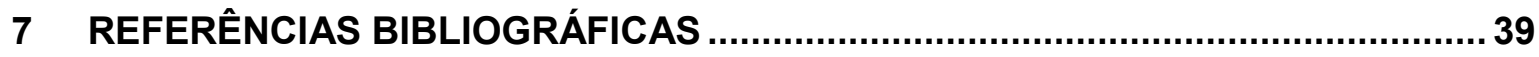

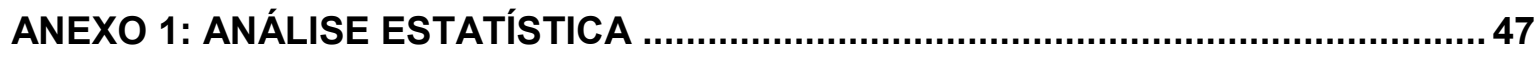

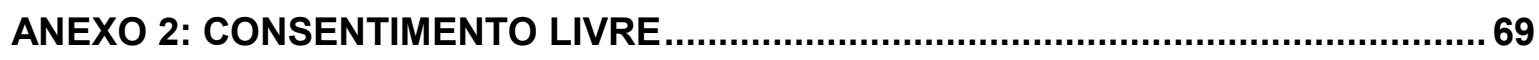

ANEXO 3: COMITÊ DE ÉTICA EM PESQUISA ……………....................................70

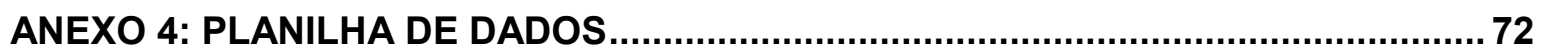




\section{LISTA DE TABELAS}

TABELA 1: Alterações do sistema imune observados nos idoso e na deficiência de zinco

TABELA 2: Recomendação de ingestão diária de zinco............................................. 07

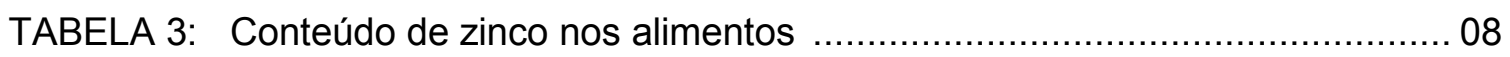

TABELA 4: Manifestações clínicas da deficiência de zinco ........................................... 14

TABELA 5: Fórmula para cálculo do peso do idoso acamado ..................................... 19

TABELA 6: Fórmula para cálculo da altura do idoso acamado ................................... 19

TABELA 7: Classificação do estado nutricional do idoso............................................ 19

TABELA 8 Parâmetros clínicos e laboratoriais avaliados e métodos de análise ou

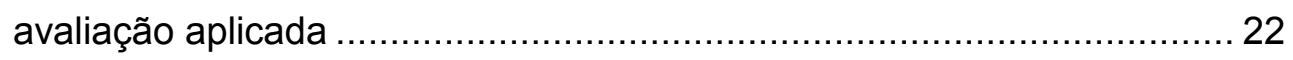

TABELA 9: Demografia, características clínicas e bioquímicas dos pacientes ........... 24

TABELA 10: Dosagem do zinco plasmático no grupo estudado ................................... 24

TABELA 11: Relação concentração do zinco plasmático e valor da albumina

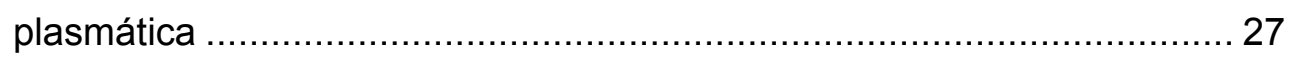

TABELA 12: Relação entre zinco plasmático e hemoglobina no sangue....................... 29

TABELA 13: Relação entre zinco plasmático e IMC ………........................................... 30

TABELA 14: Relação entre zinco plasmático e contagem de linfócitos no sangue ........ 33

TABELA 15: Relação entre zinco plasmático e proteína C reativa …………………...... 35

TABELA 16: Relação entre zinco plasmático com presença de infeç̧ão na

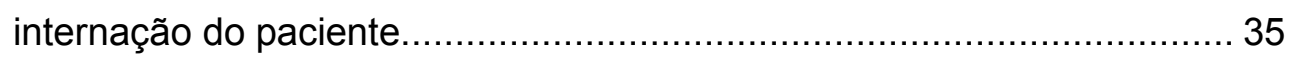

TABELA 17: Relação entre zinco plasmático com o tempo de internação hospitalar ... 36

TABELA 18: Relação entre o zinco plasmático com o tipo de alta da população estudada 


\section{LISTA DE FIGURAS}

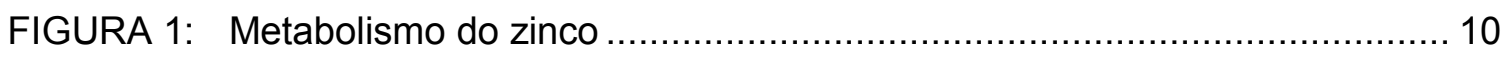

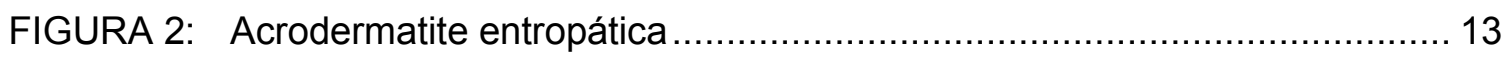

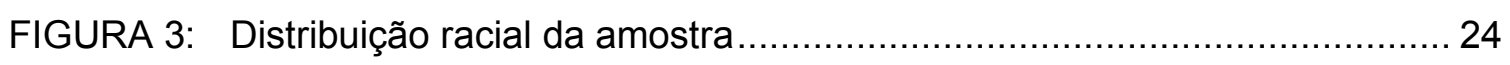

FIGURA 4: Distribuição do valor médio do zinco plasmático por sexo ....................... 26

FIGURA 5: Comparação entre os valores médios de zinco entre a população com zinco diminuído e normal

FIGURA 6: Comparação dos valores médios de albumina plasmática entre os grupos de pacientes com zinco diminuído e normal ............................. 28

FIGURA 7: Comparação dos valores médios de hemoglobina no sangue entre os pacientes com zinco diminuído e normal ........................................... 30

FIGURA 8: Comparação dos valores médios de IMC entre os grupos de pacientes com zinco diminuído e normal

FIGURA 9: Valores medianos de $\mathrm{Hb}$, albumina e IMC no grupo de pacientes com zinco plasmático abaixo do valor normal.

FIGURA 10: Valores medianos de $\mathrm{Hb}$, albumina e IMC no grupo de pacientes com zinco plasmático considerado normal

FIGURA 11: Comparação dos valores médios de contagem de linfócitos no sangue entre os grupos de zinco diminuído e normal. 


\section{GLOSSÁRIO}

Metaloproteinas - proteínas que contem um ou mais íons metálicos

Transferrina - proteína plasmática que transporta o ferro

Linfócito T - linfócito timo dependente

Linfócito Killer - linfócito timo dependente com propriedade esterminadora

CD4/CD8 - linfócito T com receptores na superfície do complexo de histocompatibilidade, o linfócito CD4 tem atividade auxiliadora e o CD8 citotóxica

Interleucina - proteínas produzidas por linfócitos e macrófagos com finalidade de ativar as células de defesa

Célula T Helper - São os intermediários da resposta imunitária que proliferam após o contato com o antígeno para ativar outros tipos de células que agirão de maneira mais directa. Existem 2 subtipos conhecidos de linfócitos T auxiliares: Th1 e Th2.

Fâneros - pêlos e unhas

Enterócito - célula epitelial de revestimento do trato digestivo

Metalotioneina - uma proteína de baixo peso molecular (aproximadamente $10 \mathrm{kD}$ ) presente no citoplasma do córtex renal e fígado. É rica em resíduos cisteína e não contém aminoácidos aromáticos. A metalotioneína demonstra alta afinidade por metais pesados bivalentes.

Nanismo - condição de tamanho de um indivíduo cuja altura é muito menor que a média de todos os sujeitos que pertencem à mesma população

Hipogonadismo - defeito no sistema reprodutor que resulta na diminuição da função das gônadas (ovários ou testículos)

Hepatoesplenomegalia - aumento do fígado e baço

Letargia - sonolência mórbida

Geofagia - é uma prática de comer substâncias terrestres (como argila), frequentemente para melhorar uma nutrição deficiente em minerais.

Alopécia - é a redução parcial ou total de pêlos ou cabelos em uma determinada área de pele

Espermatogênese - produção de espermatozóides

Bronquite Crônica - inflamação crônica da mucosa brônquica ocasionado na maioria das vezes pelo tabagismo

Enfisema Pulmonar - destruição dos septos alveolares com aumento dos espaços alveolares e fibrose pulmonar

Fração de Ejeção - percentual do volume sistólico do coração em relação ao volume do ventrículo

Poliúria - aumento da produção de urina 


\section{INTRODUÇÃO}

O organismo humano depende de alguns minerais presentes em pequena quantidade, menores do que $0,01 \%$ da composição corporal, denominados de elementos-traço. Dos elementos-traço, nove são considerados essenciais: zinco, ferro, cobre, cromo, cobalto, molibdênio, selênio, iodo e manganês (Hambidge, 2003).

O zinco faz parte do grupo IIB da tabela periódica, seu número atômico é 30 e sua massa atômica 65,380. Presente em pequena quantidade no organismo humano representa $0,003 \%$ do corpo $(1,4$ a $2,3 \mathrm{~g})$. É considerado o segundo elemento-traço de maior prevalência no organismo (Person, 2006). Está presente em maior quantidade no interior das células, sendo $40 \%$ no núcleo e $50 \%$ nas organelas do citoplasma e o restante nas membranas celulares (Stefanidou, 2006). Os órgãos com maior teor de zinco são: músculo (57\%), osso $(29 \%)$, pele $(6 \%)$, fígado $(5 \%)$ e cérebro com 1,5\% (King, 2000). Uma pequena quantidade está disponível no plasma transportado pela $\alpha_{2}$-macroglobulina e transferrina, porém só o íon livre é biologicamente ativo (Rink, 2000).

O zinco possui duas propriedades que merecem destaque. Em primeiro lugar, diferente de outros metais, o zinco é virtualmente atóxico. Os mecanismos de homeostase que regulam seu metabolismo desde absorção até distribuição e excreção das células e tecidos são tão eficientes que não são conhecidas desordens associadas com seu acúmulo. Em segundo lugar, suas propriedades químicas e físicas, incluindo sua facilidade de ligação estável com macromoléculas e sua flexibilidade que o faz altamente adaptável a se associar com diversas proteínas e enzimas de importantes funções biológicas (Okigami, 1996). 
O zinco é componente estrutural e funcional de diversas metaloenzimas e metaloproteínas, participa de reações do metabolismo celular e de importantes processos fisiológicos, tais como função imune, defesa antioxidante, crescimento e desenvolvimento. Enzimas como a anidrase carbônica dos eritrócitos, a carboxipeptidase, álcool-desidrogenase, fosfatase alcalina, superóxido dismutase e ARN e ADN polimerase contém zinco. O zinco mantém as relações espaciais e configurações necessárias para a ação destas enzimas auxiliando na ligação com substratos (Valle, 1993).

O sistema imunológico necessita do zinco. A timomodulina é um hormônio derivado do timo e importante na maturação e diferenciação dos linfócitos T, cuja atividade biológica depende desse elemento. Sua deficiência está associada com atrofia do timo (Rink, 2000). O mecanismo pelo qual o zinco interfere na resposta imunológica pode ser explicado pelas seguintes ações que o zinco tem sobre o tecido imunológico (Dardenne, 2002):

- O zinco é essencial para as enzimas: DNA polimerase, RNA polimerase e Timidinaquinase todas envolvidas na síntese de ácidos nucléicos.

- O zinco é necessário para a ação da timomodulina - proteína importante no processo de diferenciação e ativação dos linfócitos T.

- O zinco contribui para a estabilização das membranas plasmáticas melhorando o processo de fagocitose pelo macrófago.

- O zinco regula a apoptose.

Sendo então fundamental para desenvolvimento normal da imunidade nativa mediada por células, neutrófilos e linfócitos Killer naturais.

Após 12 semanas de dieta com baixo teor de zinco, voluntários humanos desenvolveram diminuição da timomodulina, diminuição da taxa de CD4+/CD8+, diminuição da interleucina 2 e atividade lítica da célula natural Killer. Todas essas alterações foram prontamente corrigidas com reposição de zinco (Prasad, 2009). 
ingestão alimentar diminui com a idade, mesmo em países desenvolvidos. A redução da secreção ácida do estômago colabora para diminuição da absorção do zinco (Tuerk, 2009). Apesar de alguns estudos sugerirem que a reposição de zinco em pacientes idosos possa proteger o paciente de infecção, os resultados ainda são controversos (Barnett, 2009).

O zinco pode ser dosado no plasma, nas hemácias, nos leucócitos e nos fâneros. A quantidade de proteína no sangue pode influenciar a concentração normal plasmática do zinco, além do mais, o valor sérico pode não refletir a quantidade de zinco no organismo. Em jejum pode ocorrer mobilização do zinco e redução do zinco plasmático (Jeejeebhoy, 2009). No entanto, apesar das críticas é a medida mais comumente empregada. Uma revisão sistemática realizada por esta pesquisa mostrou que em 37 estudos sobre avaliação do zinco no organismo 35 estudos utilizaram a dosagem plasmática, sendo que 15 estudos avaliaram apenas o zinco plasmático (Lowe, 2009). A necessidade diária de zinco é estimada em 15 mg.dia ${ }^{-1}$ (Stefanidou, 2006).

Considerando a deficiência de zinco um problema de saúde na população idosa que pode influenciar a história natural do processo de envelhecimento, há necessidade de estudar a prevalência de hipozincemia no idoso.

O objetivo da pesquisa não incluiu identificar a causa de deficiência de zinco. 


\section{OBJETIVO}

\section{$2.1 \quad$ Objetivo geral}

- Analisar a prevalência da deficiência de zinco nos pacientes idosos internados no Hospital de Referência de Araguaína, Tocantins.

\subsection{Objetivos específicos}

- Interpretar do ponto de vista clínico fatores que podem estar associados à deficiência de zinco

- Esclarecer algumas questões relacionadas com o metabolismo do zinco:

a) A internação hospitalar pode ser influenciada pela deficiência de zinco.

b) A desnutrição aguda pode estar associada com deficiência de zinco.

c) A deficiência de zinco pode alterar a resposta inflamatória.

d) A deficiência de zinco pode influenciar na contagem de linfócitos periféricos.

e) A deficiência de zinco no idoso pode estar relacionada com maior índice de infecção. 


\section{ASPECTOS RELEVANTES DA PESQUISA}

Podem ser enumerados como aspectos importantes deste estudo:

- Estabelecer padrões de referência da população da região norte relativo à concentração de Zinco plasmático;

- Conhecer as características da população idosa internada no Hospital Regional de Araguaína, TO;

- Ampliar e melhorar as informações existentes voltadas para o cenário regional fundamentado na observação clínica da amostra de pacientes;

- Avaliar a influência da deficiência de zinco no processo de envelhecimento;

- Avaliar a importância de reposição de zinco durante a internação hospitalar.

Este estudo está inserido dentro de um projeto de caráter regional com a Fundação de Medicina Tropical do Tocantins e o Programa de Pós graduação do IPEN / USP, fazendo parte de um acordo de mútua cooperação técnico científica firmado entre a Comissão Nacional de Energia Nuclear (CNEN) e a Fundação de Medicina Tropical do Tocantins (FMT) nº 01342001545/2006-29. 


\section{FISIOLOGIA DO ZINCO}

As necessidades diárias de zinco variam com a idade, sexo e períodos de gestação e amamentação. A tabela 2 mostra os valores das necessidades básicas de ingestão de zinco de acordo com a "Food and Nutrition Board" (2004).

Tabela 2: Recomendação de Ingestão Diária de Zinco (Food and Nutrition Board, 2004).

\begin{tabular}{|c|c|c|c|c|c|}
\hline & \multicolumn{4}{|c|}{$\begin{array}{l}\text { Recomendação de Ingestão Diária de Zinco } \\
\qquad\left(\mathrm{mg}^{\text {dia }}{ }^{-1}\right)\end{array}$} & \multirow[b]{2}{*}{ Amamentação } \\
\hline & Criança & Homem & Mulher & Grávida & \\
\hline 0 a 6 meses & 2 & & & & \\
\hline 7 a 12 meses & 3 & & & & \\
\hline 9 a 13 anos & & 8 & & & \\
\hline 14 ou mais & & 11 & & & \\
\hline 9 a 13 anos & & & 8 & & \\
\hline 14 a 18 anos & & & 9 & & \\
\hline 19 ou mais & & & 8 & & \\
\hline 14 a 18 anos & & & & 12 & \\
\hline 19 a 50 anos & & & & 11 & \\
\hline 14 a 18 anos & & & & & 13 \\
\hline 19 a 50 anos & & & & & 12 \\
\hline
\end{tabular}

O zinco esta presente em vários alimentos (Tabela 3). A carne vermelha magra é uma importante fonte de zinco altamente biodisponível. Muitos alimentos básicos fornecem quantidades significativas de zinco, como o arroz e o feijão, mariscos, ostras, carnes vermelhas, fígado, ovos, peixe e aves são considerados as melhores fontes de zinco. Nozes e leguminosas são consideradas fontes relativamente boas, contudo vegetais e frutas são fontes modestas. Cerca de $80 \%$ do zinco fornecido pela dieta advêm do consumo de 
alimentos de origem animal, e estes são também os que apresentam maior biodisponibilidade deste elemento.

Tabela 3: Conteúdo de Zinco nos Alimentos (Salgueiro, 2000 adaptado por Castro, LFA).

\begin{tabular}{cc}
\hline Alimentos & $\begin{array}{c}\text { Concentração de Zinco para cada } \mathbf{1 0 0} \text { g de alimento } \\
(\mathbf{m g} \%)\end{array}$ \\
\hline Trigo & 10,00 \\
\hline Fígado & 5,10 \\
\hline Carne & 3,20 \\
\hline Amendoim & 2,00 a 3,00 \\
\hline Milho & 2,50 \\
\hline Chocolate & 1,00 a 2,00 \\
\hline Peixe e Marisco & 1,50 \\
\hline Cebola & 1,40 \\
\hline Ovo & 1,35 \\
\hline Centeio & 1,30 \\
\hline Cerais & 0,50 \\
\hline
\end{tabular}

Proteína de origem animal facilita a absorção de zinco no organismo, que ocorre principalmente no duodeno e jejuno de forma ativa e passiva (Person, 2006). O zinco é eliminado principalmente nas fezes e uma pequena quantidade na urina. A capacidade do organismo de absorver mais ou menos zinco, e da mesma forma eliminar maior ou menor quantidade, está diretamente relacionada com o estoque de zinco no organismo. Assim, o homem adulto pode variar a quantidade de zinco na alimentação sem provocar grandes variações na quantidade de zinco no organismo (Krebs, 2000).

Muitos fatores da dieta foram identificados a partir de estudos experimentais como promotores ou antagonistas da absorção de zinco (Lönnerdal, 2000). Substâncias orgânicas solúveis, de baixo peso molecular, tais como aminoácidos e hidroxiácidos, agem como ligantes que unem o zinco e facilitam a sua absorção. As interações competitivas que envolvem o zinco e concentrações excessivas de outros íons com propriedades físico-químicas semelhantes, por exemplo, o cádmio (considerado extremamente tóxico), pode 
restringir a captura e transporte intestinal de zinco, portanto sua absorção. O ferro, se fornecido junto com o zinco através de suplemento pode ter efeito negativo na sua absorção. O cálcio é outro mineral que reduz a absorção do zinco.

Ácido fítico (mio-inositol hexafosfato) ou fitato é o inibidor mais potente da absorção do zinco. Os fitatos, presentes nos farelos, nas leguminosas, em cereais de grãos integrais e em quantidades menores em outros vegetais, têm um forte potencial para ligar cátions bivalentes, tais como o zinco. Felizmente, durante diversos procedimentos de preparo, tais como a fermentação e a cocção com água, a fitase presente nos grãos hidrolisa parcialmente o fitato em penta, tetra ou análogos fosforilados menores do ácido fítico, que tem capacidade reduzida de ligação aos minerais. O processo de fermentação do pão destrói o fitato. Altas concentrações de cálcio exacerbam o efeito inibidor do fitato na absorção do zinco formando um complexo cálcio-fitato-zinco no intestino, que é menos solúvel do que complexos de fitatos formados com outros íons. Outros componentes da dieta inibem a biodisponibilidade do zinco, entre estes a quantidade e tipo de fibras ingeridas. Alguns estudos indicam que em dietas com baixa ingestão de proteínas, as fibras (celulose e lignina) exacerbam o efeito adverso dos fitatos na absorção do zinco (Lönnerdal, 2000).

A absorção do zinco ocorre através da fixação no receptor e captação pelo enterócito. Zinco é absorvido em todo intestino delgado, o jejuno é o local de absorção máxima comparado com o duodeno e o íleo, o cólon não desempenha papel relevante. Albumina e alfa-2-globulina transportam o zinco para o fígado, o restante é ligado à metalotioneina que impede a transferência para o sangue. A produção de metalotioneina pelo enterócito regula a absorção do zinco, a diminuição da produção aumenta a absorção (Jeejeebhoy, 2009). A partir do fígado o zinco é distribuído para os demais tecidos de acordo com a demanda dos processos bioquímicos (Figura 1).

Diversos sistemas biológicos contribuem para a homeostase do zinco sob diferentes condições, porém o sistema gastrointestinal, especialmente o intestino delgado, fígado e pâncreas desempenham as funções decisivas neste 
processo. A captação do zinco pela superfície da borda em escova é regulada homeostaticamente por mecanismos de difusão e processos mediados por carreadores. Em situações de baixa ingestão, ocorre aumento da capacidade de transporte de carreadores, e diante da alta ingestão alimentar, ocorre um mecanismo de difusão passiva, sem saturação (Lee, 1989).

A excreção de zinco ocorre predominantemente através do sistema gastrointestinal, sendo que menores quantidades são eliminadas através da pele e urina.

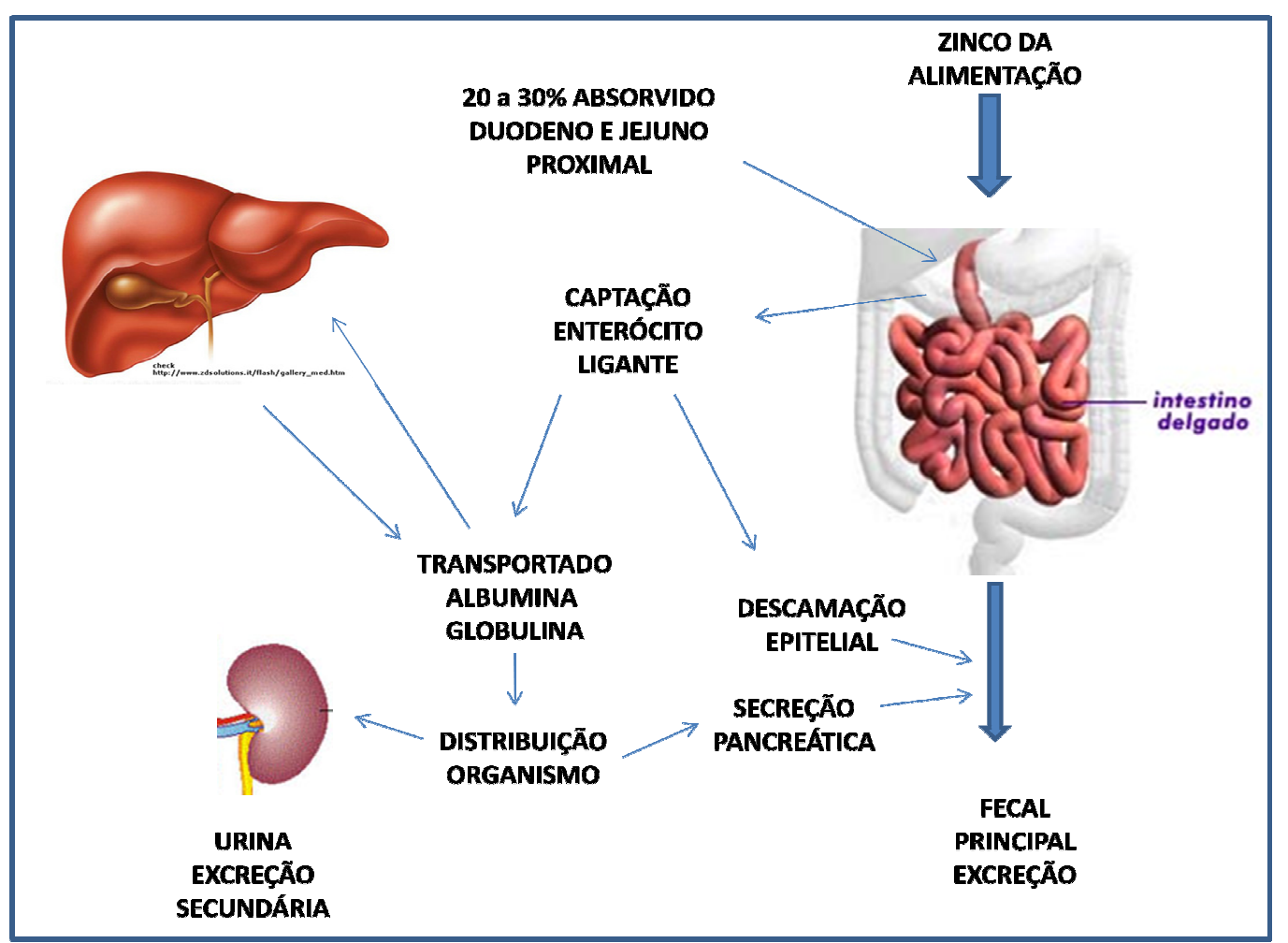

FIGURA 1: Metabolismo do zinco. De 20 a 30\% do zinco da alimentação é absorvido ativamente por meio de receptores. Transportado ligado à proteína é armazenado no fígado e distribuído ao organismo. A principal via de excreção do zinco é através das fezes, pela descamação dos enterócitos e secreção pancreática. Menor quantidade pode ser eliminada pelo rim e suor.

No pâncreas a insulina formada como uma cadeia única de aminoácidos envolvida em si mesma denominada de próinsulina é dependente de zinco para sua estocagem e liberação, quando a cadeia perde o "peptídeo C" e libera na corrente sanguínea a cadeia alfa e beta, interligadas por duas pontes dissulfidricas (Chausmer, 1998). 
A próstata é um órgão rico em zinco, o que sugere que a potência sexual masculina e o desejo sexual estejam relacionados com o zinco. Em homens portadores de insuficiência renal terminal em programa dialítico foi observado que o grupo com reposição de zinco apresentou melhor desempenho sexual em comparação ao grupo placebo (Mahajan, 1982).

Zinco está presente na gustina, um polipeptídeo salivar necessário ao desenvolvimento normal das papilas gustativas, portanto este pode ser o motivo da hipogeusia encontrada em pessoas com hipozincemia (Sandstead, 2000). Mahajan 1982, também observou que o grupo de pacientes renais crônicos com deficiência de zinco apresentava dificuldade para sentir o paladar e a reposição de zinco melhorou o sabor da alimentação.

O zinco é necessário para o crescimento e diferenciação celular, para a síntese de DNA, desenvolvimento normal do feto, da criança, da resposta imune e cicatrização dos tecidos (Hambidge, 2000). A mulher grávida com deficiência de zinco pode apresentar aborto espontâneo, malformação congênita, parto prematuro e criança de baixo peso (Chandyo, 2009).

A resposta imunológica está intimamente relacionada com o zinco, além do papel sobre o timo, é fundamental na produção inteleucina 1 e 2, assim como a atividade do linfócito T-Helper, macrófagos, neutrófilos e linfócitos natural Killer. Em indivíduos com deficiência de zinco observa-se menor resposta dos linfócitos a estímulos específicos (fitohemaglutininas) (Prasad, 1998).

Entre a defesa enzimática contra o estresse oxidativo a enzima superóxido dismutase contém zinco no seu sítio ativo e desempenha papel importante na prevenção da formação de radicais livres. A participação do zinco no sistema de proteção antioxidante é evidenciada por meio de estudos in vivo, os quais demonstram que a deficiência de zinco provoca lesões oxidativas relacionadas à ação de espécies reativas de oxigênio em animais e em humanos, e por meio de estudos in vitro, os quais demonstram o antagonismo do zinco à formação de radicais livres em modelos bioquímicos e celulares (Koury, 2003). 
O papel exato do zinco como antioxidante não foi ainda elucidado, mas as evidências disponíveis indicam ação desse mineral envolvendo vários mecanismos. Esses mecanismos incluem a regulação da expressão de metalotioneína, a atividade da enzima superóxido dismutase e a proteção de grupamentos sulfidrila de proteínas de membranas celulares por antagonismo com metais pró-oxidantes como cobre e ferro. A ação antioxidante desse mineral é indireta, uma vez que o íon zinco não é ativo em reações de óxido-redução (Koury, 2003).

Apesar do conhecimento há vários anos da importância do zinco na vida das plantas e microorganismos, a primeira descrição de um caso de deficiência de zinco ocorreu em 1958 após a observação de um jovem Iraniano, de 21 anos, apresentando nanismo, hipogonadismo, hepatoesplenomegalia, pele seca e áspera, letargia, geofagia e anemia por deficiência de ferro. Sua ingestão de proteínas era insignificante, alimentando-se a base de pão não fermentado (rico em fitato que inibe a absorção do zinco e ferro). A deficiência de zinco foi postulada para o caso devido ao fato da deficiência de ferro não explicar todos os sintomas e além do mais, baseado em observações em animais há relação entre zinco e hipogonadismo (Prasad, 2003).

Em 1973 foi descrito uma doença genética fatal, denominada de "acrodermatite enteropática" (Barnes, 1973) que melhora com a administração de zinco. Hoje, sabe-se que a doença está relacionada a um defeito na absorção do zinco (Figura 2). Esses fatos levaram o Conselho de Nutrição e Alimentação da Academia Nacional de Ciências dos Estados Unidos a declarar, em 1974, o zinco como nutriente essencial (Prasad, 1996). No entanto, passados todos esses anos entidades como a Organização Mundial da Saúde (OMS), Organização das Nações Unidas para Agricultura e Alimentação (FAO), Fundo das Nações Unidas para a Infância (UNICEF), Organização das Nações Unidas para a Educação, a Ciência e a Cultura (UNESCO), Agência Americana para o Desenvolvimento Internacional (US AID), e, governantes de países com prevalência de deficiência de zinco não tomaram medidas para mudar a situação (Prasad, 1998). 
Posteriormente, nas unidades de terapia intensiva, principalmente naqueles pacientes submetidos à nutrição parenteral prolongada sem adição de zinco observaram-se manifestações cutâneas que regrediram com a reposição de zinco (Grant, 1980). Inúmeras pesquisas mostraram a importância do zinco em várias condições clínicas, inclusive evidenciando a possibilidade da deficiência de zinco em países desenvolvidos com alimentação rica em cereais (Prasad, 1996).
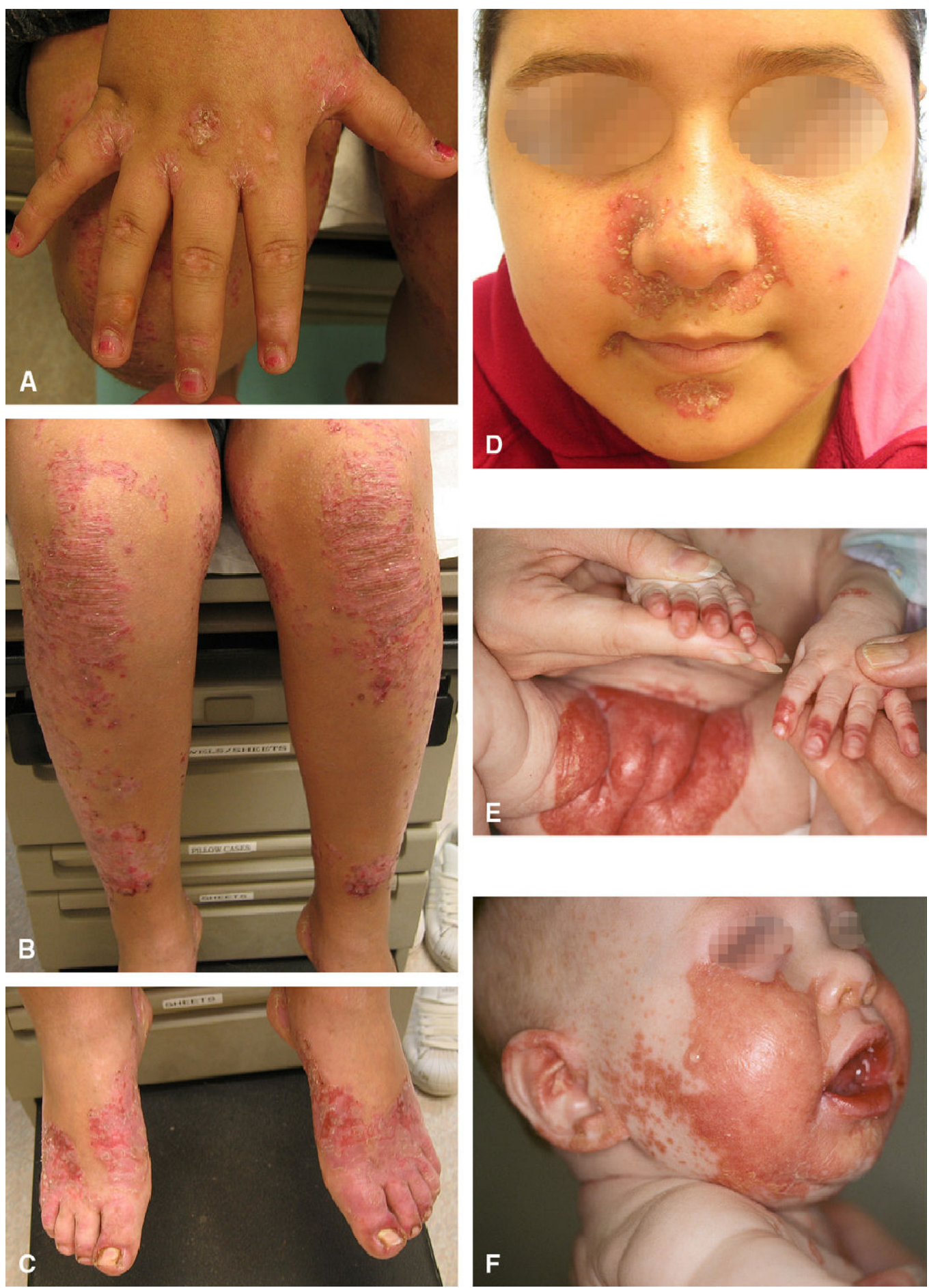

FIGURA 2: Acrodermatite enteropática (Maverakis 2007). 
Os estudos sobre deficiência de zinco nos últimos anos têm mostrado a relação entre zinco e imunodeficiência (Rink, 2000). Pacientes com deficiência discreta de zinco apresentam diminuição da imunidade, diminuição do olfato e paladar, cegueira noturna, perda da memória e diminuição da espermatogênese, enquanto que pacientes com deficiência severa apresentam grave deficiência imunológica, infecções freqüentes, dermatite pustular bolhosa, diarréia, alopecia e distúrbio mental (Shankar, 1998) (Tabela 4)

Tabela 4: Manifestações Clínicas da Deficiência de Zinco (Shankar, 1998).

\begin{tabular}{ll}
\hline \multicolumn{1}{c}{ Manifestações Clínicas da Deficiência de Zinco } \\
\hline Deficiência Discreta & \multicolumn{1}{c}{ Deficiência Severa } \\
\hline Diminuição da Imunidade & Deficiência Imunológica Severa \\
Diminuição do Olfato & Infecções Freqüentes \\
Diminuição do Paladar & Dermatite Pustular Bolhosa \\
Cegueira Noturna & Diarréia \\
Perda da Memória & Alopécia \\
Diminuição da Espermatogênese & Distúrbio Mental \\
\hline
\end{tabular}

Estudo controlado do tipo duplo cego randomizado com reposição de zinco em crianças com diarréia aguda resultou em redução importante da duração e severidade da diarréia (Sazawal, 1995).

Pacientes portadores de cirrose hepática de origem alcoólica ou viral apresentam hipozincemia, que se relaciona com a gravidade da insuficiência hepática (Goode, 1990; Barry, 1990). Estudo em animais com reposição de zinco inibiu a formação de fibrose hepática na cirrose induzida por thioacetamida (Dashti, 1997).

Lira (1998) em pesquisa realizada no nordeste brasileiro com crianças de baixo peso observou que reposição de $5 \mathrm{mg}$ de zinco diariamente por um período de 26 semanas diminuiu em 28\% a prevalência de diarréia, e 33\% a prevalência de tosse, comparado com o grupo placebo. O grupo que recebeu reposição de zinco apresentou maior ganho de peso. 
Pacientes desnutridos apresentam diarréia com mais freqüência o que pode dificultar a absorção de zinco e comprometer a resposta imunológica, predispondo à infecção intestinal (Wapnir, 2000). A reposição de zinco durante a diarréia melhora o quadro do paciente (Hambidge, 2000).

Um estudo de meta-análise de 33 pesquisas de intervenção prospectiva com reposição de zinco em crianças revelou efeito estatístico significante no crescimento e ganho de peso (Brown, 2002).

Estudos revelam que pacientes portadores de tuberculose acompanhada de desnutrição apresentam deficiência de zinco (Ray, 1998; van Lettow, 2004; Karyadi, 2000), porém não há conhecimento se a deficiência de zinco predispõe à tuberculose. Karyadi (2002) observou que a reposição de zinco em pacientes com tuberculose resultou em negativação do escarro mais precocemente.

Tabagistas podem desenvolver doença pulmonar obstrutiva crônica após grande período de exposição. Ocorre processo inflamatório nas vias aéreas e parênquima pulmonar determinando bronquite crônica e enfisema pulmonar. Dentre os mediadores da inflamação observa-se a presença de radicais livres e atividade oxidativa. Estudo realizado, com pacientes portadores de doença pulmonar obstrutiva crônica observou níveis reduzido de zinco, sendo mais acentuado naqueles com doença mais grave (Karadag, 2004)

Witte (2005) estudando trinta pacientes idosos, idade média de 75 anos, com insuficiência cardíaca com fração de ejeção inferior a $35 \%$ com reposição de micronutrientes, incluindo o zinco, observou melhora da função ventricular.

Al-Maroof (2006) estudando a concentração plasmática do zinco em 133 pacientes diabéticos observou que 82 pacientes (62\%) apresentavam zinco sérico abaixo de $70 \mu \mathrm{g} \mathrm{dL}^{-1}$. Jansen (2009) estudando em modelos animais de diabetes e pesquisa em humanos mostrou que pacientes diabéticos podem apresentar hipozincemia principalmente relacionada com a perda urinária 
associada com a poliúria osmótica da hiperglicemia. Na segunda parte da sua pesquisa Al-Maroof (2006) comparou dois grupos de diabético: o primeiro (50 pacientes) recebeu suplementação de $30 \mathrm{mg}$ de zinco oral por três meses; o segundo grupo (51 pacientes) recebeu placebo. O estudo mostra que o grupo que recebeu suplementação de zinco apresentou melhor controle da glicemia.

Estudo realizado com pacientes com estado gripal utilizando pastilhas de gluconato de zinco, comparado com grupo controle, observou que $90 \%$ dos pacientes do grupo de reposição de zinco apresentou melhora dos sintomas, enquanto $49 \%$ dos pacientes do grupo controle apresentaram melhora (Eby, 1984). Alguns autores recomendam zinco para o tratamento do resfriado comum (Rink, 2000; Kurugöl, 2006). No entanto, pesquisas mais recente questionam esse benefício e argumentam o efeito colateral com o uso tópicos de spray nasal ou gel nasal causando anosmia (Caruso, 2007; Marshall, 2007).

Pacientes portadores de doença gastrointestinal, como doença inflamatória intestinal, refluxo gastroesofágico, síndrome cólon irritável, apresentam deficiência de zinco e a administração de zinco é acompanhada de melhora clínica relacionada com a atividade antinflamatória do zinco (Faa, 2008).

Pacientes portadores de HIV com infecções oportunistas quando tratados com $45 \mathrm{mg}$ dia $^{-1}$ de zinco associado a zidovudina (AZT) em comparação com pacientes só tratado com AZT, mostraram diminuição em 50\% da ocorrência de infecção oportunista (Mocchegiani, 2000). Em pacientes com queimaduras observa-se que a administração de $36 \mathrm{mg}$ dia $^{-1}$ de zinco, aumenta o zinco na pele e diminui as complicações infecciosas (Jeejeebhoy, 2009). 


\section{PARTE EXPERIMENTAL}

\section{1 Área de estudo}

Foram estudados 88 pacientes com mais de 65 anos internados no Hospital de Referência de Araguaína, localizado na Rua 13 de Maio n. 1336 Centro, Araguaína - TO, no período de 18 meses.

Araguaína é uma cidade localizada no Norte do Tocantins, com uma população, segundo o IBGE (estimativa para 2009) (http://www.ibge.gov.br/cidadesat/topwindow.htm - consultado em 17/08/2010), 119.637 habitantes com 4.457 acima de 65 anos em uma área geográfica de $4000 \mathrm{Km}^{2}$. Araguaína como centro de referência em medicina no norte do estado inclui a macro região entorno com estimativa de mais de um milhão de habitantes (sul do Pará, sul do Maranhão, nordeste de Mato Grosso e oeste da Bahia).

O Hospital Regional de Araguaína com aproximadamente 200 leitos atende exclusivamente paciente do SUS. Reúne diversas especialidades médicas e cirúrgicas para atendimento de pacientes de maior complexidade. Dispõem de pronto-socorro clínico e cirúrgico, centro cirúrgico, centro de terapia intensiva, enfermarias, radioterapia e quimioterapia e ambulatórios. Os pacientes são encaminhados ao pronto-socorro através do SAMU, procura espontânea ou encaminhados de outros municípios.

\subsection{População investigada}

Neste estudo foi realizada uma investigação seccional, epidemiológica, transversal, sendo dosado o teor de zinco plasmático em 106 pacientes internados no pronto-socorro de clínica médica do Hospital de Referência de Araguaína, Tocantins, no período de janeiro de 2009 a junho de 2010. O critério 
de inclusão utilizado para avaliação da população foi: idade igual ou superior a 65 anos, portador de patologia clínica, independente do sexo. O critério de exclusão foi: idade inferior a 65 anos, portador de patologia cirúrgica, estar internado por mais de 48 horas e estar recebendo suplementação de zinco. A exclusão dos pacientes internados por mais de 48 horas foi para eliminar a influência da alimentação do hospital no resultado da dosagem sangüínea do zinco.

\subsection{Comitê de Ética}

Esta pesquisa de caráter prospectivo foi realizada de acordo com as Normas Brasileiras para pesquisas envolvendo seres humanos (1996), e, aprovada pela Comissão de Ética em Pesquisa da Fundação de Medicina Tropical do Governo do Estado do Tocantins Processo número 213 (Anexo 3). Todos os sujeitos da pesquisa assinaram o termo de consentimento Livre e esclarecido de participação no estudo (Anexo 2).

\subsection{Variáveis Analisadas}

Foram avaliados a antropometria, clínica, raça, gênero, idade e exames laboratoriais no Hospital das Clínicas de Araguaina,To para a realização desta pesquisa.

\subsubsection{Avaliação antropométrica}

$\mathrm{Na}$ avaliação antropométrica foram aferidas as medidas de peso, altura, perímetro braquial e a dobra cutânea subescapular. Todas as aferições foram efetuadas pelo grupo de acadêmicos de medicina da Faculdade de Medicina do Instituto Tocantinense - Presidente Antônio Carlos, treinados e supervisionados pelo pesquisador e baseadas nas técnicas habituais de mensuração (Lohman, 1988; Schlickmann Frainer, 2007; WHO, 1995).

Por meio das mensurações realizadas foram obtidos os seguintes parâmetros nutricionais: 


\section{a) Determinação do Índice de Massa Corporal (IMC)}

A medida do peso dos pacientes em estudo foi realizada utilizando dois métodos distintos:

O grupo de idosos que deambulavam foram avaliados na balança da marca Welmy, com a pessoa envergando a roupa habitual, sem sapatos. A medida da altura foi realizada com a pessoa descalça em estadiômetro acoplado a balança. O cálculo do IMC foi feito utilizando a fórmula peso $(\mathrm{kg}) /$ altura $\left(\mathrm{m}^{2}\right)$.

O grupo de idosos acamados, para cálculo do IMC, foi utilizado à fórmula altura do joelho para cálculo da altura total do paciente e a fórmula do peso segundo Chumlea (1988) que leva em consideração a circunferência da panturrilha $(\mathrm{CP}$ em $\mathrm{cm})$, altura do joelho $(\mathrm{AJ} \mathrm{em} \mathrm{cm})$, circunferência do braço (CB $\mathrm{em} \mathrm{cm}$ ) e prega cutânea subescapular (PSE em $\mathrm{mm}$ ). A prega cutânea foi medida com Adipômetro Cescorf - Plicômetro Clínico. As fórmulas empregadas são descritas nas Tabelas 5 e 6.

Tabela 5: Fórmula para cálculo do peso do idoso acamado.

\begin{tabular}{ll}
\hline Homem & Peso $(\mathrm{Kg})=(0,98 \times \mathrm{CP})+(1,16 \times \mathrm{AJ})+(1,73 \times \mathrm{CB})+(0,37 \times \mathrm{PSE})-81,69$ \\
\hline Mulher & Peso $(\mathrm{Kg})=(1,27 \times \mathrm{CP})+(0,87 \times \mathrm{AJ})+(0,98 \times \mathrm{CB})+(0,4 \times \mathrm{PSE})-62,35$
\end{tabular}

Tabela 6: Fórmula para cálculo da altura do idoso acamado.

Homem Altura $(\mathrm{cm})=64,19-(0,04 \times$ idade em anos $)+(2,02 \times$ altura joelho $\mathrm{em} \mathrm{cm})$
Mulher Altura $(\mathrm{cm})=84,88-(0,24 \times$ idade em anos $)+(1,83 \times$ altura joelho em $\mathrm{cm})$

Atualmente, para a população idosa o ponto de corte na classificação do IMC (Tabela 7) deve ser mais alto em função da maior necessidade de tecido adiposo para proteção contra desnutrição e agudização de outras patologias (Cervi, 2005).

Tabela 7: Classificação do estado nutricional do idoso.

\begin{tabular}{cc}
\hline $\begin{array}{c}\text { IMC } \\
(\text { Kg.m }\end{array}$ & Classificação \\
\hline$<22$ & Magro \\
\hline $22 \mathrm{e} 27$ & Eutrófico \\
\hline$>27$ & Excesso de Peso \\
\hline
\end{tabular}




\section{b) Avaliação clínica}

Pacientes admitidos no pronto-socorro do foram atendidos pelo médico de plantão que realizou o exame clínico e solicitou os exames complementares de acordo com as características de cada paciente. Foi considerado para esta pesquisa apenas o diagnóstico inicial dos pacientes.

\section{c) Exames laboratoriais}

\section{Coleta e amostragem}

As dosagens bioquímicas de zinco plasmático e demais parâmetros clínicos foram realizados em amostras de sangue obtidas dos pacientes após jejum noturno de 10 às $12 \mathrm{~h}$. O sangue venoso foi coletado pelo Laboratório Analisys e colocado em tubos de polietileno contendo EDTA (acido etilenodiaminotetraacético) como anticoagulante. A seguir, os tubos foram transportados para o Laboratório Álvaro (www.alvaro.com.br - Centro de Análises e Pesquisas Clínicas) onde o sangue foi centrifugado, o plasma separado e então congelados $\left(-15^{\circ} \mathrm{C}\right)$ até o momento das dosagens. Demais amostras de sangue foram segregadas segundo procedimentos pré-estabelecidos, por parâmetro, pelo laboratório Clinico Álvaro.

\section{Determinação de Níveis Plasmáticos de Zinco}

O zinco plasmático foi determinado com o auxílio de um espectrofotômetro de absorção atômica, após diluição adequada com água deionizada (1:3). Os padrões foram preparados com solução padrão de titrisolMerck $\left(\mathrm{ZnCl}_{2}\right)$ e com solução de revestimento para análises de soro e plasma (Merck). Todo o material utilizado para a coleta e dosagem das amostras foram lavados com solução de Extran (Merck) seguido de uma solução de ácido nítrico P.A. a $30 \%$ e enxaguado com água deionizada (WHO,2007).

De acordo com Jeejeebhoy (2009), os valores de concentração normal de zinco podem variar de 80 a $120 \mu \mathrm{g} . \mathrm{dL}^{-1}$ ou 12 a $18 \mu \mathrm{mol} . \mathrm{L}^{-1}$. Porém, segundo a OMS, para análise dos dados devem ser utilizados limites apropriados, dependendo das características do estudo populacional, e fazer a 
correção para o período do dia ou períodos decorridos desde a última refeição, a menos que a coleta da amostra tenha sido padronizada (WHO, 2007). Os limites mais baixos sugeridos para a concentração de zinco no soro considerando o jejum matinal e sexo feminino (mulheres não grávidas) é de 70 $\mu \mathrm{g} \cdot \mathrm{dL}^{-1}$ e para o sexo masculino de $74 \mu \mathrm{g} \cdot \mathrm{dL}^{-1}$. Pesquisa nacional de saúde e nutrição realizada nos EUA, no período de 1976 a 1980, estabeleceu o ponto de corte inferior do zinco para população acima de 60 anos de $70 \mu \mathrm{g} \cdot \mathrm{dL}^{-1}$ (Hotz, 2003). Neste estudo consideramos o valor normal de zinco plasmático acima de $70 \mu \mathrm{g} \cdot \mathrm{dL}^{-1}$.

Como forma de avaliar a logística da pesquisa foi realizada a dosagem de zinco plasmático em nove voluntários sadios de classe média alta do município de Araguaina, com resultados variando de 84 a $143 \mu \mathrm{g} \cdot \mathrm{dL}^{-1}$, com media e DP de $104 \pm 17 \mu \mathrm{g} \cdot \mathrm{dL}^{-1}$.

\section{Parâmetros bioquímicos}

Foram analisados os seguintes parâmetros bioquímicos:

a) albumina, dosagem sorológica através do método colorimétrico (verde de bromocresol) com valor normal de 3,5 a 4,8 g.dL-1;

b) Contagem de linfócitos através da amostra de sangue total de forma eletrônica no equipamento Micro 60 / Abx e manual com microscópio e coloração Panótico, com valores normais variando 800 a 4950 cels. $\mathrm{mm}^{-3}$. Os valores da contagem de linfócitos foram classificados em três grupos: contagem inferior a 800 linfócitos; contagem entre 801 e 1600 linfócitos e contagem superior a 1600 linfócitos (Pablo, 2003);

c) Proteina $C$ reativa medida através de plasma citratado através da metodologia amidolítico - cromogênico, sendo o valor normal menor que seis.

A Tabela 8 apresenta um resumo dos parâmetros clínicos e laboratoriais avaliados neste estudo e respectivo processo de análise. 


\section{Tratamento Matemático e Estatístico dos Dados}

Para representar o perfil espacial de cada parâmetro foram realizadas representações gráficas do tipo Blox-plot. Essa metodologia possibilita a visualização da assimetria da distribuição, a faixa de variação dos dados, além de permitir a detecção de possíveis pontos extremos, que podem ou não ser excluídos da análise. Também foi verificada a normalidade dos dados sob análise aplicando-se o teste de Shapiro-Wilks`s (Anexo 1).

Tabela 8: Parâmetros clínicos e laboratoriais avaliados e métodos de análise.

\begin{tabular}{|c|c|}
\hline Parâmetros & Métodos de Análise ou de Avaliação \\
\hline IDADE & $\begin{array}{l}\text { Documento de identidade apresentado pelo paciente ou } \\
\text { familiar }\end{array}$ \\
\hline SEXO & Identificação do paciente \\
\hline RAÇA & Identificação do paciente \\
\hline $\begin{array}{l}\text { DATA } \\
\text { INTERNAÇÃO }\end{array}$ & Prontuário do paciente \\
\hline DATA ALTA & Prontuário do paciente \\
\hline $\begin{array}{l}\text { T EMPO de } \\
\text { INTERNAÇÃO }\end{array}$ & Diferença entre a data de internação e alta \\
\hline DIAGNÓSTICO & Clínico e Complementar na entrada do paciente \\
\hline INFECÇÃO & $\begin{array}{l}\text { Identificação da presença de infecção no ato da admissão } \\
\text { do paciente }\end{array}$ \\
\hline HEMOGLOBINA & Espectofotometria \\
\hline LINFÓcITOS & $\begin{array}{l}\text { Contagem morfológica eletrônica de células ou manual com } \\
\text { microscópio coloração Panótico }\end{array}$ \\
\hline $\begin{array}{l}\text { PROTEINA C } \\
\text { REATIVA }\end{array}$ & Método Amidolítico-Cromogênico em plasma citratado \\
\hline ALBUMINA & $\begin{array}{l}\text { Colorimétrico } \\
\text { (Verde de Bromocresol) }\end{array}$ \\
\hline ZINCO & Espectrometria de absorção atômica - com chama (AA) \\
\hline
\end{tabular}




\section{RESULTADOS E DISCUSSÃO}

No período da pesquisa foi dosado a concentração de zinco plasmático de 88 pacientes no Hospital Regional de Araguaína, TO. A tabela 9 apresenta um resumo contendo os resultados obtidos neste estudo, abordando as informações de demografia, características clínicas e bioquímicas dos pacientes avaliados. 0 anexo 4 mostra os resultados obtidos da avaliação de cada paciente.

A idade dos pacientes variou de 65 a 94 anos, com média de 79,5 anos. A concentração de zinco variou de 40 a 129,5 $\mu \mathrm{g} \cdot \mathrm{dL}^{-1}$, (Tabela 9).

A Figura 3 apresenta os resultados da avaliação da distribuição racial da amostra de pacientes avaliados período 2009-2010 $(n=88)$. Na amostra havia 58 homens $(65,9 \%)$ e 30 mulheres $(34,1 \%)$, com predomínio da raça parda (64 pacientes), característico da região, e quatro caucasianos, um índio, três negros, e, 16 indeterminados

Os resultados referentes à dosagem do zinco plasmático no grupo estudado são apresentados na Tabela 10. Trinta e um pacientes $(34,1 \%)$ apresentavam concentração de zinco abaixo do valor normal (valor menor 70 $\mu \mathrm{g} \cdot \mathrm{dL}^{-1}$ ) e cinqüenta e sete pacientes $(65,9 \%)$ com concentração de zinco denominada de normal (valor acima de $70 \mu \mathrm{g} \cdot \mathrm{dL}^{-1}$ ). No grupo com deficiência de zinco havia 11 mulheres e 20 homens. Dos 30 pacientes do sexo feminino, onze apresentavam zinco abaixo do normal representando $36,6 \%$. Dos 58 pacientes do sexo masculino, vinte apresentavam zinco abaixo do normal, representando $34,4 \%$. 
Tabela 9: Demografia, características clínicas e bioquímicas dos pacientes

\begin{tabular}{|c|c|c|c|c|c|c|c|}
\hline & \multicolumn{2}{|c|}{ Pacientes } & & & & \\
\hline & & $\mathbf{N}$ & $(\%)$ & & & & \\
\hline \multirow{3}{*}{ Sexo } & Masculino & 58 & 64,15 & & & & \\
\hline & Feminino & 30 & 35,85 & & & & \\
\hline & Total & 88 & 100 & & & & \\
\hline \multirow[b]{2}{*}{ Parâmetros } & \multirow{2}{*}{$\begin{array}{l}\text { Valores de } \\
\text { Normalidade ou } \\
\text { Referência }\end{array}$} & & & \multicolumn{3}{|c|}{ Concentração } & \\
\hline & & & & $\mathbf{X}$ & DP & $\begin{array}{c}\text { Máxim } \\
0\end{array}$ & Mínimo \\
\hline Idade (anos) & Maior que 65 & & & 76,5 & 6,6 & 94 & 65 \\
\hline Zinco ( $\mu \mathrm{g} \cdot \mathrm{dL}^{-}$ & Maior que 70 & & & 80,2 & 21,2 & 129,5 & 40 \\
\hline $\begin{array}{l}\text { Albumina } \\
\left(\text { g.dL }{ }^{-1}\right)\end{array}$ & 3,5 a 4,8 & 80 & & 3,4 & 0,6 & 4,8 & 1,9 \\
\hline $\begin{array}{l}\text { Linfócitos } \\
\text { Totais } \\
\left.\text { (cel. } \mathrm{mm}^{-3}\right)\end{array}$ & 800 a 4950 & 86 & & 1472 & 610 & 3200 & 490 \\
\hline IMC $\left(\mathrm{Kg} \cdot \mathrm{m}^{-2}\right)$ & $22-27$ & 43 & & 23,0 & 4,92 & 37,39 & 14,60 \\
\hline Proteina C & $<$ ou $=6$ & 73 & & & & & \\
\hline \multirow{2}{*}{$\begin{array}{l}\text { Hemoglobina } \\
(\mathrm{Hb})\left(\mathrm{g} \cdot \mathrm{dL}^{-1}\right)\end{array}$} & Homem: $13,5-17,5$ & 58 & & 12,3 & 2,2 & 16.8 & 6,6 \\
\hline & Mulher: $12-16$ & 30 & & 12,2 & 2,2 & 17,6 & 7,1 \\
\hline
\end{tabular}

$\mathrm{X} \pm \mathrm{DP}=$ media e desvio padrão; $\mathrm{N}=$ número de pacientes;

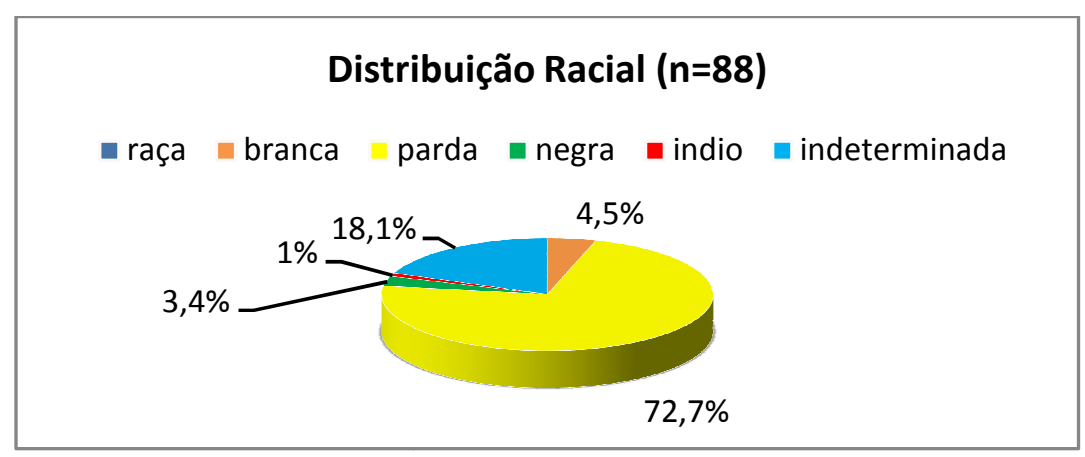

FIGURA 3: Distribuição racial da amostra.

Tabela 10: Dosagem do zinco plasmático no grupo estudado.

\begin{tabular}{lcccccc}
\hline $\begin{array}{l}\text { Zinco } \\
\text { Plasmático }\end{array}$ & \multicolumn{2}{c}{ Amostra } & \multicolumn{3}{c}{ Sexo } \\
\hline & $(\mathrm{n})$ & $(\%)$ & $(\mathrm{n})$ & $(\%)$ & $(\mathrm{n})$ & $(\%)$ \\
\hline \multicolumn{1}{l}{$\begin{array}{l}\text { Normal } \\
\left(>70 \mu \mathrm{g} \cdot \mathrm{dL}^{-1}\right)\end{array}$} & 57 & 65,9 & 38 & 66,6 & 19 & 33,3 \\
\hline $\begin{array}{l}\text { Diminuído } \\
\left(<70 \mu \mathrm{dL} \cdot \mathrm{dL}^{-1}\right)\end{array}$ & 31 & 34,1 & 20 & 64,5 & 11 & 35,5 \\
\hline Total & 88 & 100 & 58 & 65,9 & 30 & 34,1 \\
\hline
\end{tabular}


Dos oitenta e oito pacientes estudados 57 (65,9\%) apresentavam zinco plasmático dentro do limite da normalidade. Trinta e um pacientes $(34,1 \%)$ apresentavam zinco abaixo do limite da normalidade (Tabela 10).

Pesquisa realizada na Grécia com 214 idosos sadios 18,7\% apresentavam deficiência de zinco (Kanoni, 2006). Estudo realizado em idosos saudáveis na Universidade de São Paulo, no programa envelhecendo com sucesso, dosou zinco plasmático de 87 pacientes obtendo valor médio de $98,1 \mu \mathrm{g} \cdot \mathrm{dL}^{-1}\left(66,6\right.$ a $\left.139,7 \mu \mathrm{g} \cdot \mathrm{dL}^{-1}\right)$. Nessa amostra apenas um paciente apresentou zinco plasmático abaixo da normalidade (Saiki, 2009). Pesquisa realizada nos EUA, na população de idosos negros de baixa renda observou $39 \%$ com deficiência de zinco (Wagner, 1980). Nosso estudo foi realizado no hospital público do estado do Tocantins que atende o sistema único de saúde (SUS), com pacientes portadores de patologias clínicas que apresentavam piora do quadro, e procuravam atendimento de emergência, numa amostra que predominou a raça parda na população de baixa renda. Os resultados sugerem que idosos saudáveis tendem a apresentar valores maiores de zinco plasmático, enquanto, idosos com comorbidades ou de condições sócio-econômica desfavorável tendem a apresentar valores do zinco plasmático abaixo do normal.

Tradicionalmente não há predomínio de sexo sobre deficiência de zinco (McKenzie, 1979), embora alguns estudos mostrassem que mulheres em idade fértil podem apresentar deficiência de zinco principalmente associada à deficiência de ferro (Chandyo, 2009). Neste estudo observa-se que o valor médio do zinco no sexo masculino é maior do que a média do valor do zinco no sexo feminino, 88,72 e 80,67 $\mu \mathrm{g} \cdot \mathrm{dL}^{-1}$ respectivamente (Figura 4). Trata-se de uma amostra de idosos, portanto espera-se que ciclo menstrual não tenha responsabilidade nessa diferença 


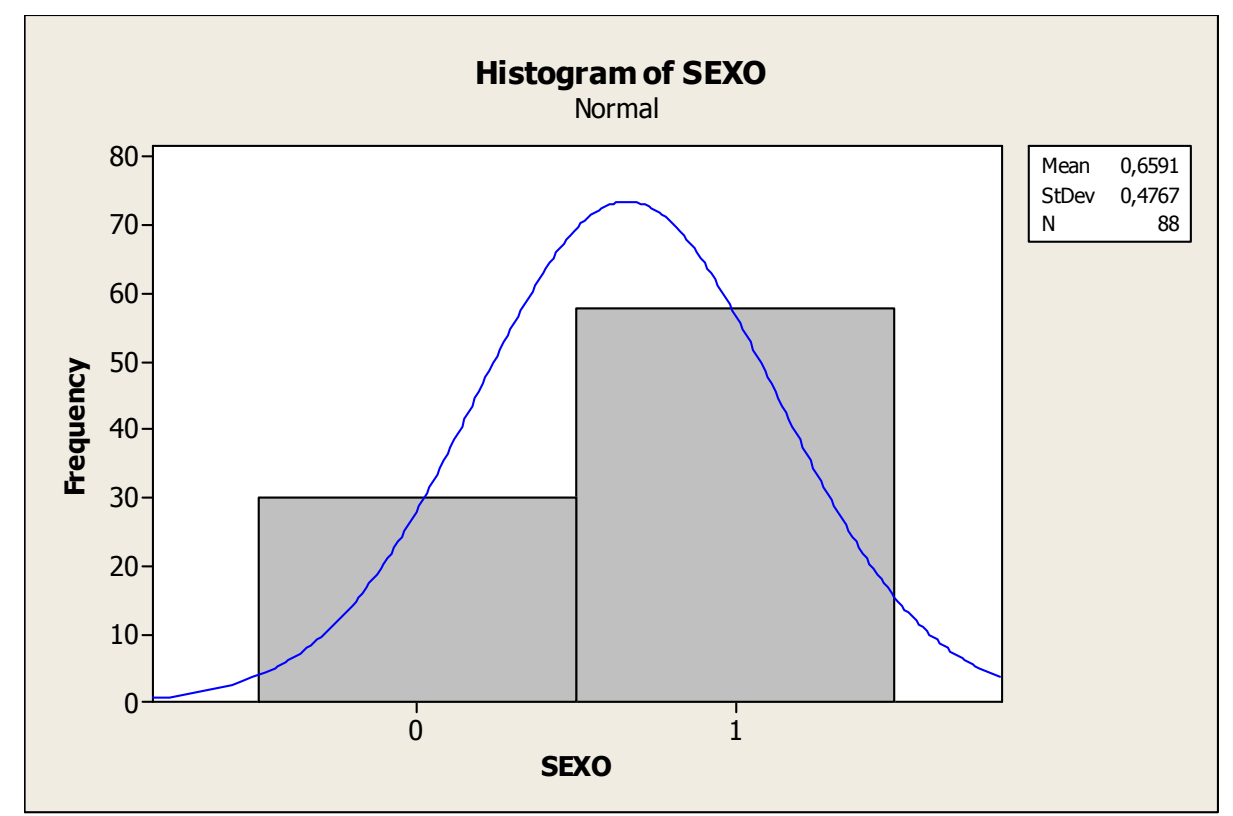

FIGURA 4: Distribuição do valor médio do zinco por sexo. 0 representa o sexo feminino e 1 sexo masculino.

Embora não tenha sido realizado inquérito alimentar na pesquisa a observação de deficiência de zinco no idoso está relacionada com: diminuição da ingestão alimentar; redução do acesso a uma variedade de alimentos devido à pobreza e incapacidade física e aumento da incidência de doenças que aumentam a necessidade de alguns minerais ou interferem na sua utilização (Nordstrom, 1982).

$\mathrm{Na}$ análise dos dados a amostra foi dividida em dois grupos: grupo de pacientes com dosagem sérica do zinco abaixo do valor considerado normal e o grupo de pacientes com dosagem sérica do zinco dentro de valores normais. $O$ valor médio do zinco plasmático do grupo de hipozincemia foi de $59,22 \mu \mathrm{g} . \mathrm{dL}^{-1}$ (DP: $\pm 9,2 \mu \mathrm{g} \cdot \mathrm{dL}^{-1}$ ), enquanto o valor médio encontrado no grupo com zinco plasmático considerado normal foi de 104,20 $\mu \mathrm{g} \cdot \mathrm{dL}^{-1}$ (DP: $\pm 16 \mu \mathrm{g} \cdot \mathrm{dL}^{-1}$ ) (Figura 5) 


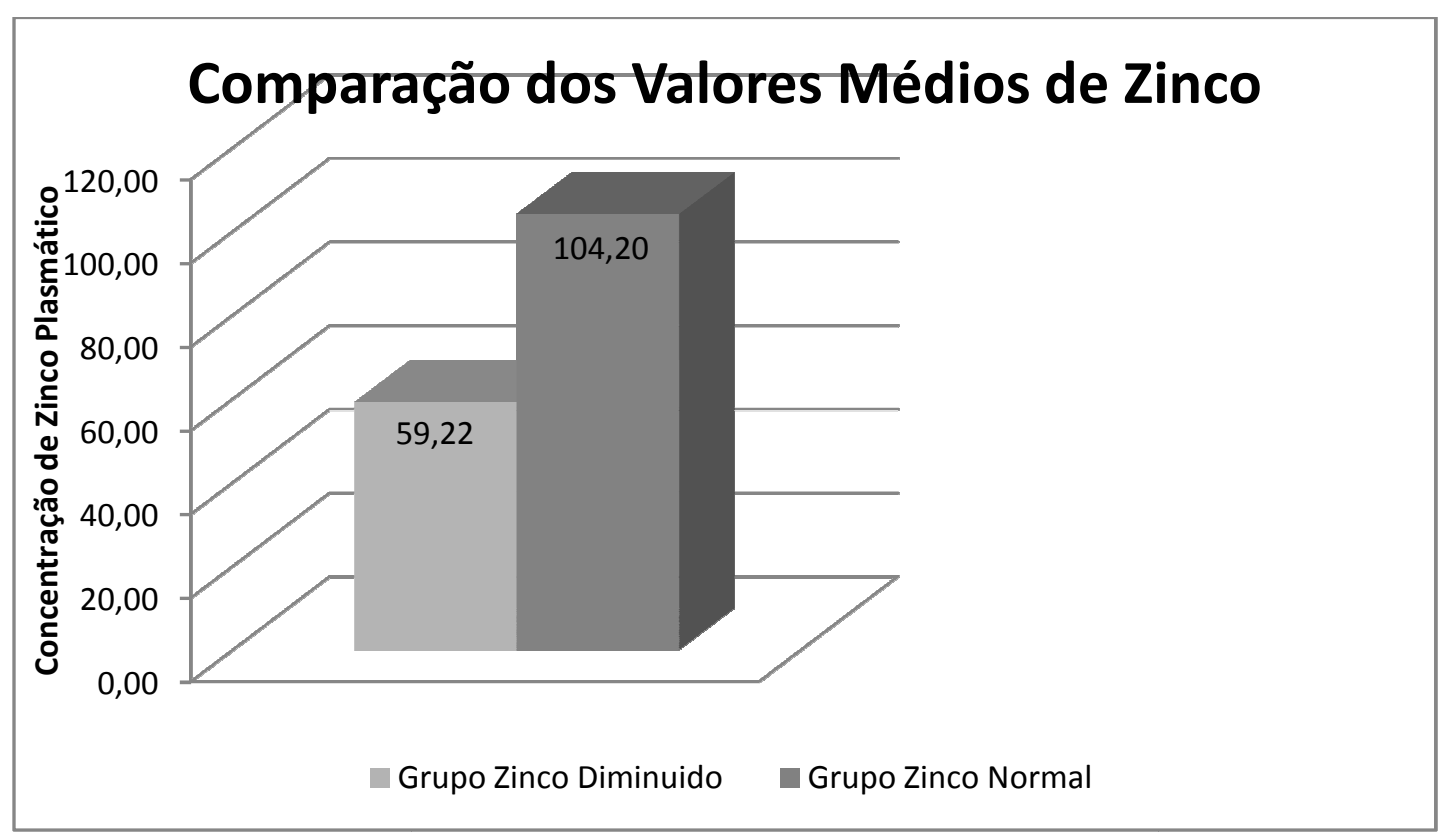

FIGURA 5: Concentração de Zn plasmático em $\mu g . \mathrm{dL}^{-1} \mathrm{VS}$ valor médio do Zn plasmático para $\mathrm{n}=88$.

Os resultados da relação da concentração do zinco com o valor da albumina, para $(n=80)$ são apresentados na Tabela 11. Analisando o comportamento da concentração plasmática do zinco relacionada com a concentração de albumina plasmática dosada em 80 pacientes observa-se que $38,5 \%$ dos pacientes com hipoalbuminemia apresentavam hipozincemia, enquanto que $26,8 \%$ dos pacientes com albumina normal apresentavam zinco plasmático diminuído. Entre os pacientes com zinco normal observa-se predomínio de pacientes com albumina sérica elevada, $73,2 \%$.

Tabela 11: Relação da concentração do zinco com o valor da albumina $(n=80)$

\begin{tabular}{lccccc}
\hline \multicolumn{1}{c}{ Zinco Plasmático } & \multicolumn{5}{c}{$\begin{array}{c}\text { Albumina Plasmática (n=80) } \\
\left(\mathbf{g} \cdot \mathbf{d L} \mathbf{H}^{-1}\right)\end{array}$} \\
\hline & $(\mathrm{n})$ & $(\%)$ & $(\mathrm{n})$ & $(\%)$ \\
\hline $\begin{array}{l}\text { Normal } \\
\left(>70 \mu \mathrm{g} \cdot \mathrm{dL}^{-1}\right)\end{array}$ & 24 & 61,5 & 30 & 73,2 \\
\hline $\begin{array}{l}\text { Diminuído } \\
\left(<70 \mu \mathrm{g} \cdot \mathrm{dL}^{-1}\right)\end{array}$ & 15 & 38,5 & 11 & 26,8 \\
\hline Total & 39 & 100 & 41 & 100 \\
\hline ALBUMINA: VALOR DE REFERENCIA: 3,5 a $4,8 \mathrm{~g} \cdot \mathrm{dL}^{-1}$ & & &
\end{tabular}

A dosagem da albumina sérica é um parâmetro nutricional freqüentemente utilizado. Valores inferiores a $3,5 \mathrm{~g} \cdot \mathrm{dL}^{-1}$ são indicativos de 
desnutrição ou podem estar associado a aumento do catabolismo, perdas urinárias ou insuficiência hepática. A diminuição de substratos protéicos ou energéticos no fígado, ou deficiência de zinco pode contribuir para hipoalbuminemia (Vannucchi, 1996).

Neste estudo, foi dosada albumina plasmática em 80 pacientes (Tabela 11). Os resultados mostraram que do total de pacientes avaliados 39 pacientes apresentavam valores de albumina plasmática inferiores a $3,5 \mathrm{~g} \cdot \mathrm{dL}^{-1}$, desse grupo 15 pacientes $(40,8 \%)$ apresentavam zinco plasmático inferior a $70 \mu \mathrm{g} \cdot \mathrm{dL}^{-1}$. Comparando o valor médio obtido para a albumina no grupo de hipozincemia com a média do grupo de zinco normal observa-se uma concordância de valores (Figura 6). O grupo de pacientes com zinco plasmático abaixo do normal apresentava um valor médio de albumina de 3,22 g.dL ${ }^{-1}$ (DP: $\pm 0,6$ g.dL ${ }^{-1}$ ) enquanto o grupo de pacientes com zinco acima de $70 \mu \mathrm{g} \cdot \mathrm{dL}^{-1}$ apresentavam valor médio da albumina de $3,58 \mathrm{~g} \cdot \mathrm{dL}^{-1}\left(\mathrm{DP}: \pm 0,61 \mathrm{~g} \cdot \mathrm{dL}^{-1}\right.$ ).

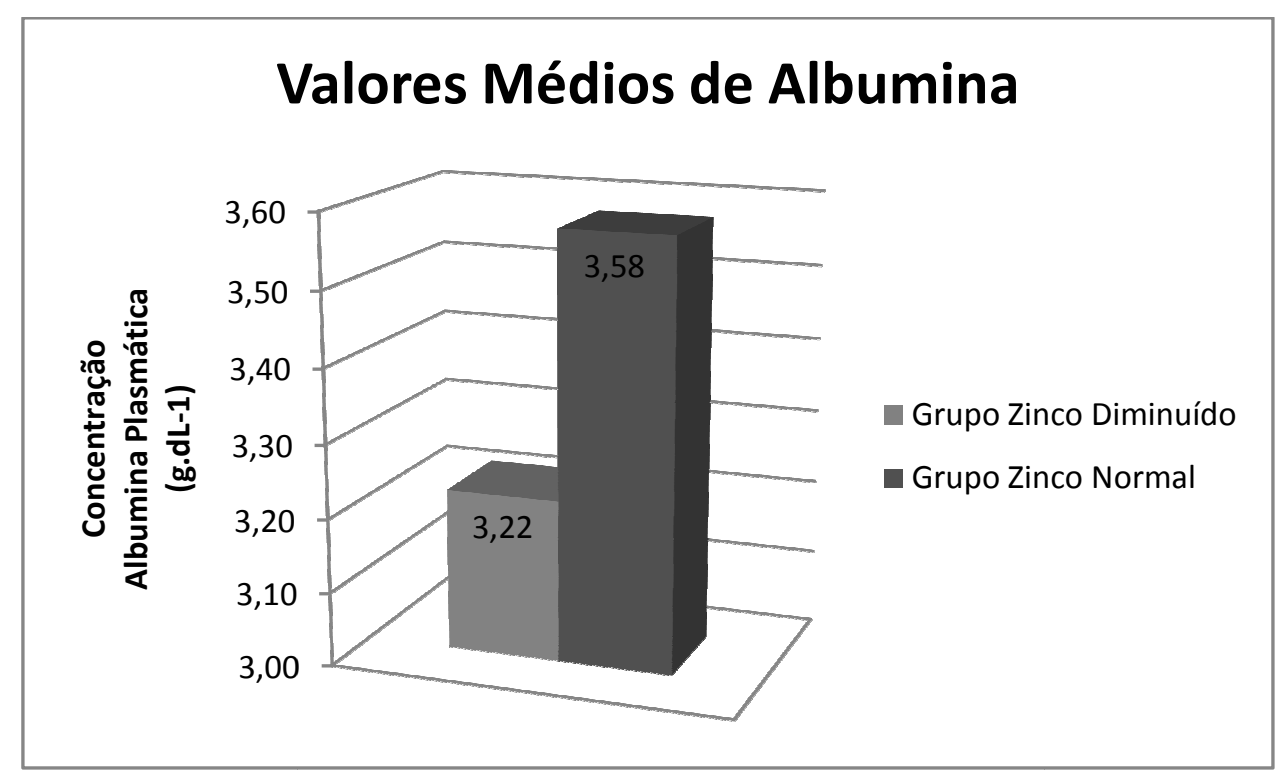

FIGURA 6: Comparação dos valores médios de albumina plasmática entre os grupos de pacientes com zinco plasmático diminuído e normal.

A Tabela 12 apresenta uma avaliação dos resultados da relação da concentração do zinco com a hemoglobina $(\mathrm{Hb})(\mathrm{n}=88)$ no sangue. Analisando os valores de hemoglobina no sangue com o zinco plasmático observa-se no grupo de pacientes com zinco diminuído, tanto no sexo masculino como no feminino, 
uma percentagem maior de pacientes com hemoglobina abaixo do valor normal para o sexo, $39 \%$ verso $23,5 \%$ para o sexo masculino e $50 \%$ verso $31,2 \%$ para o sexo feminino. Comparando com o grupo de pacientes com zinco plasmático normal observa-se maior percentagem de pacientes com hemoglobina dentro de valores normais para o sexo, $76,5 \%$ verso $61 \%$ para os homens e $68,8 \%$ verso $50 \%$ para as mulheres.

Tabela 12: Relação da concentração do zinco em função da concentração de hemoglobina $(\mathrm{Hb})$ no sangue periférico, dosada 88 pacientes.

\begin{tabular}{lcccccccc}
\hline $\begin{array}{l}\text { Zinco } \\
\text { Plasmático }\end{array}$ & \multicolumn{9}{c}{$\begin{array}{c}\text { Masculino } \\
(\mathrm{n}=58)\end{array}$} & \multicolumn{5}{c}{$\begin{array}{c}\text { Feminino } \\
(\mathrm{n}=30)\end{array}$} \\
\hline & Hb Diminuída & Hb Normal & Hb Diminuída & Hb Normal \\
\hline & $(\mathrm{n})$ & $(\%)$ & $(\mathrm{n})$ & $(\%)$ & $(\mathrm{n})$ & $(\%)$ & $(\mathrm{n})$ & $(\%)$ \\
\hline & 25 & 61 & 13 & 76,5 & 6 & 50 & 11 & 68,8 \\
\hline $\begin{array}{l}\text { Normal } \\
\left(>70 \mu g . \mathrm{dl}^{-1}\right)\end{array}$ & 16 & 39 & 4 & 23,5 & 6 & 50 & 5 & 31,2 \\
\hline $\begin{array}{l}\text { Diminuído } \\
\left(>70 \mu g . \mathrm{dl}^{-1}\right)\end{array}$ & 41 & 100 & 17 & 100 & 12 & 100 & 16 & 100 \\
\hline Total & & & & & & & \\
\hline
\end{tabular}

Analisando-se os valores médios obtidos nos dois grupos de pacientes observa-se uma tendência de um valor menor de hemoglobina no grupo de concentração do zinco menor que o valor de referência normal (Figura 7). O valor médio da hemoglobina no grupo de zinco plasmático diminuído foi de $11,8 \mathrm{~g} \cdot \mathrm{dL}^{-1}$ (DP: $\pm 2,3 \mathrm{~g} \cdot \mathrm{dL}^{-1}$ ) e no grupo de zinco plasmático normal foi de $12,8 \mathrm{~g} \cdot \mathrm{dL}^{-1}$ (DP: \pm 2,25 g.dL $\left.{ }^{-1}\right)$.

A concentração da hemoglobina plasmática também pode ser interpretada como um marcador nutricional. 


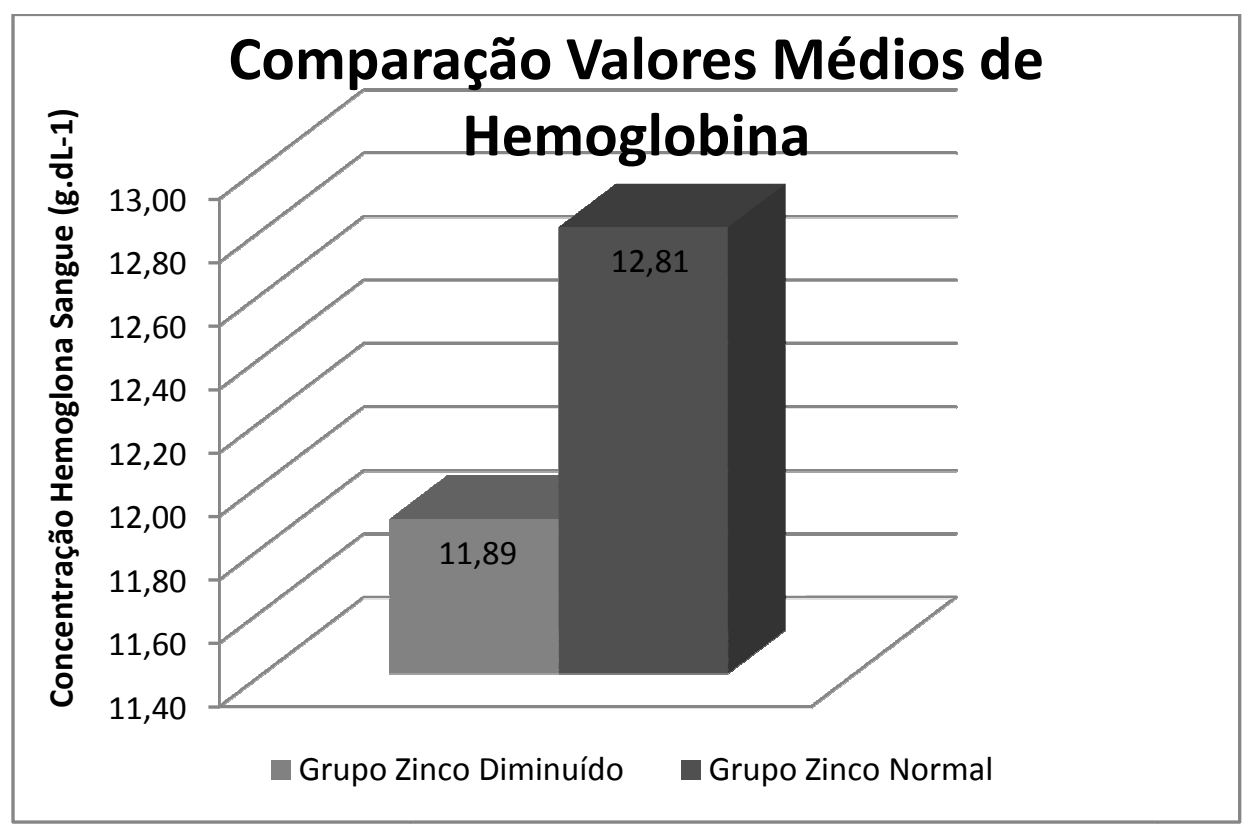

FIGURA 7: Comparação dos valores médios de hemoglobina no sangue entre os grupos de pacientes com zinco plasmático diminuído e normal.

Devido a dificuldades operacionais foi avaliado o IMC em apenas 43 pacientes, de um total de 88 pacientes (Tabela 15). Do total de pacientes avaliados (43) quanto ao IMC, vinte e três pacientes apresentaram IMC correspondendo a magreza. Dos 23 pacientes que apresentaram IMC menor que vinte e dois, 11 pacientes $(47,8 \%)$ apresentaram deficiência de zinco, valor abaixo da normalidade. No entanto, no grupo de pacientes com IMC maior que 27, nenhum apresentou zinco diminuído. No grupo eutrófico foi obtido zinco normal na maioria, 76,9\% (Tabela 13).

Tabela 13: Relação da concentração de Zn plasmático em função do IMC, dosada em 43 pacientes.

\begin{tabular}{|c|c|c|c|c|c|c|}
\hline \multirow[t]{3}{*}{ Zinco Plasmático } & \multicolumn{6}{|c|}{$\begin{array}{c}\text { Classificação IMC }\left(\mathrm{Kg}^{\left.-\mathrm{m}^{-2}\right)}\right. \\
(\mathrm{n}=43)\end{array}$} \\
\hline & \multicolumn{2}{|c|}{$\begin{array}{l}\text { Magreza } \\
<22\end{array}$} & \multicolumn{2}{|c|}{$\begin{array}{l}\text { Eutrófico } \\
22 \text { e } 27\end{array}$} & \multicolumn{2}{|c|}{$\begin{array}{l}\text { Obeso } \\
>27\end{array}$} \\
\hline & $(\mathrm{n})$ & $(\%)$ & $(n)$ & $(\%)$ & $(n)$ & $(\%)$ \\
\hline $\begin{array}{l}\text { Normal } \\
\left(>70 \mu \mathrm{g} \cdot \mathrm{dL}^{-1}\right)\end{array}$ & 12 & 52,2 & 10 & 76,9 & 7 & 100 \\
\hline $\begin{array}{l}\text { Diminuído } \\
\left(<70 \mu \mathrm{g} \cdot \mathrm{dL}^{-1}\right)\end{array}$ & 11 & 47,8 & 3 & 23,1 & 0 & 0 \\
\hline Total & 23 & 100 & 13 & 100 & 7 & 100 \\
\hline
\end{tabular}


O estudo possibilitou realizar uma avaliação do estado nutricional a partir dos valores médios de IMC no grupo de pacientes com zinco diminuído e valor de referencia dentro da normalidade (Tabela 13). Em 43 pacientes foi calculado o índice de massa corporal (IMC) sendo que em 23 foram observado valores inferiores a $22 \mathrm{Kg} \cdot \mathrm{m}^{-2}$. Neste grupo 11 pacientes $(47,8 \%)$ apresentaram hipozincemia. Estes pacientes demonstram sinais de desnutrição crítica podendo a diminuição do zinco plasmático estar relacionada com a menor ingestão de alimentos. Cabe salientar que pacientes desnutridos diminuem a capacidade de absorção de zinco, pela atrofia das vilosidades do intestino assim como pela diminuição de ligantes nos enterócitos (Wapnir, 2000). O grupo de pacientes com zinco plasmático abaixo do normal apresenta um valor médio de IMC de 19,59 $\mathrm{Kg} \cdot \mathrm{m}^{-2}$ (DP: $\pm 2,5 \mathrm{Kg} \cdot \mathrm{m}^{-2}$ ), característico da magreza, comparado com valor médio do IMC de $24,07 \mathrm{Kg} \cdot \mathrm{m}^{-2}$ (DP: $\pm 4,4 \mathrm{Kg} \cdot \mathrm{m}^{-2}$ ), característico do eutrófico, no grupo de zinco com valores de referência normal (Figura 8).

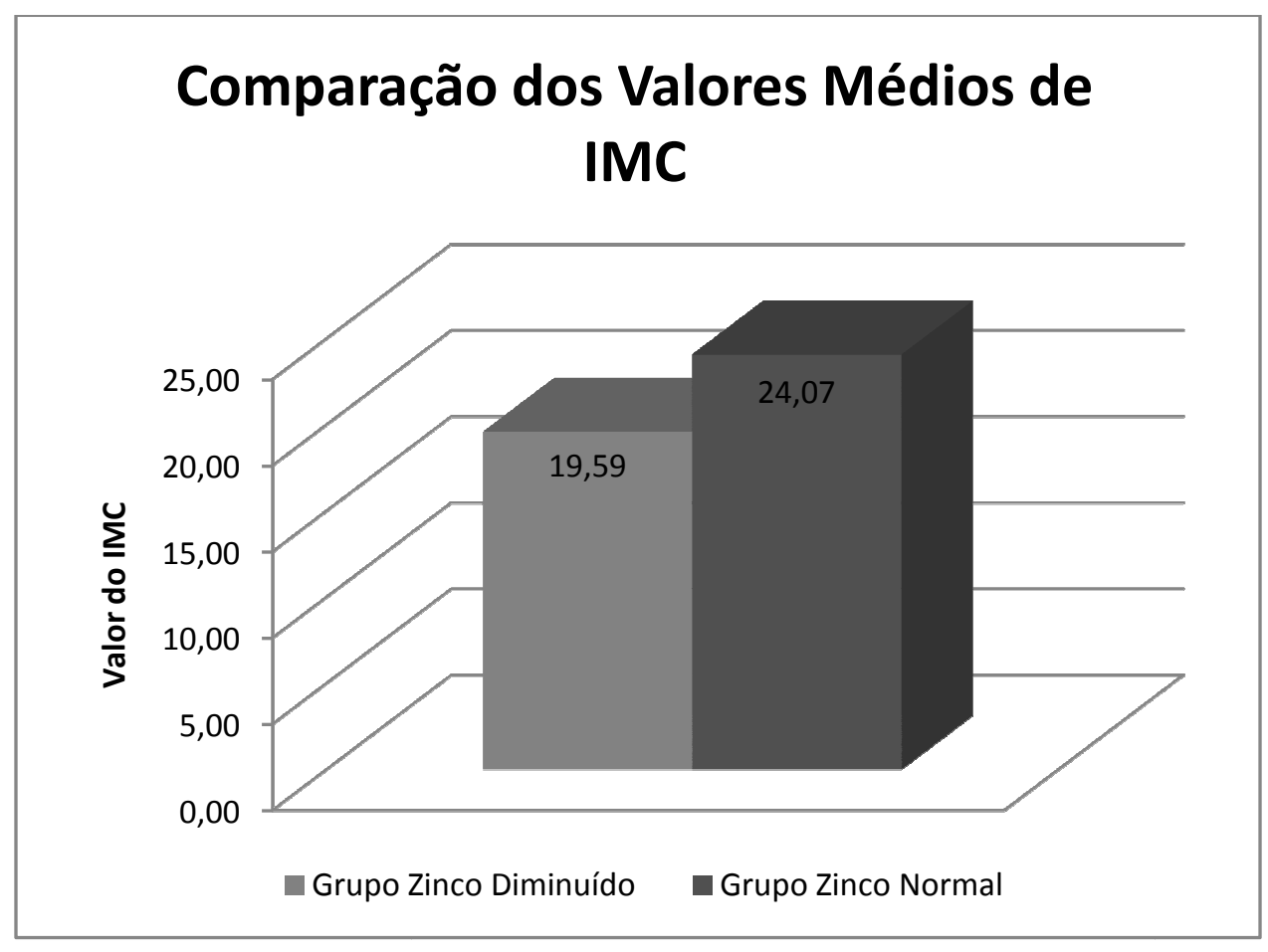

FIGURA 8: Comparação dos valores médios de IMC entre os grupos de pacientes com zinco plasmático diminuído e normal.

Nesta pesquisa observa-se que há uma relação entre o valor do zinco plasmático e parâmetros nutricionais. O grupo de pacientes com valor diminuído de zinco também apresentavam valores menores de IMC, albumina e 
hemoglobina (Figura 9 e 10). Portanto, podemos afirmar que pacientes desnutridos deverão apresentar valores menores de zinco plasmático. O que não podemos afirmar se este fato reflete diminuição do zinco corporal.

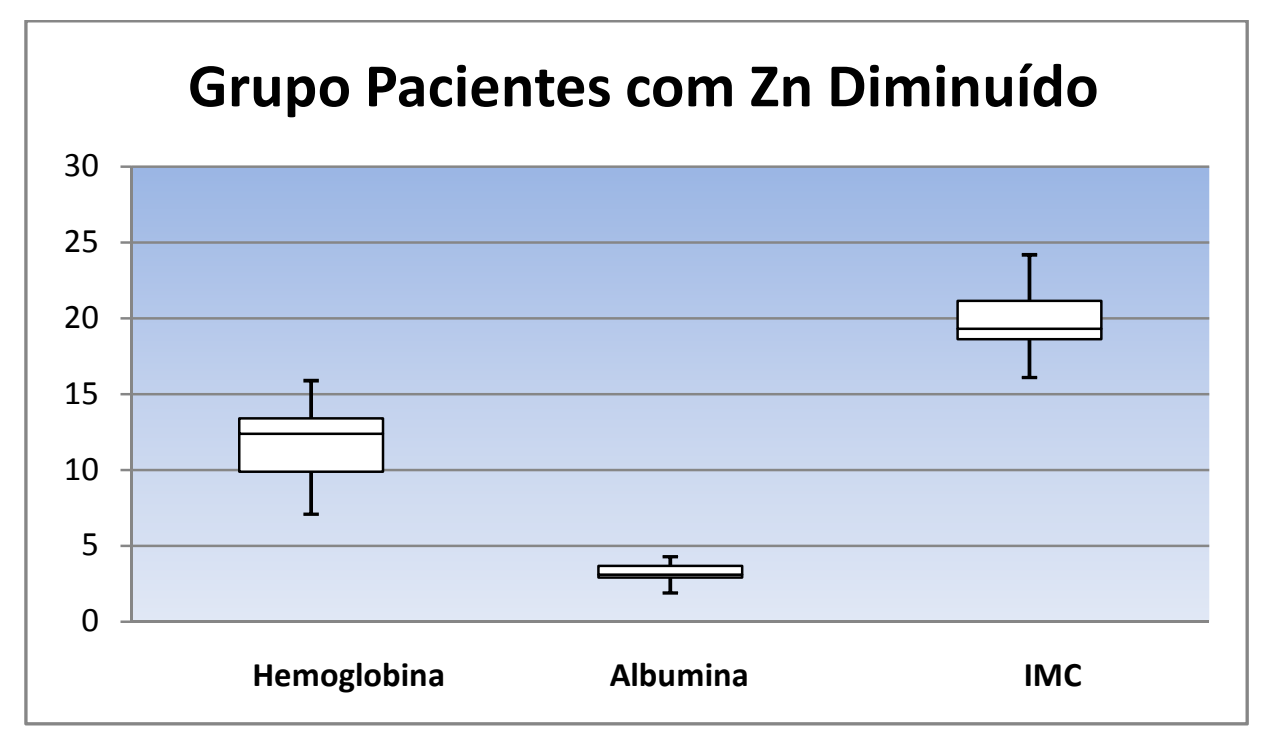

FIGURA 9: Valores medianos de Hemoglobina, Albumina e IMC no grupo de pacientes com zinco plasmático abaixo do valor normal.

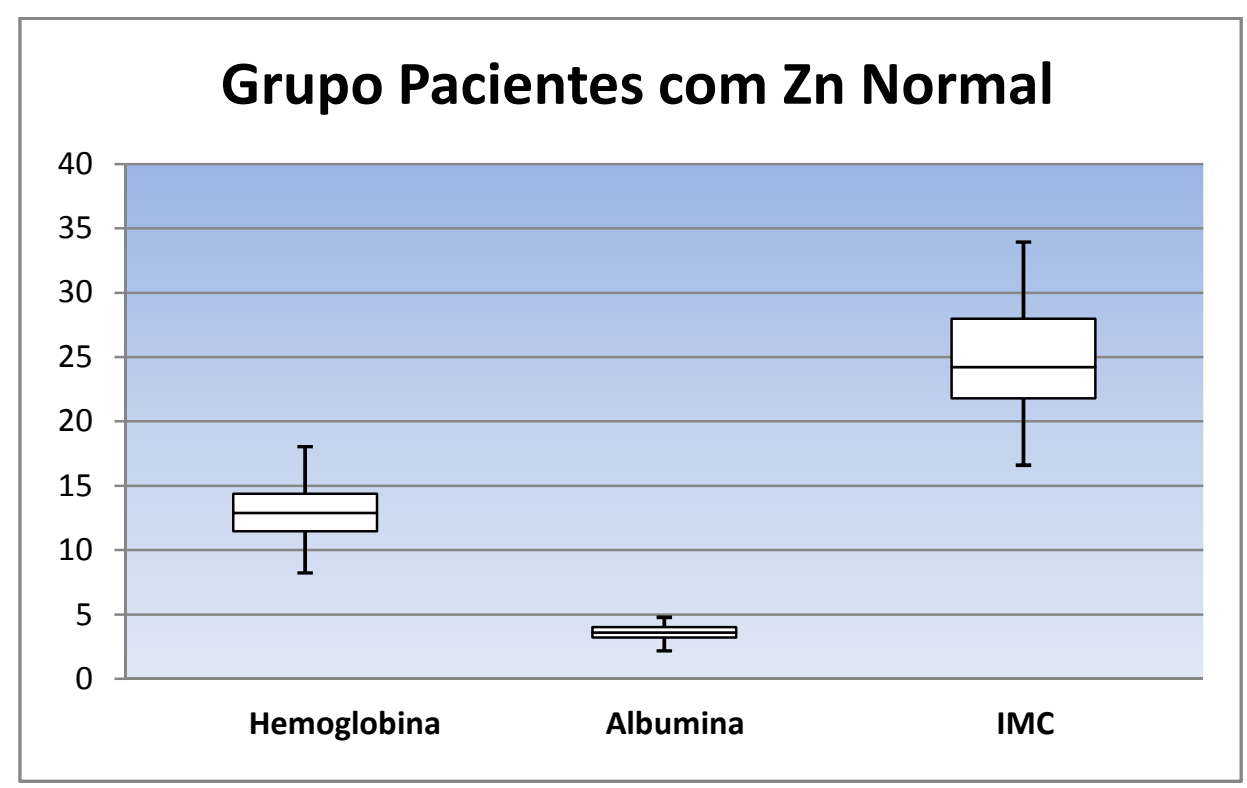

FIGURA 10: Valores medianos de Hemoglobina, Albumina e IMC no grupo de pacientes com zinco plasmático considerado normal.

A concentração de zinco plasmático também foi analisada em função dos valores de linfócitos no sangue periférico dosada em 86 pacientes. Os valores de linfócitos foram avaliados dividindo-se os resultados obtidos em três 
grupos: grupo 1 - contagem superior a 1600 células. $\mathrm{mm}^{-3}$; grupo 2 - contagem entre 1600 e 801 células. $\mathrm{mm}^{-3}$; grupo 3 - contagem inferior a 800 linfócitos no sangue periférico. Os resultados, apresentados na Tabela 14, permitiram observar que sete pacientes apresentavam contagem de linfócito inferior a 800 cels. $\mathrm{mm}^{-3}$, quarenta e oito apresentavam contagem de linfócitos entre 801 e 1600 cels. $\mathrm{mm}^{-3}$, e trinta e um apresentavam linfócitos acima de 1600 cels. $\mathrm{mm}^{-3}$, . O percentual de pacientes com hipozincemia nos três grupos de contagem de linfócito foi de $28,6 \%$ no grupo abaixo de $800,35,4 \%$ no grupo entre 801 e 1600 , e $35,5 \%$ no grupo acima de 1600 linfócitos.

Tabela 14: Relação da concentração de Zn plasmático em função da contagem de linfócitos no sangue periférico, dosada em 86 pacientes.

\begin{tabular}{lcccccc}
\hline Zinco Plasmático & \multicolumn{7}{c}{$\begin{array}{c}\text { Contagem de Linfócito }\left(\mathbf{c e l} . \mathrm{mm}^{-3}\right) \\
\text { Intervalos de referência } \\
(\mathbf{n = 8 6 )}\end{array}$} \\
\hline & \multicolumn{2}{c}{$<$ ou $=800$} & \multicolumn{2}{c}{$801-1600$} & \multicolumn{2}{c}{$>1600$} \\
\hline & $(\mathrm{n})$ & $(\%)$ & $(\mathrm{n})$ & $(\%)$ & $(\mathrm{n})$ & $(\%)$ \\
\hline $\begin{array}{l}\text { Normal } \\
\left(>70 \mu \mathrm{g} \cdot \mathrm{dL}^{-1}\right)\end{array}$ & 5 & 71,4 & 31 & 64,6 & 20 & 64,5 \\
\hline $\begin{array}{l}\text { Diminuído } \\
\left(<70 \mu \mathrm{gg} \cdot \mathrm{dL}^{-1}\right)\end{array}$ & 2 & 28,6 & 17 & 35,4 & 11 & 35,5 \\
\hline Total & 7 & 100 & 48 & 100 & 31 & 100 \\
\hline
\end{tabular}

Analisando os dados, da contagem de linfócitos periféricos observa-se que no grupo com valores muito reduzido (menor que 800 cels. $\mathrm{mm}^{-3}$ linfócitos), do total de sete pacientes, dois pacientes $(28,6 \%)$ apresentavam deficiência de zinco. Considerando o grupo intermediário com contagem de linfócito entre 801 e 1600 cels. $\mathrm{mm}^{-3}$ observa-se que do total de 48 pacientes, $17(35,4 \%)$ apresentavam hipozincemia. Considerando os dados obtidos o grupo com valores de zinco dentro da faixa de normalidade do total de 56 pacientes apenas cinco (8,9\%) apresentam linfopenia. A Figura 11 mostra os valores médios de contagem de linfócitos no grupo de zinco plasmático normal com 1611 linfócitos. $\mathrm{mm}^{-3}$ (DP: \pm 656 linfócitos. $\mathrm{mm}^{-3}$ ) comparado com o grupo de pacientes com zinco abaixo do valor normal com 1426 linfócitos. $\mathrm{mm}^{-3}$ (DP: \pm 523 linfócitos. $\mathrm{mm}^{-3}$ ) observa-se que pacientes com deficiência de zinco a média de contagem de linfócitos é menor. 


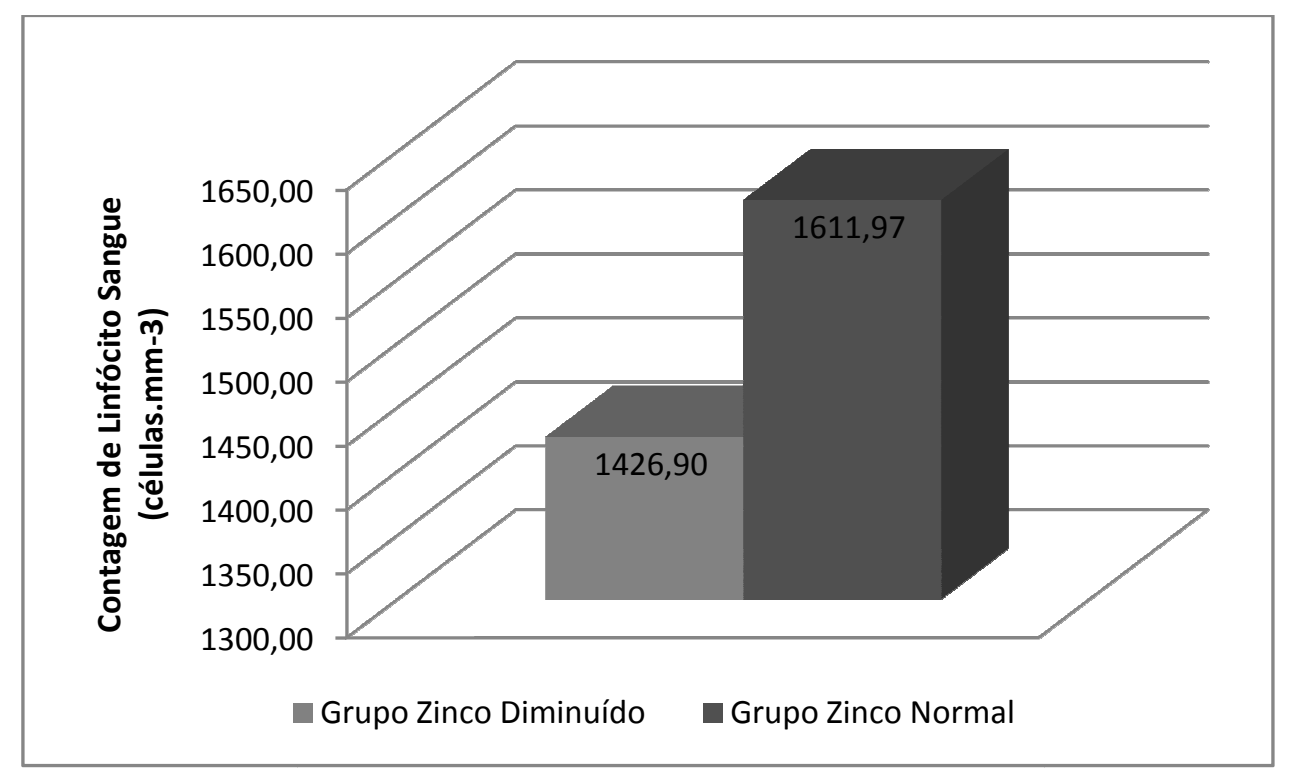

FIGURA 11: Comparação dos valores médios da contagem de linfócitos no sangue entre os grupos de pacientes com zinco plasmático diminuído e normal.

Pacientes submetidos à nutrição parenteral sem reposição de zinco apresentam linfopenia (Dardenne, 2002). Pacientes portadores de Acrodermatite Enteropática apresentam deficiência de zinco e linfopenia (Fraker, 2000). Estudo (Prasad, 2007) realizado com voluntários submetidos à dieta pobre em zinco mostrou que estes desenvolveram diminuição da atividade da timodulina, que foi restaurada com a administração de zinco. Também foi observada a diminuição da produção de interferon-Y. A deficiência de zinco está relacionada com diminuição da atividade do linfócito natural Killer, diminuição da fagocitose dos macrófagos e neutrófilos. Ao contrário, excesso de zinco pode determinar diminuição da atividade do linfócito T (Rink, 2001).

Camundongos com deficiência de zinco apresentam elevação dos corticosteróides, principalmente corticosterona, e adrenalectomia previne a atrofia do timo durante o período de deficiência de zinco. Portanto, deficiência de zinco pode estar relacionada com ativação do eixo neuro-endócrino. Pacientes que apresentam desnutrição protéico-calórica mostram elevação dos glicocorticóides e isso pode estar relacionado com deficiência de zinco (Fraker, 2004).

Devido a dificuldades operacionais foi avaliada a concentração de proteína C em apenas 73 pacientes, Tabela 15. Analisando os resultados 
podemos observar que quarenta e três pacientes apresentaram proteína $\mathrm{C}$ maior que seis, e, trinta apresentavam valor inferior a seis. Do grupo de pacientes que apresentaram resultados com proteína C diminuída 10 pacientes $(33,3 \%)$ apresentavam deficiência de zinco e 20 pacientes $(66,6 \%)$ apresentaram zinco dentro do valor de normalidade. No grupo de pacientes que apresentaram resultados de proteína C aumentada 14 pacientes (32,5\%) apresentaram deficiência de zinco e 29 deles $(67,5 \%)$ apresentavam zinco dentro do valor de normalidade.

Tabela 15: Relação da concentração de Zn plasmático em função da dosagem de proteína $\mathrm{C}$ no sangue periférico, dosada em 73 pacientes.

\begin{tabular}{|c|c|c|c|c|}
\hline \multirow[t]{3}{*}{ Zinco Plasmático } & \multicolumn{4}{|c|}{$\begin{array}{c}\text { Proteína C } \\
(n=73)\end{array}$} \\
\hline & \multicolumn{2}{|c|}{ Aumentada } & \multicolumn{2}{|c|}{ Diminuída } \\
\hline & $(n)$ & $(\%)$ & $(n)$ & $(\%)$ \\
\hline $\begin{array}{l}\text { Normal } \\
\left(>70 \mu \mathrm{g} \cdot \mathrm{dL}^{-1}\right)\end{array}$ & 29 & 67,5 & 20 & 66,7 \\
\hline $\begin{array}{l}\text { Diminuído } \\
\left(<70 \mu \mathrm{g} \cdot \mathrm{dL}^{-1}\right)\end{array}$ & 14 & 32,5 & 10 & 33,3 \\
\hline Total & 43 & 100 & 30 & 100 \\
\hline
\end{tabular}

A concentração de Zn plasmático também foi avaliada levando-se em conta a presença ou não de infecção na hora de internação do paciente (Tabela 16). Dos 88 pacientes analisados 24 apresentavam infecção e 68 não apresentaram quadro infeccioso. Vinte e nove por cento dos pacientes com infecção apresentavam deficiência de zinco, e, trinta e sete por cento dos pacientes sem infecção apresentavam deficiência de zinco

Tabela 16: Relação do zinco com a identificação da presença de infecção na internação do paciente.

\begin{tabular}{lccccc}
\hline $\begin{array}{l}\text { Zinco Plasmático } \\
\text { (Concentração) }\end{array}$ & \multicolumn{5}{c}{ Presença de Infecção } \\
\hline & (n) & $(\%)$ & $(\mathrm{n})$ & $(\%)$ \\
\hline $\begin{array}{l}\text { Normal } \\
\left(>70 \mu \mathrm{g} \cdot \mathrm{dL}^{-1}\right)\end{array}$ & 17 & 70,9 & 40 & 62,5 \\
\hline $\begin{array}{l}\text { Diminuído } \\
\left(<70 \mu \mathrm{g} \cdot \mathrm{dL}^{-1}\right)\end{array}$ & 7 & 29,1 & 24 & 37,5 \\
\hline Total & 24 & 100 & 64 & 100 \\
\hline
\end{tabular}


Analisando os resultados da presença de infecção com relação à concentração de zinco (Tabela 16) observa-se que a presença de infecção na internação não está relacionada com a deficiência de zinco. Da mesma forma, analisando a Tabela 11 pode-se observar que não houve diferença significativa na resposta inflamatória entre os grupos com zinco plasmático abaixo do normal e zinco plasmático normal. Diversos estudos evidenciam o papel do zinco no controle da inflamação e que pacientes com deficiência de zinco apresentam diminuição da resposta inflamatória (Lesourd, 1997; Vasto, 2006).

Considerando o tempo de internação hospitalar, a amostra foi dividida em três grupos: Tempo de permanência curto (menos de uma semana), tempo intermediário (duas semanas) e longa permanência (mais de duas semanas). No grupo de pacientes com menor permanência observa-se um predomínio de pacientes com zinco normal, apenas $22,8 \%$ dos pacientes de curta permanência apresentam deficiência de zinco. No entanto, os grupos de maior permanência hospitalar há um maior número de pacientes com deficiência de zinco, 47,2\% no grupo intermediário, de duas semanas e $35,2 \%$ no grupo considerado de longa permanência, de duas semanas ou mais (Tabela 17).

Tabela 17: Relação da concentração de Zn plasmático em função do tempo de internação hospitalar registrada para 88 pacientes.

\begin{tabular}{lcccccc}
\hline Zinco Plasmático & \multicolumn{7}{c}{$\begin{array}{c}\text { Internação Hospitalar } \\
\text { Semanas } \\
(\mathbf{n = 8 8})\end{array}$} \\
\hline & Menos de 1 semana & \multicolumn{2}{c}{ 2 semanas } & Mais de 2 semanas \\
\hline & $(\mathrm{n})$ & $(\%)$ & $(\mathrm{n})$ & $(\%)$ & $(\mathrm{n})$ & $(\%)$ \\
\hline $\begin{array}{l}\text { Zinco Normal } \\
\left(>70 \mu \mathrm{g} \cdot \mathrm{dL}^{-1}\right)\end{array}$ & 27 & 77,2 & 19 & 52,8 & 11 & 64,8 \\
\hline $\begin{array}{l}\text { Zinco Diminuído } \\
\left(<70 \mu \mathrm{gg} \cdot \mathrm{dL}^{-1}\right)\end{array}$ & 8 & 22,8 & 17 & 47,2 & 6 & 35,2 \\
\hline Total & 35 & 100 & 36 & 100 & 17 & 100 \\
\hline
\end{tabular}

Apesar da pesquisa não envolver o curso dos pacientes durante a hospitalização, foi avaliado a correlação do tempo de internação hospitalar com o valor plasmático do zinco (Tabela 17). Observa-se que pacientes com maior tempo de internação apresentam deficiência de zinco. Normalmente o tempo de internação hospitalar está relacionado com demora na recuperação e/ou 
aparecimento de complicações, que no idoso acamado pode estar relacionado com o desenvolvimento de úlcera de pressão e infecções respiratórias e urinárias. Interroga-se qual o papel do zinco na evolução clínica dos pacientes?

Quanto ao desfecho da internação destes pacientes observa-se que há pequena diferença entre os dois grupos de pacientes, sendo que há taxa de mortalidade um pouco maior nos pacientes com zinco diminuído (Tabela 18.)

Tabela 18: Relação do zinco plasmático com o tipo de alta da população estudada.

\begin{tabular}{llcc}
\hline Grupo de Paciente & Tipo de Alta & \multicolumn{3}{c}{ Pacientes } \\
\hline \multirow{3}{*}{ Zinco diminuído } & & $(\mathrm{n})$ & $(\%)$ \\
& Óbito & 4 & 12,90 \\
\cline { 2 - 4 } & Melhora & 25 & 80,65 \\
\cline { 2 - 4 } & Outros & 2 & 6,45 \\
\hline \multirow{2}{*}{ Zinco Normal } & & 6 & \\
& Óbito & 45 & 10,53 \\
\cline { 2 - 4 } & Melhora & 6 & 78,95 \\
\cline { 2 - 4 } & Outros & 10,53 \\
\hline
\end{tabular}




\section{CONCLUSÃO}

1. Foi observado diferença entre sexos na deficiência de zinco na faixa etária estudada com menor valor médio no sexo feminino.

2. Do ponto de vista clínico, foi observado que a deficiência de zinco está relacionada com desnutrição.

3. Deficiência de zinco pode estar relacionada com piores condições sócioeconômica.

4. Deficiência de zinco pode estar relacionado com linfopenia.

5. Deficiência de zinco pode estar relacionada com diminuição da resposta imunológica.

6. O projeto permitiu concluir também que a permanência hospitalar é influenciada pela deficiência de zinco. Os resultados mostraram que os grupos de maior permanência hospitalar, com duas ou mais semanas de internação, apresentaram um maior número de pacientes com deficiência de zinco.

7. Foi observado que existe correlação entre os parâmetros: idoso - magro hipoalbuminemia - deficiência de zinco - diminuição da defesa (linfopenia) maior tempo de permanência.

8. Apesar dos avanços no conhecimento fisiopatológico sobre a deficiência de zinco há necessidade de se realizar estudos mais abrangentes, incluindo diferentes faixas etárias, populações de referencia por áreas, avaliação de alimentação para podermos correlacionar com mais segurança a necessidade de reposição de zinco para tratamento e prevenção de complicações no idoso. 


\section{REFERÊNCIAS BIBLIOGRÁFICAS}

Al-Maroof RA and Al-Sharbatti SS. Serum zinc levels in diabetic patients and effect of zinc supplementation on glycemic control of type 2 diabetics. Saudi Med J. 2006;27:344-350

Barnes PM, Moynahan EJ. Zinc deficiency in acrodermatitis enteropathica: multiple dietary intolerance treated with synthetic zinc. Proc $\mathbf{R}$ Soc Med. 1973;66:327-329.

Barnett J, Hamer DH, Meydani SN. Low zinc status: a new risk factor for pneumonia in elderly? Nutr Rev.2009;68:30-37.

Barry M, Keeling PW, Feely J. Tissue zinc status and drug elimination in patients with chronic liver disease. Clin Sci. 1990;78:547-549.

Brown KH, Peerson JM, Rivera J, Allen LH. Effect of supplemental zinc on the growth and serum zinc concentrations of prepuberal children: meta-analysis of randomized controlled trials. Am J Clin Nutr. 2002;75:1062-1071.

Caruso TJ, Prober CG and Gwaltney JM. Treatment of naturally acquired common colds with zinc: A structured review. Clin Infect Dis. 2007;45:569-574.

Cervi A, Franceschini SCC, Priore SE. Análise crítica do uso do índice de massa corporal para idosos. Rev Nutr. Campinas, 2005;18:765-775.

Chandyo RK, Strand TA, Mathisen M, Ulak M, Adhikari RK, Bolann BJ and Sommerfelt $\mathrm{H}$. Zinc deficiency is common among healthy women of reproductive age in Bhaktapur, Nepal. J Nutr. 2009;139:594-597.

Chausmer AB. Zinc, Insulin and diabetes. J Am Coll Nutr.1998;17:109-115.

Chumlea WC et al. Prediction of body weight for noambulatory elderly from anthropometric. J Am Diet Assoc. 1988; 88: 564-568. 
Dardenne M. Zinc and immune function. Eur J Clin Nutr. 2002;56:20S-23S.

Dashti HM, Mathew TC, Jadaon MM, Ashkanani E. Zinc and liver cirrhosis: Biochemical and histopathologic assessment. Nutrition. 1997;13:206-212.

Eby GA, Davis DR and Halcomb WW. Reduction in duration of common colds by zinc gluconate lozenges in double-blind study. Antimicrob Agents Chemother. 1984;25:20-24.

Faa G, Nurchi VM, Ravarino A, Fanni D, Nemolato S, Gerosa C, Van Eyken P, Geboes K. Zinc in gastrointestinal and liver disease. Coord Chem Rev. 2008;252:1257-1269.

Fraker PJ. Roles for Cell Death in Zinc Deficiency. J Nutr. 2005;135:359-362.

Fraker PJ, King LE, Laakko T, Vollmer TL. Reprogramming of the immune system during zinc deficiency. Annu Rev Nutr.2004;24:277-298.

Goode HF, Kelleher J, Walker BE. Relation between zinc status and hepatic functional reserve in patients with liver disease. Gut. 1990;31:694-697.

Grant JP. Handbook of Total Parenteral Nutrition. Saunders, Philadelphia, 1980; p 163.

Hambidge, M. Human Zinc Deficiency. J Nutr. 2000;130:1344S-1349S.

Hambidge, M. Biomarkers of mineral trace intake and status. $J$ Nutr. 2003;133:948S-955S.

Haynes L. The effect of aging on cognate function and development of immune memory. Curr Opin Immunol. 2005;17:476-479.

Hotz C, Peerson JM, Brown KH. Suggested lower cutoffs zinc concentrations for assessing zinc status: reanalysis of the second National Healt and Nutrition Examination Survey data (1976-1980). Am J Clin Nutr. 2003;78:756-764.

Instituto Brasileiro de Geografia e Estatística. IBGE. www.ibge.gov.br/cidadesat/topwindow.htm. Acessado em 17/08/2010. 
Institute of Medicine of the national academies. http/MWW.iom.edu/Global/News\%20Annoucements/ /media/Files/Activity\%20 Files/Nutrition/DRIs/DRISummaryListing2.ashx. Acessado em 17/08/2010.

Jansen J, Karges W and Rink L. Zinc and diabetes - clinical links and molecular mechanisms. J Nutr Biochem. 2009;20:399-417.

Jeejeebhoy K. Zinc: An essential trace element for parenteral nutrition. Gastroenterology.2009;137:S7-S12.

Kanoni S, Dedoussis G, Manios Y, Malavolta M, Mocchegiani E. Health status, blood and anthropometrical indices from Greek old and nonagenarian subjects. Biogerontology.2006;7:329-337.

Karadag F, Cildag O, Altinisik M, Kozaci LD, Kiter G and Altun C. Trace elements as a component of stress in COPD. Respirology.2004;9:33-37.

Karyadi E, Schultink W, Nelwan RHH, Gross R, Amin Z, Dolmans WMV, van der Meer JWM, Hautvast JGAJ, West CE. Poor Micronutrient Status of Active Pulmonary tuberculosis Patients in Indonesia. J Nutr.2000;130:2953-2958.

Karyadi E, West CE, Schultink W, Nelwan RHH, Gross R, Amin Z, Dolmans WMV, Schlebush H, van der Meer JWM. A double-blind, placebo-controlled study of vitamin $A$ and zinc supplementation in persons with tuberculosis in Indonesia: effects on clinical response and nutritional status. Am J Clin Nutr. 2002;75:720-727.

King JC, Shames DM, Woodhouse LR. Zinc Homeostasis in Humans. J Nutr.2000;130:1360S-1366S.

Koury JC e Donangelo CM. Zinco, estresse oxidativo e atividade física. Rev Nutr, Campinas, 2003;16:433-441.

Krebs NF. Overview of Zinc Absorption and Excretion in the human Gastrointestinal Tract. J Nutr.2000;130:1374S-1377S.

Kurugöl Z, Akilli M, Bayram N and Koturoglu G. The prophylactic and therapeutic effectiveness of zinc sulphate on common cold children. Acta Paediatr.2006;95:1175-1181. 
Lee $\mathrm{HH}$, Prasad AS, Brewer GJ and Owyang C. Zinc absorption in human small intestine. Am J Gastrointest Liver Physiol. 1989;256:687-691.

Lesourd BM. Nutrition and immunity in elderly: modification of immune responses with nutritional treatments. Am J Clin Nutr.1997;66:478S-484S.

Lira PIC, Ashworth A, Morris SS. Effect of zinc supplementation on morbidity, immune function, and growth of low-birth-weight, full-term infants in northeast Brazil. Am J Clin Nutr. 1998;68:418S-424S.

Lorgeril M, Salen P, Defaye P. Importance of nutrition in chronic heart failure patients. Eur Heart J.2005;26:2215-2217.

Lohman TG, Roche AF \& Martorell R. 1988. Anthropometric Standardization Reference Manual. Champaign, Illinois: Human Kinetics.

Lönnerdal B. Dietary factors influencing zinc absorption. J Nutr. 2000;130:1378S-1387S.

Lowe NM, Fekete K, Decsi T. Methods of assessment of zinc status in humans: a systematic review. Am J Clin Nutr.2009;89:2040S-2051S.

Mahajane SK, Prasad AS, Rabbani P, Briggs WA and McDonald FD. Zinc deficiency: a reversible complication of uremia. Am J Clin Nutr.1982;36:11771183.

Marcellini F, Giuli C, Papa R, Gagliardi C, Dedoussis G, Herbein G, Fulop T, Monti D, Rink L, Jajte J, Mocchgiani E. Zinc status, psychological and nutritional assessment in old people recruited in five European countries: Zincage study. Biogerontology.2006;7:339-345.

Marshall I. Withdrawn: Zinc for the common cold. Cochrane Database Syst Rev.2000;2:CD001364.

Maverakis E, Fung MA, Lynch PJ, Draznin M, Michael DJ, Ruben B, Fazel N. Acrodermatitis enteropathica and an overview of zinc metabolism. J Am Acad Dermatol. 2007;56:116-124. 
McKenzie JM. Content of zinc serum, urine, hair and toenails of New Zealand adults. Am J Clin Nutr.1979;32:570-579.

Mocchegiani E, Muzzioli M. Therapeutic Application of Zinc in Human Immunodeficiency Virus against Opportunistic Infection. $\mathbf{J}$ Nutr. 2000;130:1424S-1431S.

Mocchegiani E, Giacconi R, Muzzioli M, Cipriano C. Zinc, Infections and immunosenescence. Mech Ageing Dev. 2000;121:21-35.

Mocchegiani E, Rink L, Blasco M. Zinc and ageing (ZINCAGE Project). Biogerontology. 2006;7:305-306.

Nordstrom JW. Trace mineral nutrition in the elderly. Am J Clin Nutr.1982; 36:788-795.

Okigami, H. Zinco - um estudo superficial. J Biomolec Med Free Rad. $1996 ; 2: 37-41$

Person OC, Botti AS, Féres MCLC. Repercussões clínicas da deficiência de zinco em humanos. Arq Med ABC.2006;31:46-52.

Prasad AS. Zinc deficiency in women, infants and children. J Am Coll Nutr. 1996;15:113-120.

Prasad AS. Zinc: The Biology and Therapeutics of an Ion. Ann Intern Med. 1996;125:142-143.

Prasad AS. Zinc Deficiency in Humans: A Neglected Problem. J Am Coll Nutr. 1998; 17:542-543.

Prasad AS. Zinc deficiency. Has been known of for 40 years but ignored by health organizations. BMJ.2003;326:409-410.

Prasad AS. Zinc: Mechanisms of host defense. J Nutr.2007;137:1345-1349.

Prasad AS. Zinc: role in immunity, oxidative stress and chronic inflammation. Curr Opin Clin Nutr Metab Care.2009;12:646-652. 
Ray M, Kumar L, Prasad R. Plasma zinc status in Indian childhood tuberculosis: impact of antituberculosis therapy. Int J Tuberc Lung Dis.1998;2:719-725.

Rink L, Kirchner H. Zinc-Alterede Immune Function and Cytokine Production. J Nutr. 2000;130:1407S-1411S.

Rink L, Gabriel P. Extracellular and immunological actions of zinc. BioMetals.2001;14:367-383.

Saiki M, Sumita NM, Jaluul O, Jacob-Filho W and Vasconcelos MBA. Evaluation of serum trace element, biochemical and hematological data of a healthy elderly group residing in São Paulo city, Brazil. J Radioanal Nucl Chem. 2009;281:107-111.

Salgueiro MJ, Zubillaga M, Lysionek A, Sarabia MI, Caro R, De Paoli T, Hager A, Weill R, Boccio J. Zinc as an essential micronutrient: a review. Nutr Res. 2000;20:737-755.

Sandstead HH. Zinc: Growth, development and function. Trace Elem Exp Med. 2000;1:41-49.

Sazawal S, Black RE, Bhan MK, Bhandari N, Sinha A, Jalla S. Zinc supplementation in young children with acute diarrhea in India. $\mathbf{N}$ Eng $\mathbf{J}$ Med.1995;333:839-844.

SCHLICKMANN FRAINER, Deivis Elton et al. Padronização e confiabilidade das medidas antropométricas para pesquisa populacional. ALAN [online]. 2007, vol.57, n.4 ISSN 0004-0622.

Shankar AH, Prasad AS. Zinc and immune function: the biological basis of altered resistance to infection. Am J Clin Nutr.1998;68:447S-463S.

Stefanidou M, Maravelias C, Dona A, Spiliopoulou C. Zinc: a multipurpose trace element. Arch Toxicol.2006;80:1-9.

Tuerk MJ, Fazel N. Zinc deficiency. Curr Opin Gastroenterol. 2009; 25:136143. 
van Lettow M, Harries AD, Kumwenda JJ, Zijlstra EE, Clark TD, Taha TE, Semba RD. Micronutrient malnutrition and wasting in adults with pulmonary tuberculosis with and without HIV co-infection in Malawi. BMC Infect Dis. 2004; 4:61-68.

Valle BL, Falchuk KH. The biochemical basis of zinc physiology. Physiol Rev. 1993;73:79-118.

Vasto S, Mocchegiani E, Candore G, Listi F, Colonna-Romano G, Lio D, Malavolta M, Giacconi R, Cipriano C, Caruso C. Inflammation, genes and zinc in ageing and age-related disease. Biogerontology. 2006;7:315-327.

Vannucchi H, De Unamuno MRD, Marchini JS. Avaliação do estado nutricional. Medicina, Ribeirão Preto, 1996;29:5-18.

Wagner PA, Krista ML, Bailey LB, Christakis GJ, Jernigan JA, Araujo PE, Appledorf H, Davis CG, Dining JS. Zinc status of elderly black Americans from urban low-income households. Am J Clin Nutr. 1980;33:1771-1777.

Wapnir RA. Zinc deficiency, Malnutrition and Gastrointestinal Tract. J Nutr. 2000;130:1388S-1392S.

Witte KKA, Nikitin NP, Parker AC, von Haehling S, Volk HD, Anker SD, Clark $A L$, Cleland JGF. The effect of micronutrient supplementation on quality-of-life and left ventricular function in elderly patients with chronic heart failure. Eur Heart J. 2005;26:2238-2244.

WHO (WORLD HEALTH ORGANIZATION), 1995. Physical Status: the Use and interpretation of Anthropometry. WHO Technical Report Series, $\mathrm{n}$ 854 . Genève: WHO.

WHO (WORLD HEALTH ORGANIZATION), 2007, Avaliando os niveis de zinco na população através da concentração de zinco no soro. www.izincg.org/publications/files/Portuguese_brief2.pdf

Wood RJ. Assessment of marginal Zinc Status in Humans. $J$ Nutr. 2000;130:1350S-1354S. 
ZINCAGE . Nutritional zinc,oxidative stress and immunosenescence: biochemical, genetic and lifestyle implecations for healthy ageing.Project acronym: ZINCAGE. http// www.zincage.org. Acessado em 25 de fevereiro de 2009. 


\section{ANEXO 1: ANÁLISE ESTATÍSTICA}
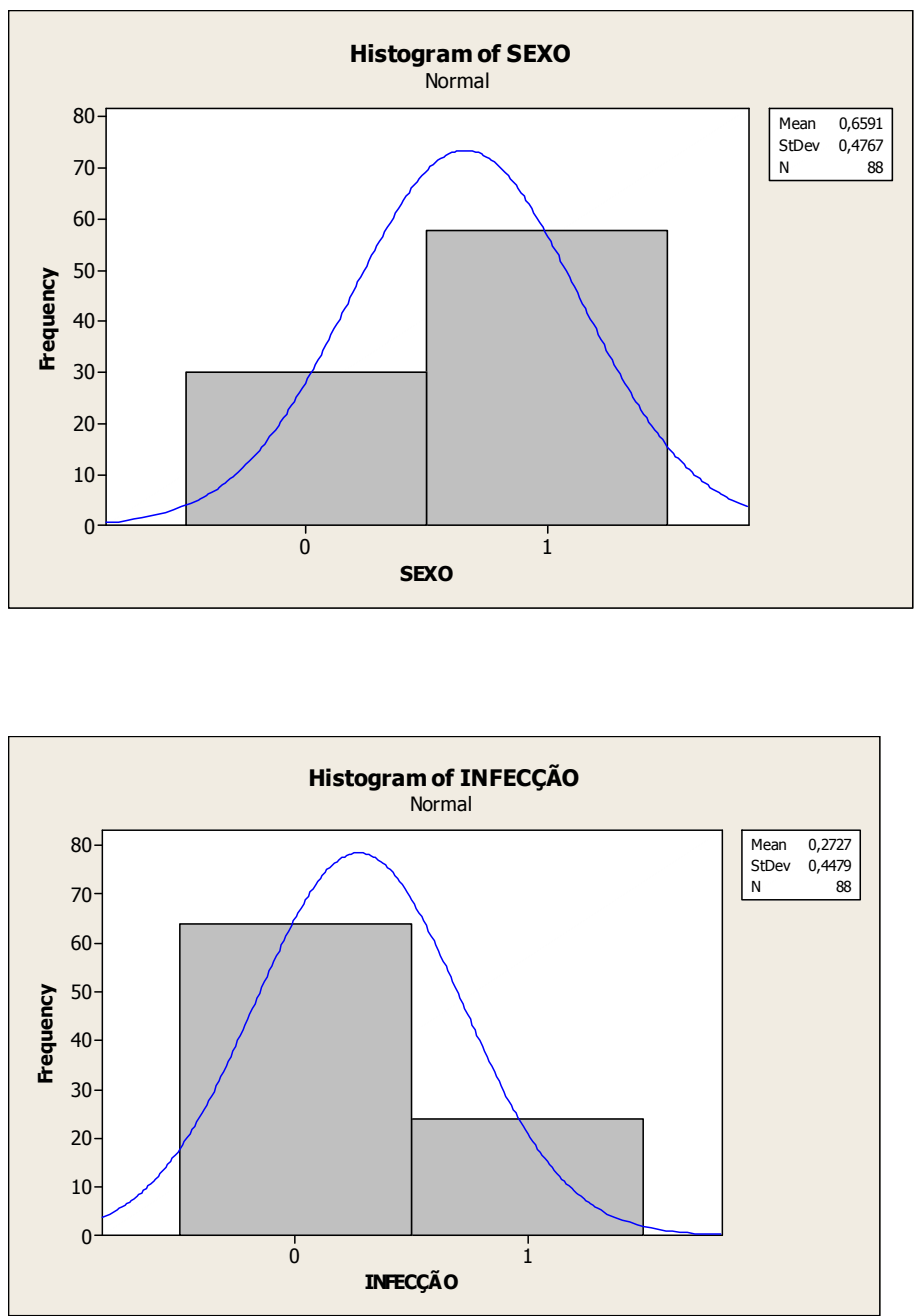

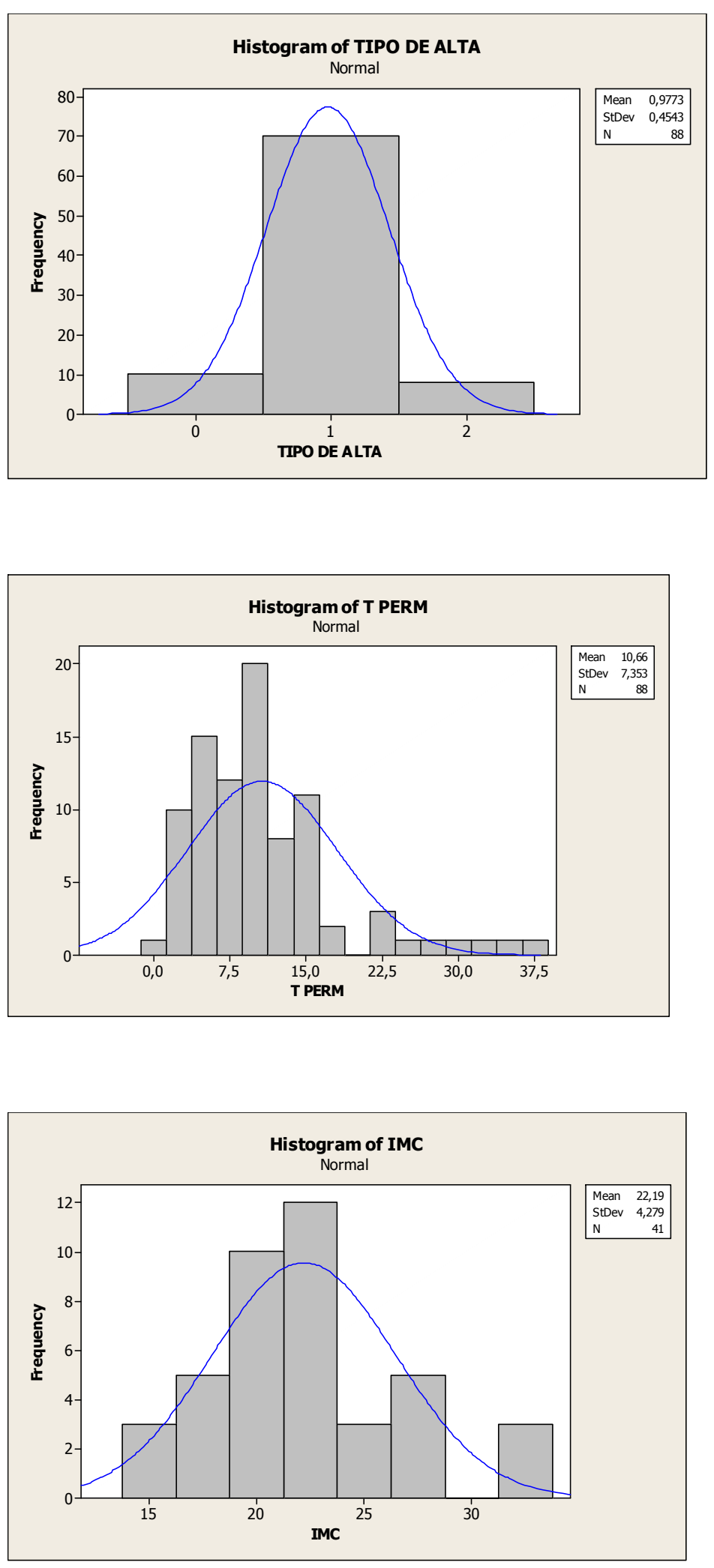

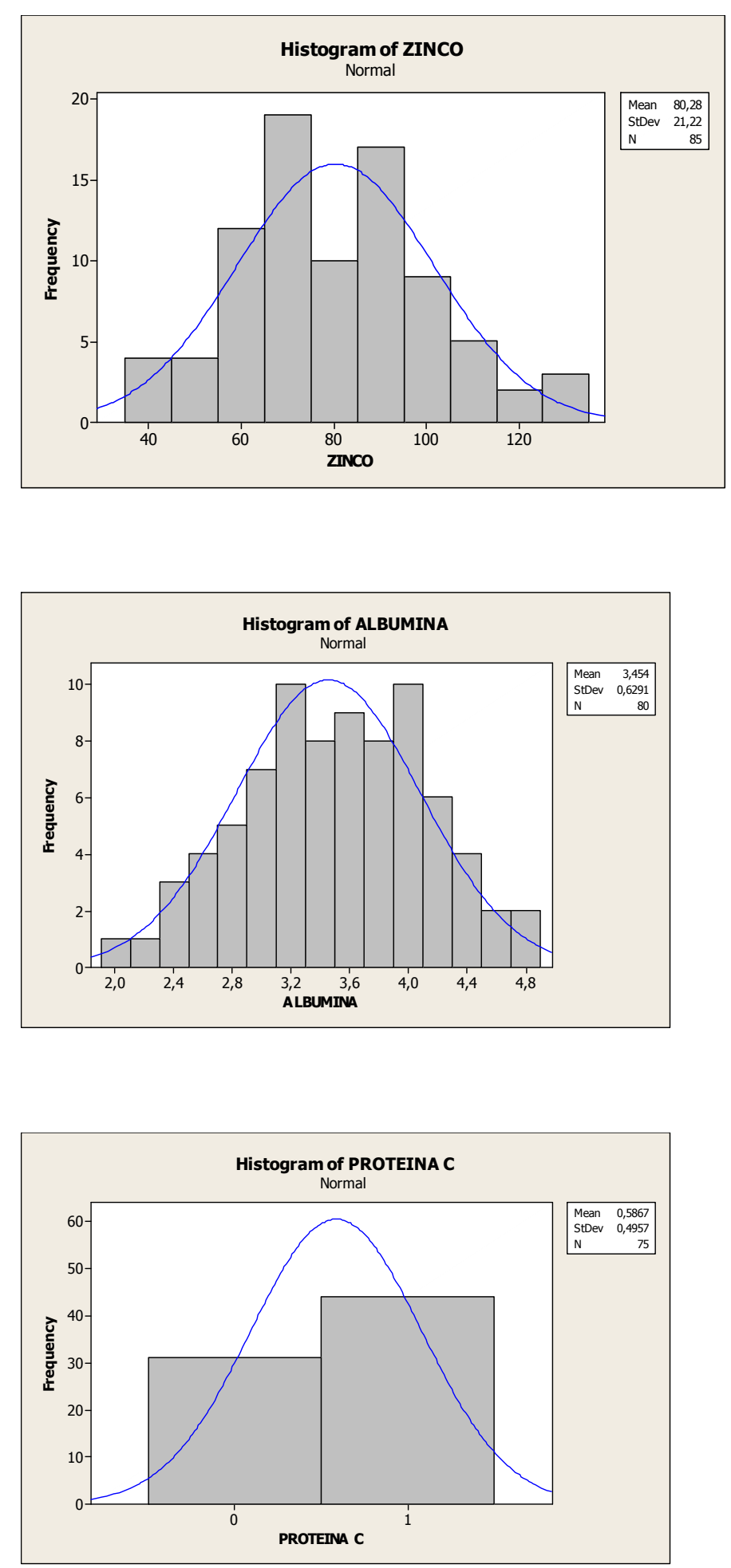

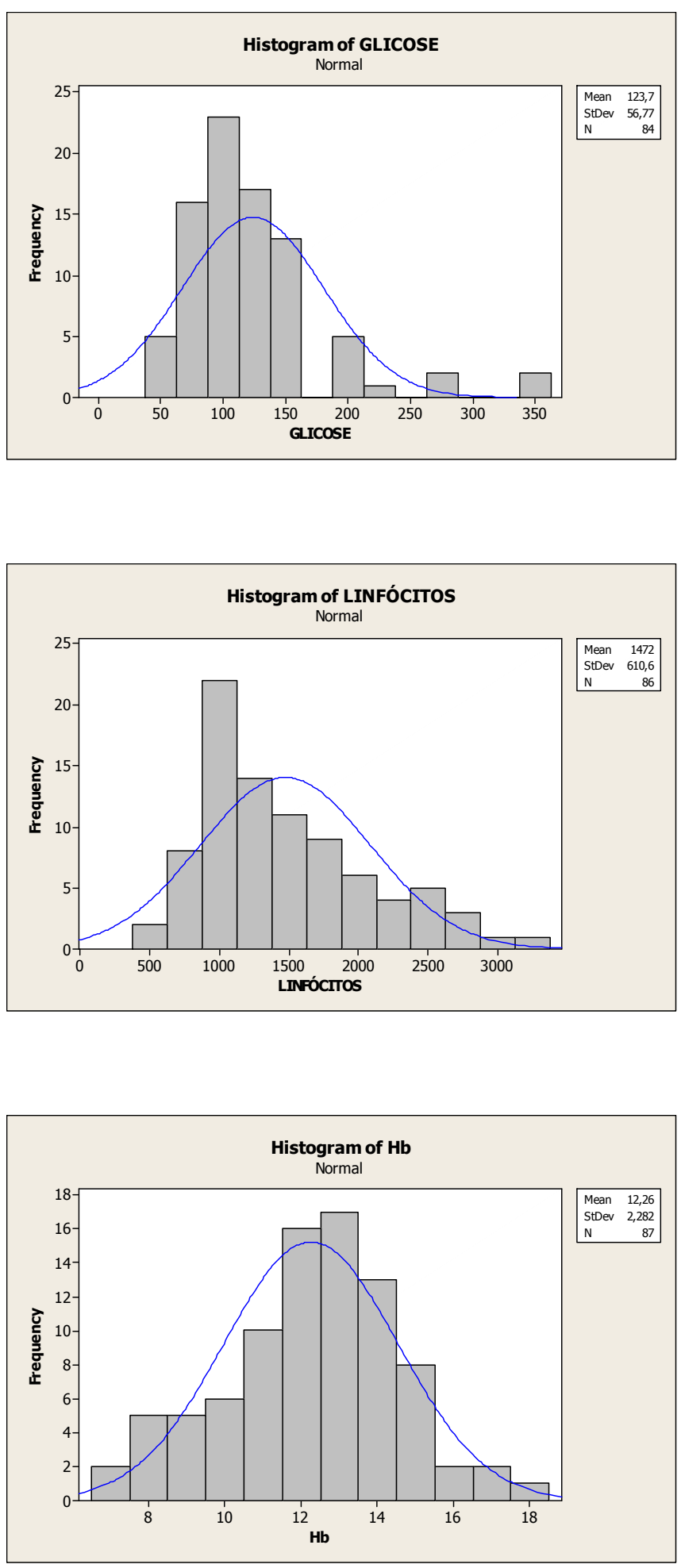


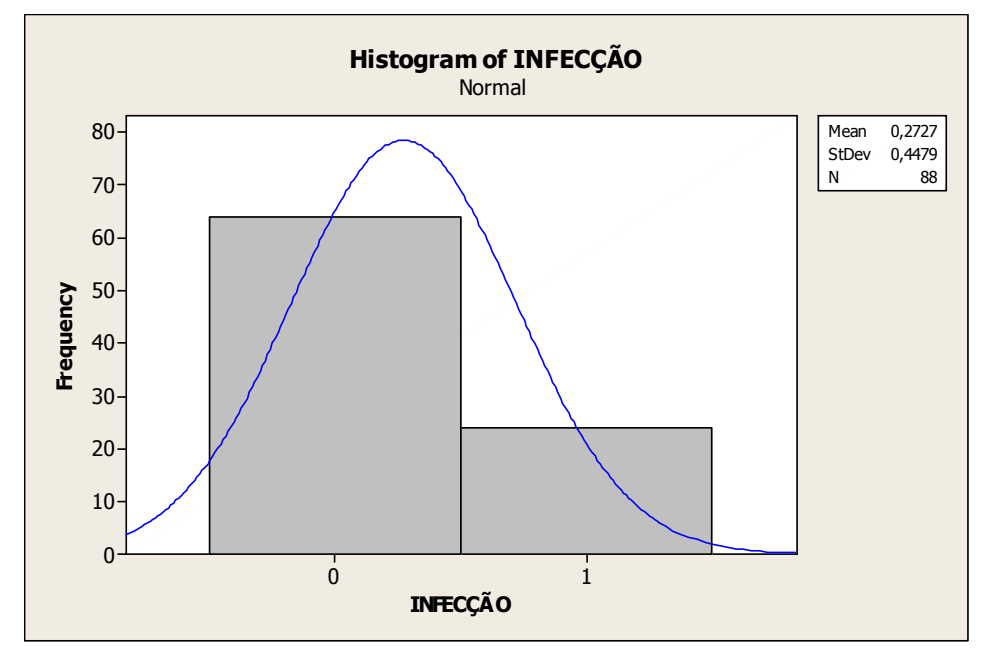

Correlations: ZINCO; SEXO

Pearson correlation of ZINCO and $\mathrm{SEXO}=0,053$

$\mathrm{P}$-Value $=0,628$

Regression Analysis: ZINCO versus SEXO

The regression equation is

$\mathrm{ZINCO}=78,7+2,37 \mathrm{SEXO}$

85 cases used, 3 cases contain missing values

$\begin{array}{lrrrrr}\text { Predictor } & \text { Coef } & \text { SE Coef } & \text { T } & P \\ \text { Constant } & 78,714 & 3,959 & 19,88 & 0,000 \\ \text { SEXO } & 2,370 & 4,878 & 0,49 & 0,628\end{array}$


$S=21,3208 \quad R-S q=0,3 \% \quad R-S q(\operatorname{adj})=0,0 \%$

Analysis of Variance

$\begin{array}{lrrrrr}\text { Source } & \text { DF } & \text { SS } & \text { MS } & F & P \\ \text { Regression } & 1 & 107,3 & 107,3 & 0,24 & 0,628 \\ \text { Residual Error } & 83 & 37729,8 & 454,6 & & \\ \text { Total } & 84 & 37837,2 & & & \end{array}$

Unusual Observations

$\begin{array}{rrrrrrr}\text { Obs } & \text { SEXO } & \text { ZINCO } & \text { Fit } & \text { SE Fit } & \text { Residual } & \text { St Resid } \\ 81 & 0,00 & 122,00 & 78,71 & 3,96 & 43,29 & 2,07 \mathrm{R} \\ 82 & 1,00 & 124,00 & 81,08 & 2,85 & 42,92 & 2,03 \mathrm{R} \\ 83 & 0,00 & 128,50 & 78,71 & 3,96 & 49,79 & 2,38 \mathrm{R} \\ 84 & 1,00 & 129,50 & 81,08 & 2,85 & 48,42 & 2,29 \mathrm{R} \\ 85 & 1,00 & 134,00 & 81,08 & 2,85 & 52,92 & 2,50 \mathrm{R}\end{array}$

$\mathrm{R}$ denotes an observation with a large standardized residual. 


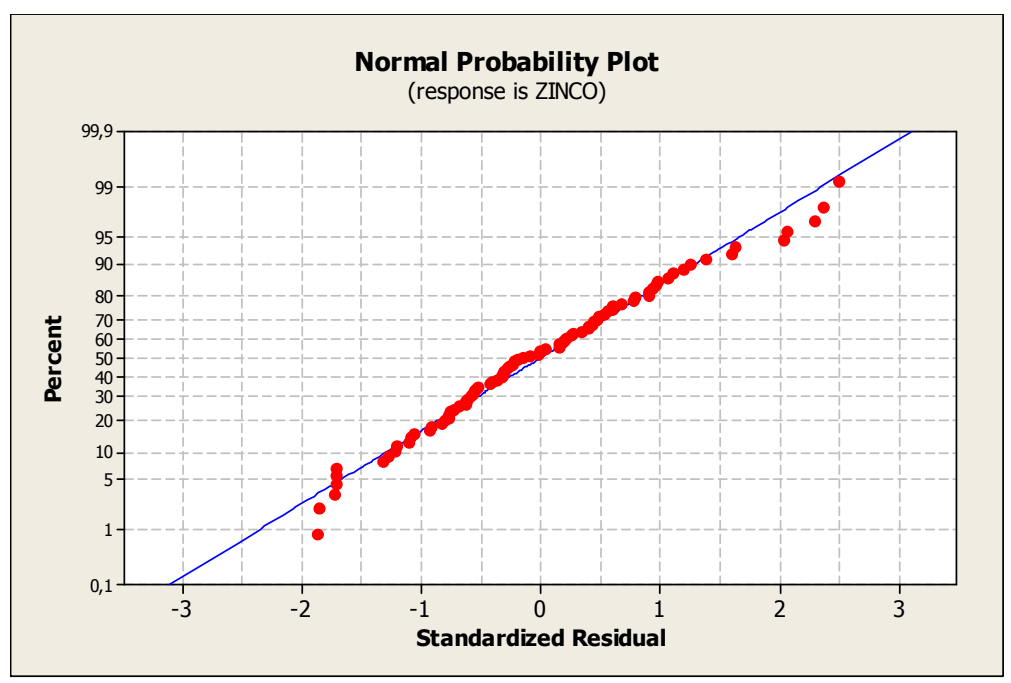

Residuals vs Fits for ZINCO

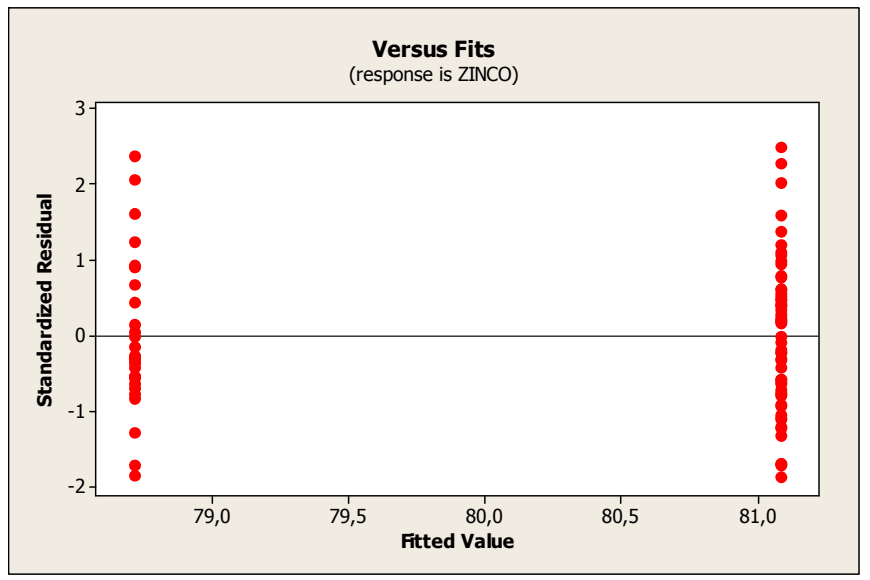

\section{Residual Histogram for ZINCO}

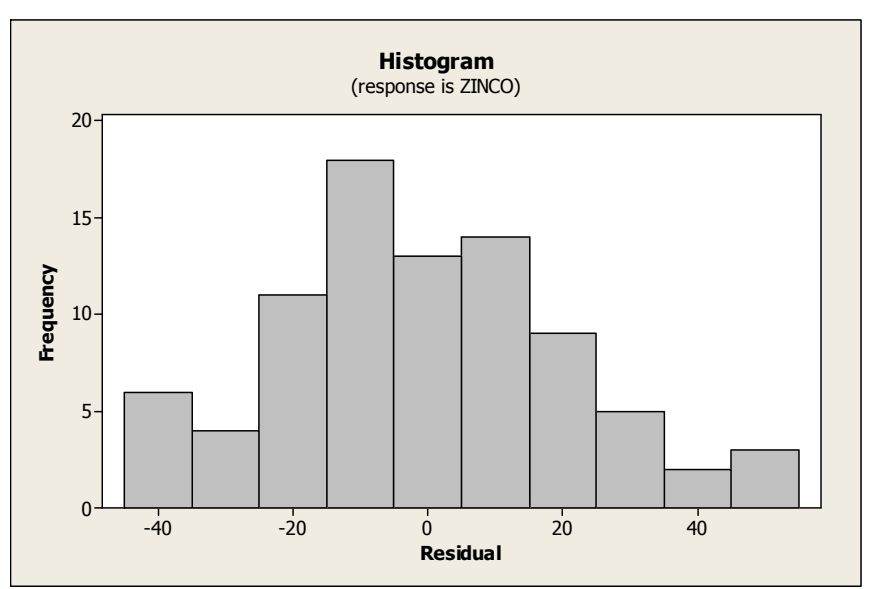




\section{Probability Plot of RESI1}

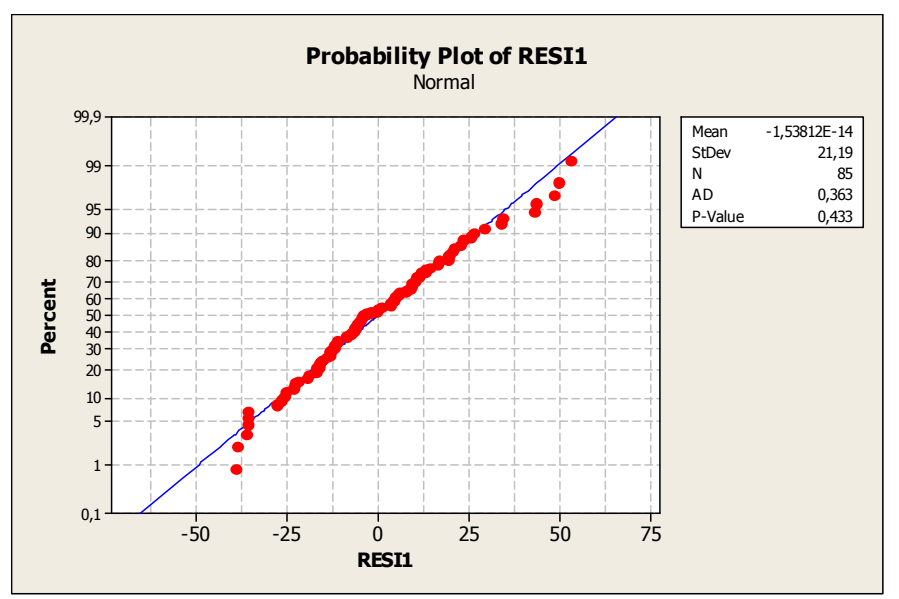

Correlations: ZINCO; GLICOSE

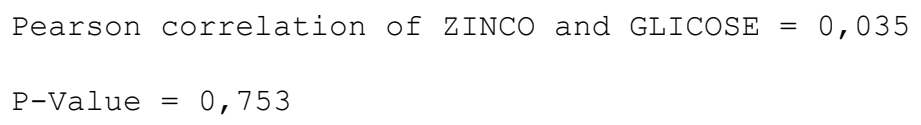

Regression Analysis: ZINCO versus GLICOSE

The regression equation is

ZINCO $=79,3+0,0131$ GLICOSE

81 cases used, 7 cases contain missing values

$\begin{array}{lrrrrr}\text { Predictor } & \text { Coef } & \text { SE Coef } & \text { T } & \text { P } \\ \text { Constant } & 79,259 & 5,617 & 14,11 & 0,000 \\ \text { GLICOSE } & 0,01312 & 0,04164 & 0,32 & 0,753\end{array}$


$S=21,2564 \quad R-S q=0,1 \% \quad R-S q(\operatorname{adj})=0,0 \%$

Analysis of Variance

$\begin{array}{lrrrrr}\text { Source } & \text { DF } & \text { SS } & \text { MS } & \text { F } & \text { P } \\ \text { Regression } & 1 & 44,9 & 44,9 & 0,10 & 0,753 \\ \text { Residual Error } & 79 & 35695,1 & 451,8 & & \\ \text { Total } & 80 & 35739,9 & & & \end{array}$

Unusual Observations

$\begin{array}{rrrrrrr}\text { Obs } & \text { GLICOSE } & \text { ZINCO } & \text { Fit } & \text { SE Fit } & \text { Residual } & \text { St Resid } \\ 22 & 350 & 65,60 & 83,85 & 9,77 & -18,25 & -0,97 \mathrm{X} \\ 43 & 360 & 77,10 & 83,98 & 10,17 & -6,88 & -0,37 \mathrm{X} \\ 69 & 274 & 97,80 & 82,86 & 6,74 & 14,94 & 0,74 \mathrm{X} \\ 72 & 277 & 101,40 & 82,89 & 6,86 & 18,51 & 0,92 \mathrm{X} \\ 82 & 136 & 124,00 & 81,04 & 2,43 & 42,96 & 2,03 \mathrm{R} \\ 83 & 70 & 128,50 & 80,18 & 3,22 & 48,32 & 2,30 \mathrm{R} \\ 84 & 78 & 129,50 & 80,28 & 3,00 & 49,22 & 2,34 \mathrm{R} \\ 85 & 108 & 134,00 & 80,68 & 2,44 & 53,32 & 2,53 \mathrm{R}\end{array}$

$\mathrm{R}$ denotes an observation with a large standardized residual.

$\mathrm{X}$ denotes an observation whose $\mathrm{X}$ value gives it large leverage.

Normplot of Residuals for ZINCO 


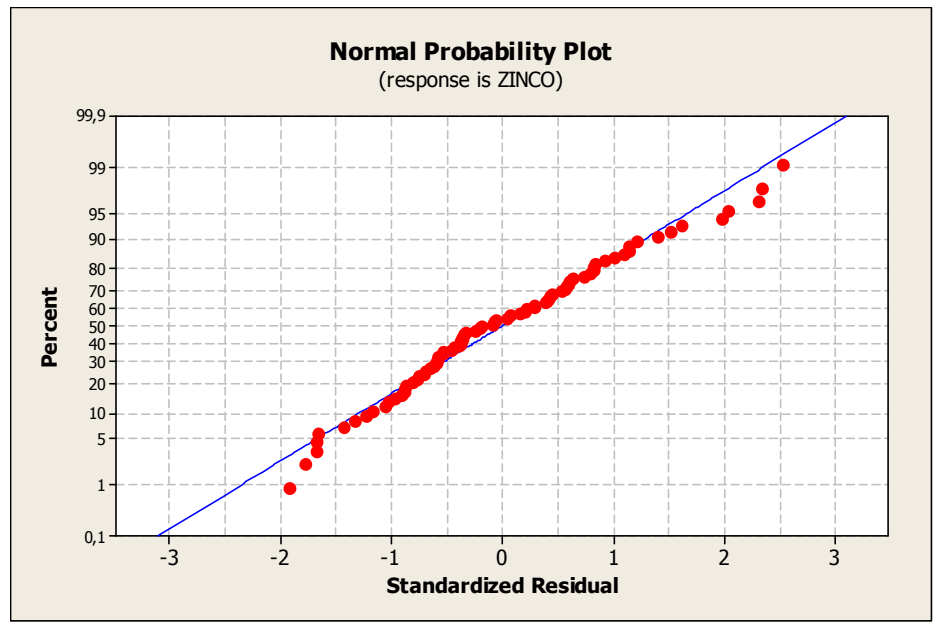

Residuals vs Fits for ZINCO

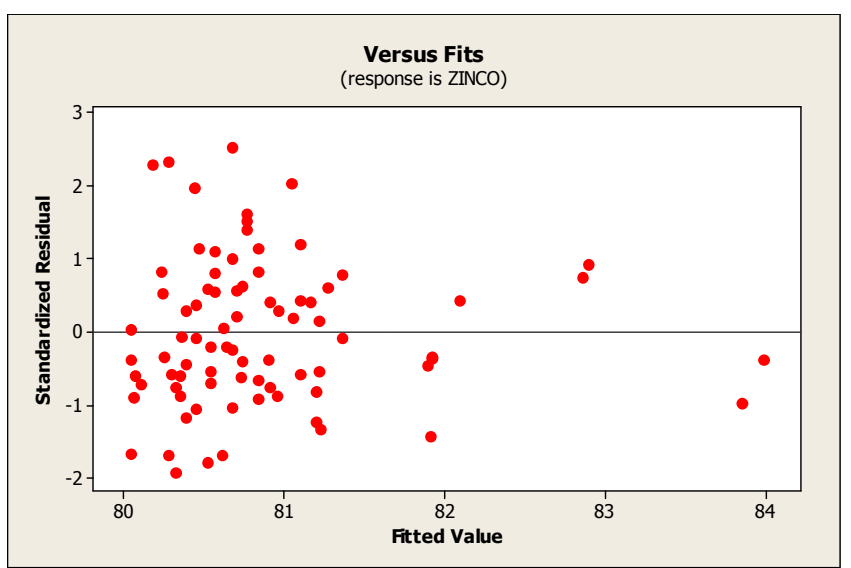

\section{Residual Histogram for ZINCO}

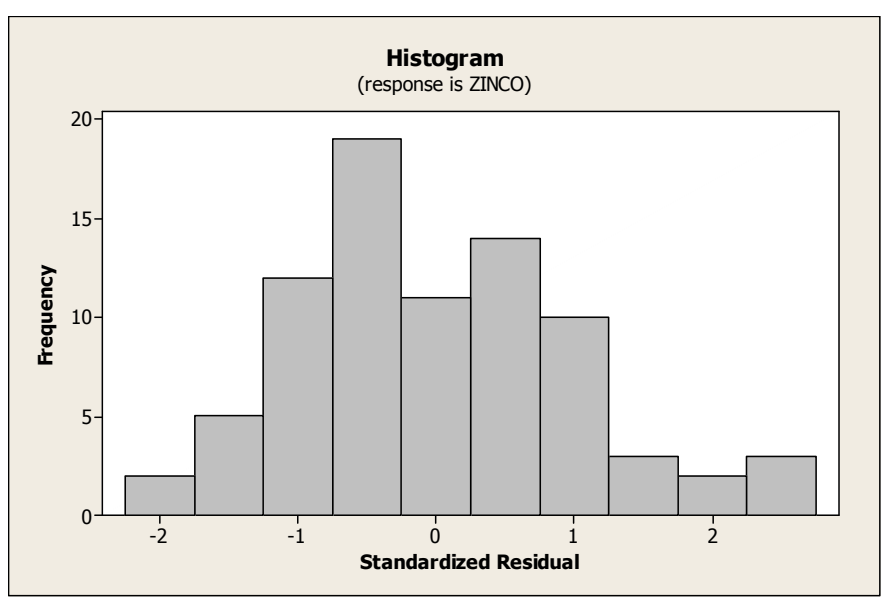

Probability Plot of RESI2 


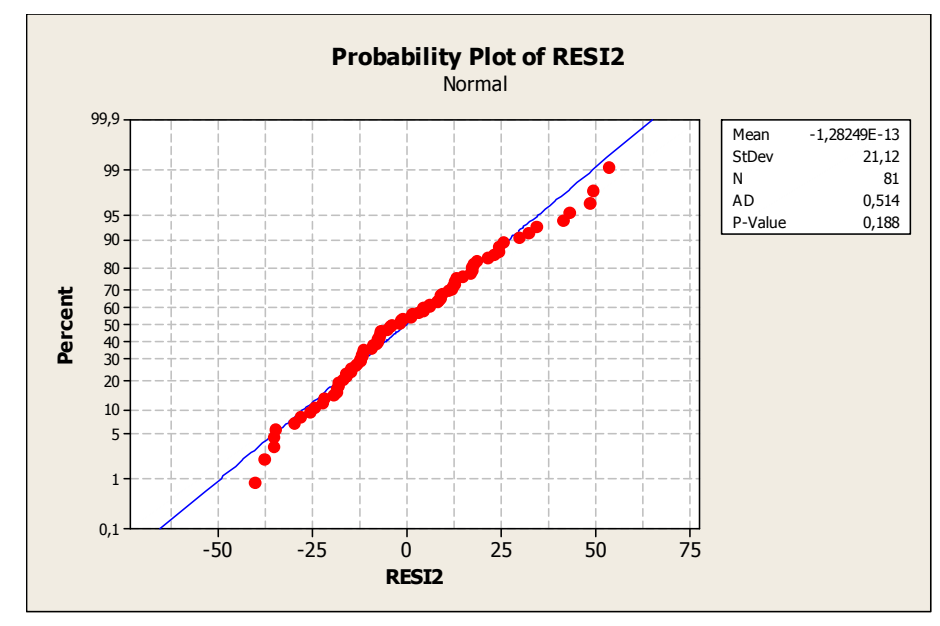

\title{
Correlations: ZINCO; ALBUMINA
}

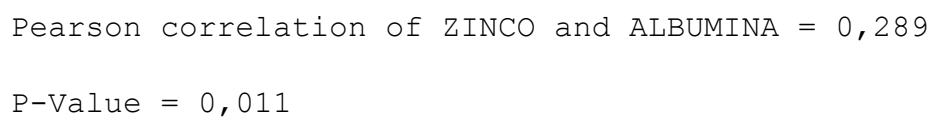

Regression Analysis: ZINCO versus ALBUMINA

\author{
The regression equation is \\ ZINCO $=49,4+9,46$ ALBUMINA
}

77 cases used, 11 cases contain missing values

$\begin{array}{lrrrrr}\text { Predictor } & \text { Coef } & \text { SE coef } & \text { T } & \text { P } \\ \text { Constant } & 49,38 & 12,83 & 3,85 & 0,000 \\ \text { ALBUMinA } & 9,464 & 3,625 & 2,61 & 0,011\end{array}$


Analysis of Variance

$\begin{array}{lrrrrr}\text { Source } & \text { DF } & \text { SS } & \text { MS } & \text { F } & \text { P } \\ \text { Regression } & 1 & 2576,0 & 2576,0 & 6,82 & 0,011 \\ \text { Residual Error } & 75 & 28338,6 & 377,8 & & \\ \text { Total } & 76 & 30914,6 & & \end{array}$

Unusual Observations

$\begin{array}{rrrrrrr}\text { Obs } & \text { ALbUMinA } & \text { ZINCO } & \text { Fit } & \text { SE Fit } & \text { Residual } & \text { St Resid } \\ 15 & 1,90 & 61,50 & 67,36 & 6,16 & -5,86 & -0,32 \mathrm{X} \\ 80 & 2,30 & 114,90 & 71,15 & 4,83 & 43,75 & 2,32 \mathrm{R} \\ 82 & 3,30 & 124,00 & 80,61 & 2,32 & 43,39 & 2,25 \mathrm{R} \\ 83 & 4,00 & 128,50 & 87,24 & 2,90 & 41,26 & 2,15 \mathrm{R} \\ 85 & 4,20 & 134,00 & 89,13 & 3,41 & 44,87 & 2,34 \mathrm{R}\end{array}$

$\mathrm{R}$ denotes an observation with a large standardized residual.

$\mathrm{X}$ denotes an observation whose $\mathrm{X}$ value gives it large leverage.

Normplot of Residuals for ZINCO 


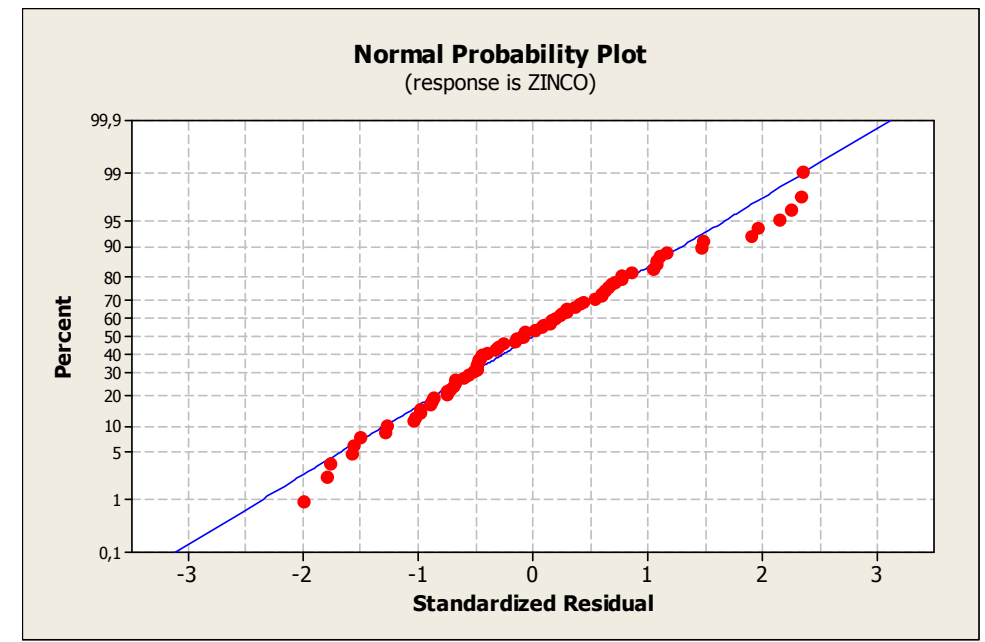

Residuals vs Fits for ZINCO

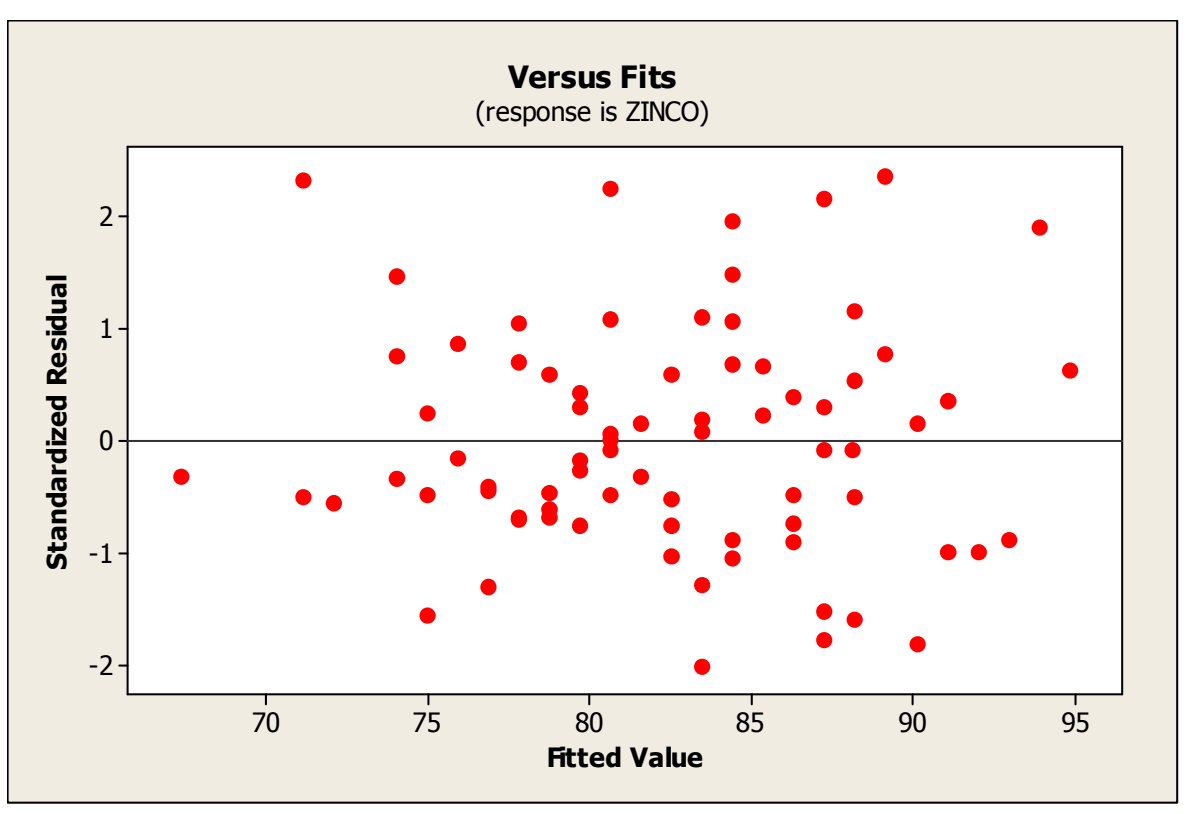

Residual Histogram for ZINCO 


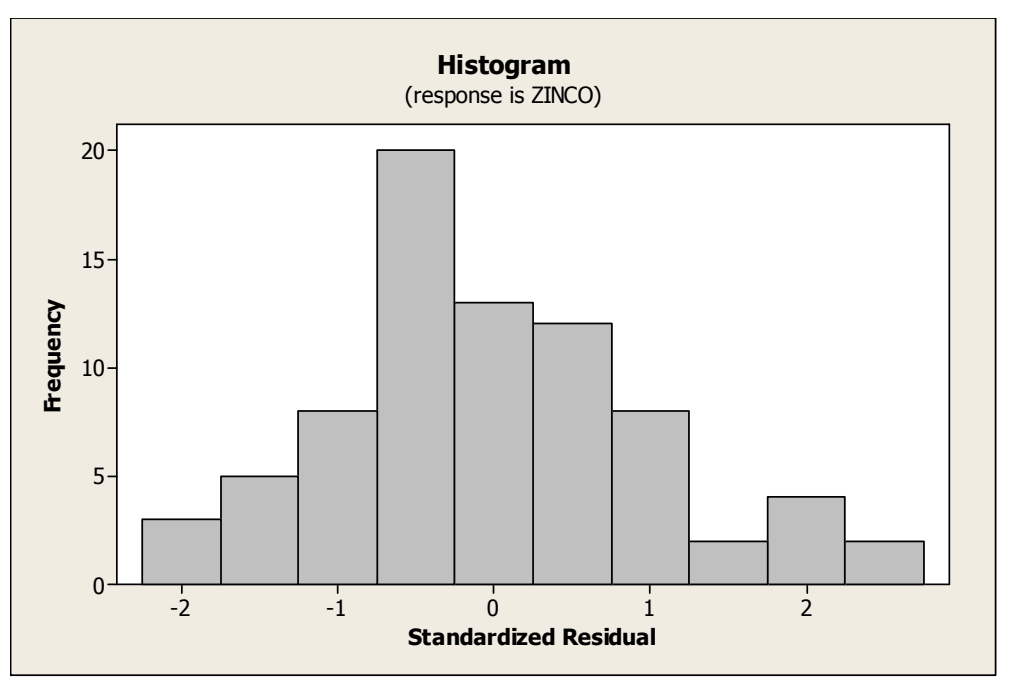

\section{Probability Plot of RESI2}

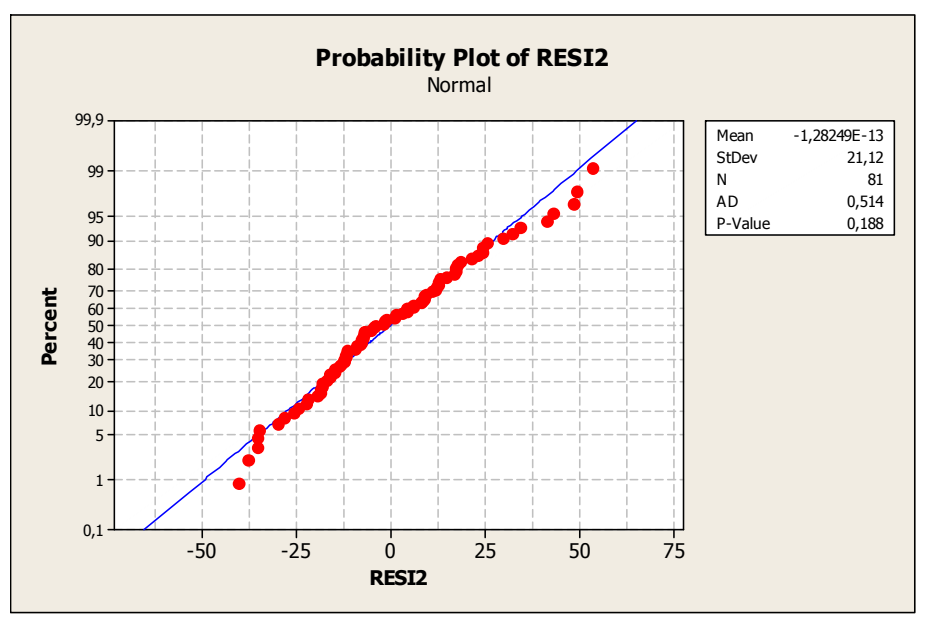

Correlations: ZINCO; PROTEINA C

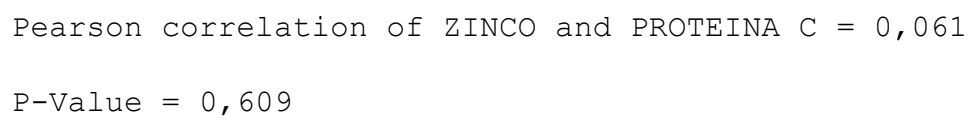


72 cases used, 16 cases contain missing values

$\begin{array}{lrrrr}\text { Predictor } & \text { Coef } & \text { SE Coef } & \text { T } & P \\ \text { Constant } & 81,513 & 3,722 & 21,90 & 0,000 \\ \text { PROTEINA C } & 2,533 & 4,932 & 0,51 & 0,609 \\ & & & \\ \text { S }=20,7230 & \text { R-Sq }=0,4 \% & \text { R-Sq }(\operatorname{adj})=0,0 \%\end{array}$

Analysis of Variance

$\begin{array}{lrrrrr}\text { Source } & \text { DF } & \text { SS } & \text { MS } & F & \text { P } \\ \text { Regression } & 1 & 113,3 & 113,3 & 0,26 & 0,609 \\ \text { Residual Error } & 70 & 30060,9 & 429,4 & & \\ \text { Total } & 71 & 30174,2 & & & \end{array}$

Unusual Observations

$\begin{array}{rrrrrrr}\text { Obs } & \text { PROTEINA C } & \text { zINCO } & \text { Fit } & \text { SE Fit } & \text { Residual } & \text { St Resid } \\ 83 & 1,00 & 128,50 & 84,05 & 3,24 & 44,45 & 2,17 \mathrm{R} \\ 84 & 0,00 & 129,50 & 81,51 & 3,72 & 47,99 & 2,35 \mathrm{R} \\ 85 & 1,00 & 134,00 & 84,05 & 3,24 & 49,95 & 2,44 \mathrm{R}\end{array}$

$\mathrm{R}$ denotes an observation with a large standardized residual. 


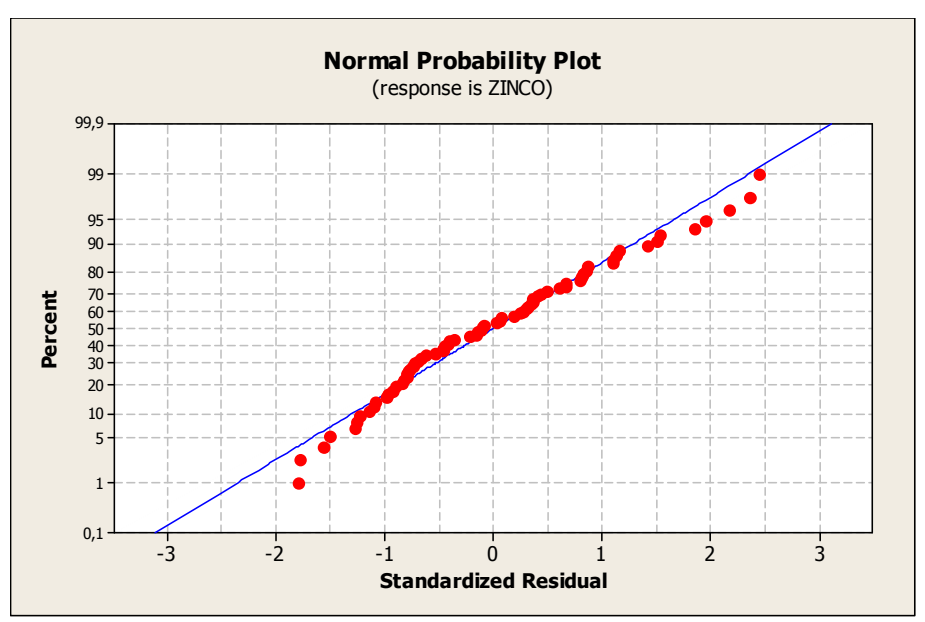

Residuals vs Fits for ZINCO

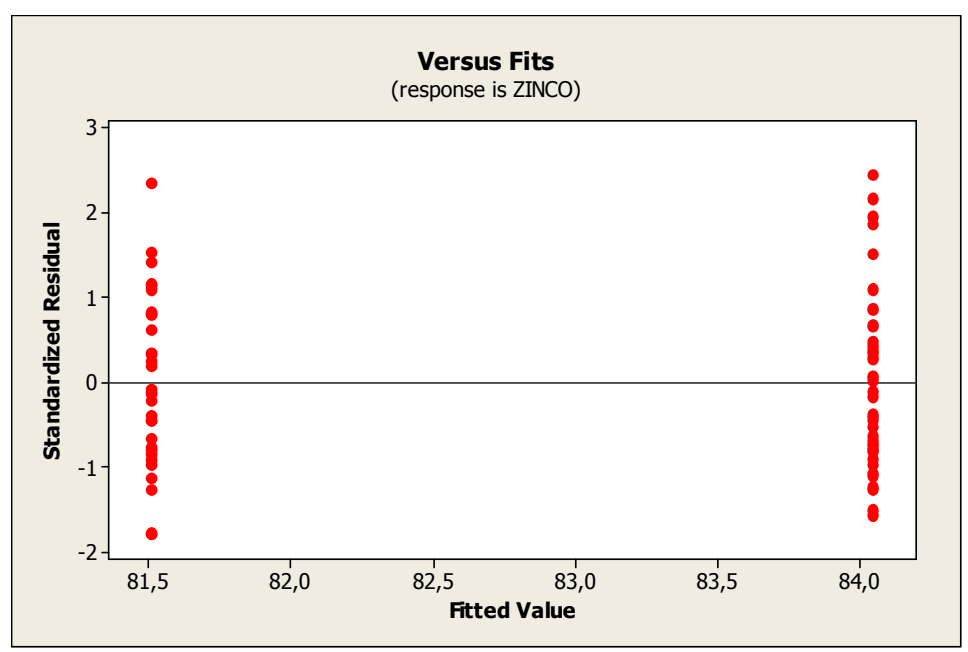

\section{Residual Histogram for ZINCO}

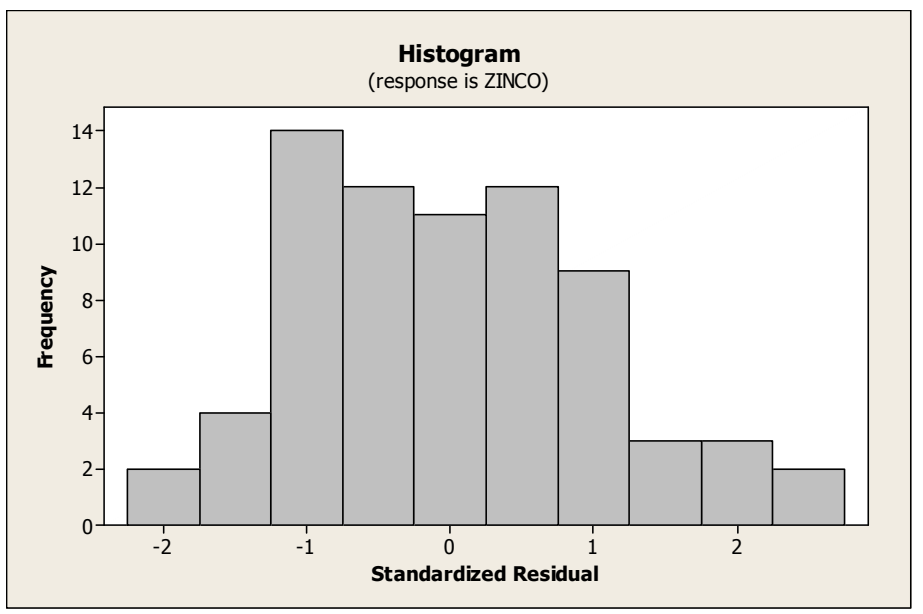




\section{Probability Plot of RESI4}

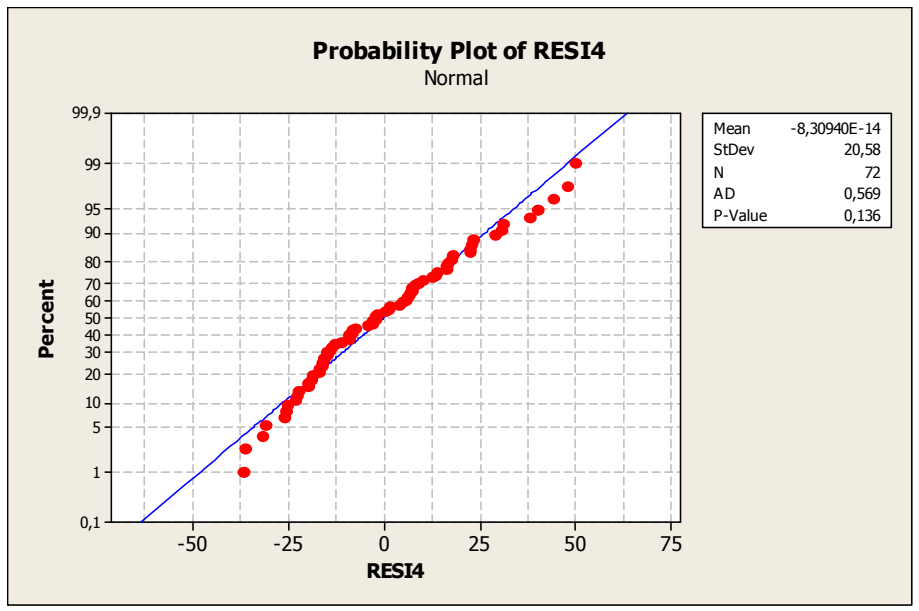

Correlations: ZINCO; IMC

Pearson correlation of ZINCO and $\mathrm{IMC}=0,430$

$\mathrm{P}-$ Value $=0,006$

Regression Analysis: ZINCO versus IMC

The regression equation is

$\operatorname{ZINCO}=36,1+2,08$ IMC

40 cases used, 48 cases contain missing values

$\begin{array}{lrrrrr}\text { Predictor } & \text { Coef } & \text { SE Coef } & \text { T } & \text { P } \\ \text { Constant } & 36,10 & 15,81 & 2,28 & 0,028 \\ \text { IMC } & 2,0777 & 0,7083 & 2,93 & 0,006\end{array}$

$\mathrm{S}=17,9522 \quad \mathrm{R}-\mathrm{Sq}=18,5 \% \mathrm{R}-\mathrm{Sq}(\operatorname{adj})=16,3 \%$ 
Analysis of Variance

$\begin{array}{lrrrrr}\text { Source } & \text { DF } & \text { SS } & \text { MS } & \text { F } & \text { P } \\ \text { Regression } & 1 & 2773,1 & 2773,1 & 8,60 & 0,006 \\ \text { Residual Error } & 38 & 12246,7 & 322,3 & & \\ \text { Total } & 39 & 15019,8 & & & \end{array}$

Unusual Observations

$\begin{array}{rrrrrrr}\text { Obs } & \text { IMC } & \text { ZINCO } & \text { Fit } & \text { SE Fit } & \text { Residual } & \text { St Resid } \\ 78 & 31,9 & 110,40 & 102,38 & 7,59 & 8,02 & 0,49 \times \\ 81 & 20,0 & 122,00 & 77,62 & 3,17 & 44,38 & 2,51 \mathrm{R} \\ 85 & 32,8 & 134,00 & 104,31 & 8,21 & 29,69 & 1,86 \times \\ 87 & 31,6 & * & 101,67 & 7,37 & * & * x\end{array}$

$\mathrm{R}$ denotes an observation with a large standardized residual.

$\mathrm{X}$ denotes an observation whose $\mathrm{X}$ value gives it large leverage.

\section{Normplot of Residuals for ZINCO}

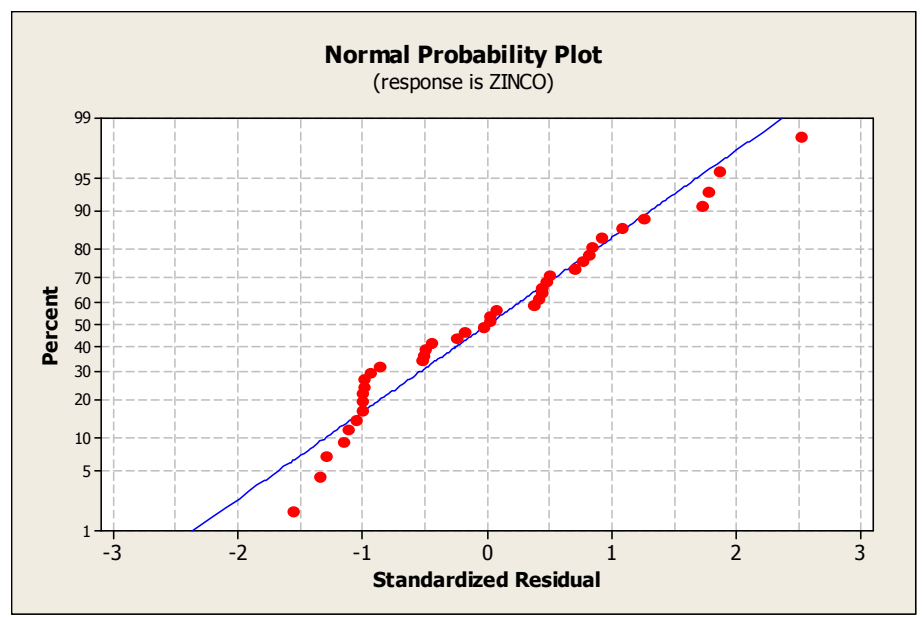

\section{Residuals vs Fits for ZINCO}




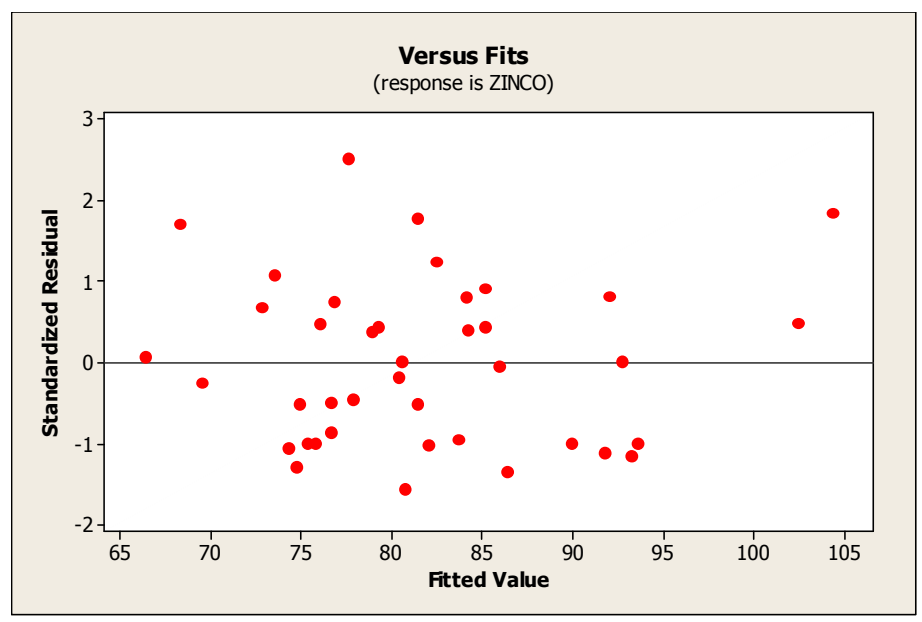

Residual Histogram for ZINCO

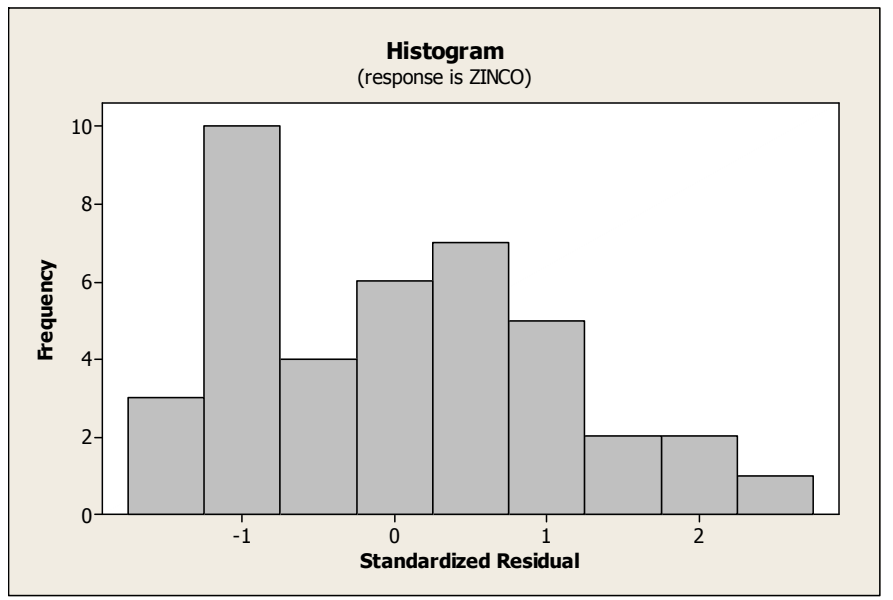

\section{Probability Plot of RESI5}

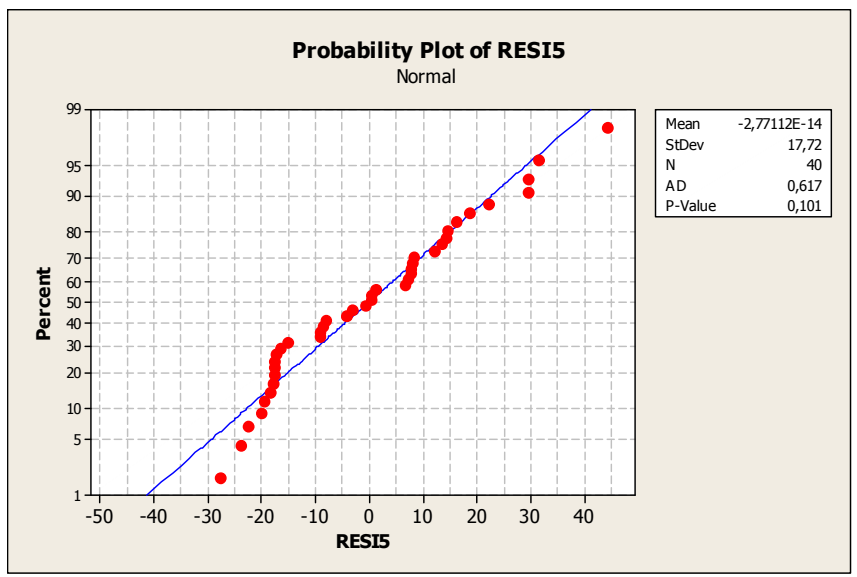




\section{Correlations: ZINCO; INFECÇÃO}

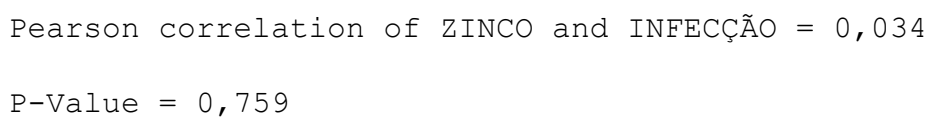

Regression Analysis: ZINCO versus INFECÇÃO

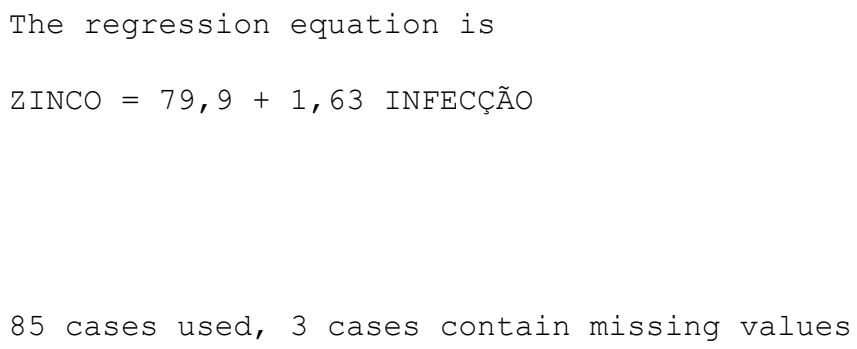




$\begin{array}{rrrrrrr}\text { Obs } & \text { INFECÇÃO } & \text { zINCO } & \text { Fit } & \text { SE Fit } & \text { Residual } & \text { St Resid } \\ 82 & 0,00 & 124,00 & 79,85 & 2,69 & 44,15 & 2,09 \mathrm{R} \\ 83 & 0,00 & 128,50 & 79,85 & 2,69 & 48,65 & 2,30 \mathrm{R} \\ 84 & 0,00 & 129,50 & 79,85 & 2,69 & 49,65 & 2,35 \mathrm{R} \\ 85 & 0,00 & 134,00 & 79,85 & 2,69 & 54,15 & 2,56 \mathrm{R}\end{array}$

\section{Normplot of Residuals for ZINCO}

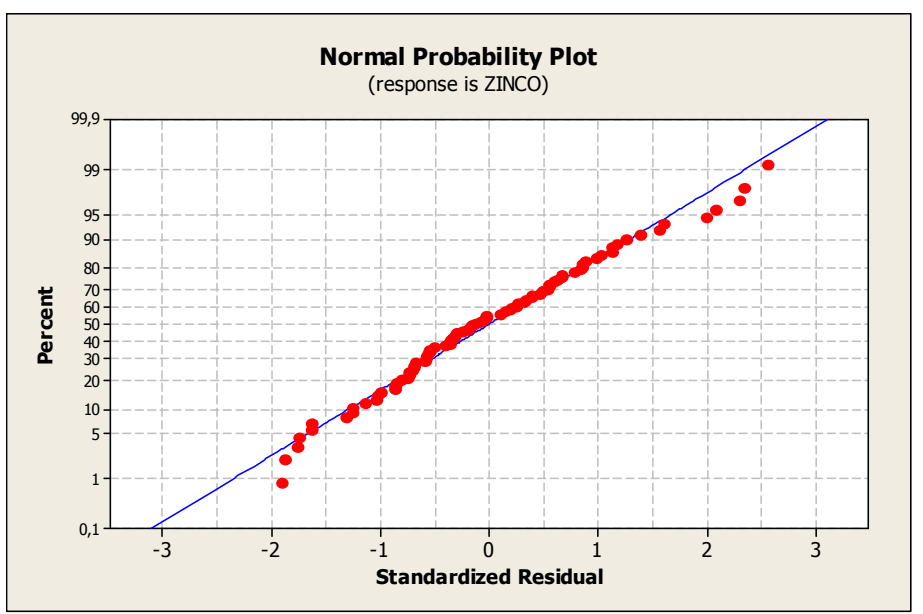

\section{Residuals vs Fits for ZINCO}

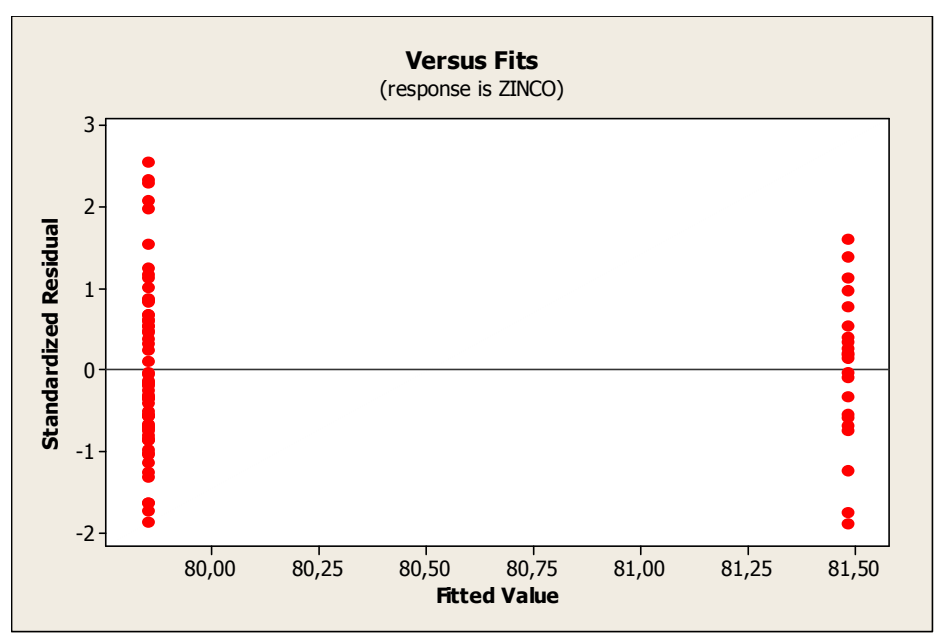


Residual Histogram for ZINCO

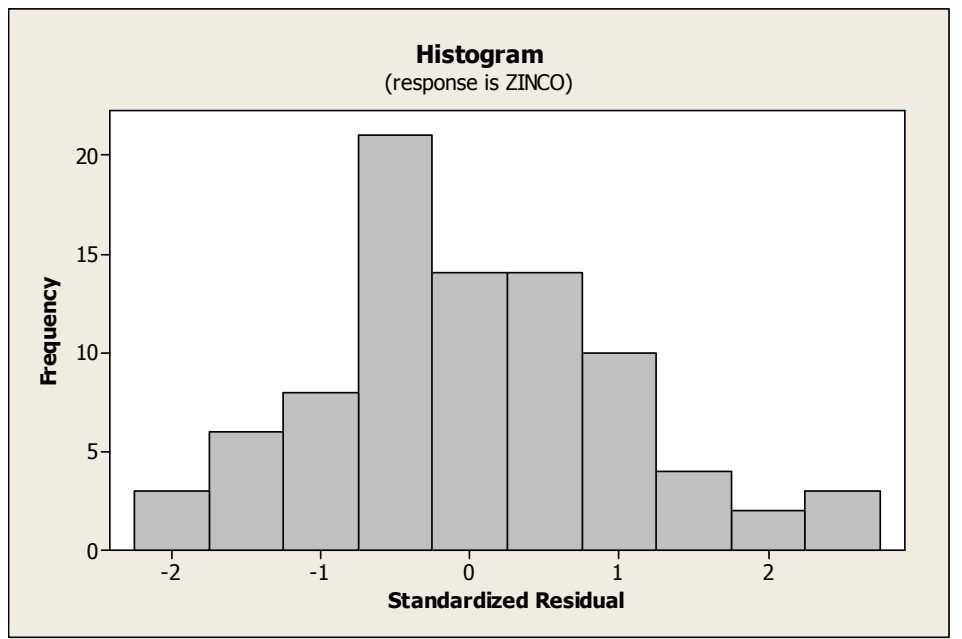

\section{Probability Plot of RESI6}

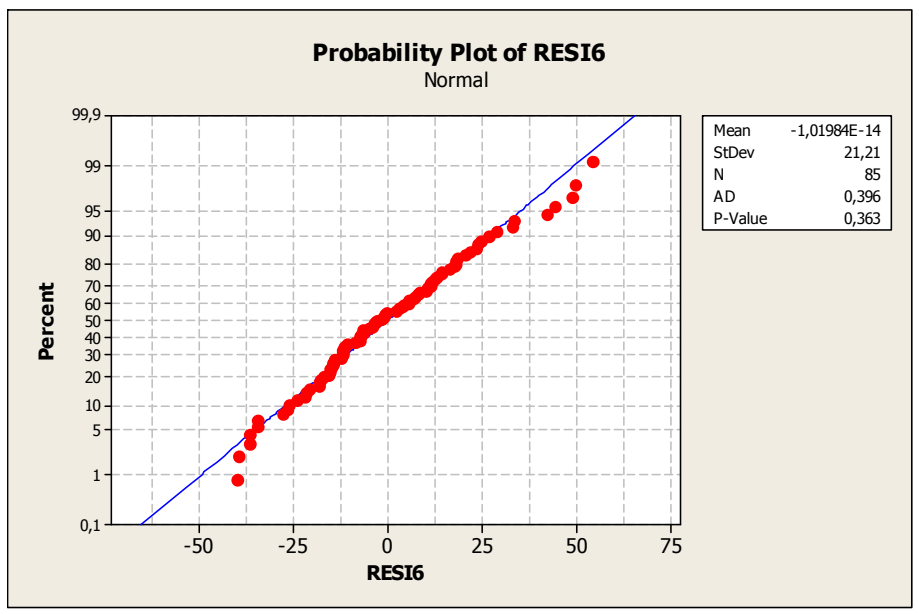




\section{ANEXO 2: CONSENTIMENTO LIVRE}

\section{PREVALÊNCIA DA DEFICIÊNCIA DE ZINCO NO IDOSO}

Pesquisador: Luis Fernando D’Albuquerque e Castro

Orientadora: Dra. Maria Aparecida Faustino Pires

Araguaina,

\section{Consentimento Livre}

$\mathrm{Eu}$, discuti com o Dr. Luis Fernando D'Albuquerque e Castro sobre a minha decisão em participar deste estudo. Ficou claro que farei exames complementares de avaliação clínica, dosagem do zinco plasmático. Fica claro para mim quais são os propósitos da pesquisa, os procedimentos a serem realizados, seus desconforto e riscos, as garantias de confidencialidade e de esclarecimentos permanentes. Ficou claro também que a minha participação é isenta de despesas. Concordo voluntariamente em participar deste estudo e poderei retirar o meu consentimento a qualquer momento, antes ou durante o mesmo, sem penalidades ou prejuízos, ou perda de qualquer benefício que eu possa ter adquirido.

Assinatura do paciente ou representante legal

Assinatura da testemunha

Declaro que obtive de forma apropriada e voluntária o Consentimento Livre e Esclarecido deste paciente ou representante legal para a participação neste estudo 
ANEXO 3: COMITÊ DE ÉTICA EM PESQUISA

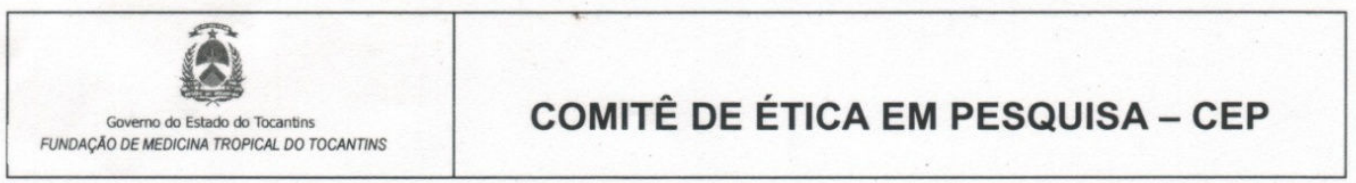

\begin{tabular}{|l|c|c|}
\hline \multicolumn{2}{|c|}{ PARECER CONSUBSTANCIADO } & \multirow{2}{*}{ PROCESSO No } \\
\cline { 1 - 2 } PROJETO DE PESQUISA & $X$ & 213 \\
\hline TRABALHO DE CONCLUSÃO DE CURSO & & \\
\hline
\end{tabular}

O parecer consubstanciado do relator será utilizado como subsídio para o Comitê de Ética em Pesquisa da Fundação de Medicina Tropical do Tocantins elaborar seu parecer final.

1 - Identificação da Proposta de Projeto de Pesquisa/Trabalho de Conclusão de Curso
\begin{tabular}{|l|}
\hline Titulo: \\
Estudo sobre a prevalência da deficiência de Zinco na população idosa. \\
\hline $\begin{array}{l}\text { Coordenador do Projeto ou Professor Orientador do TCC: } \\
\text { Luis Fernando D'Albuquerque e Castro }\end{array}$ \\
\hline Aluno(a) Participante (TCC): \\
\hline $\begin{array}{l}\text { Curso/ Faculdade: } \\
\text { Instituto-de pesquisas energéticas e nucleares - USP }\end{array}$ \\
\hline
\end{tabular}

2 - Análise do Projeto de Pesquisa/Trabalho de Conclusão de Curso

Projeto exeqüivel, apresentando-se como importante instrumento no auxilio ao tratamento dos idosos internados, trazendo benefícios a saúde da população como um todo.

2.1 - Objetivos e Adequação metodológica (Verificar a exeqüibilidade da proposta, isto é, se existe clareza do objeto, compatibilidade entre os objetivos, a fundamentação teórica e a metodologia ou plano de ação, evidenciando consistência entre objetivos, procedimentos, açōes de execuçăo da pesquisa e capacidade do proponente, demonstrada por outros trabalhos similares.)

- Objetivos dispostos com clareza, teoricamente bem fundamentados e executáveis através da metodologia proposta.

2.2 - Avaliação do Questionário a ser aplicado e do Termo de Consentimento Livre e Esclarecido:

- O questionário a ser aplicado está coerente com as informações que o pesquisador se propõe levantar;

- TCLE apresenta linguagem clara e objetiva, mas não disponibiliza os endereços, telefones e e-mails do pesquisador e do CEP-FMT para eventuais necessidades de contato entre as partes;

- O TCLE necessita, ainda, ser apresentado em duas vias, uma das quais deve permanecer com o sujeito de pesquisa.

2.3 - Revisão Bibliográfica

- Satisfatória. 
3 - Qualificação do Pesquisador/Orientador (Indicar os atributos do Pesquisador/Orientador, salientando a titulação e experiência compativel com a função de orientação; qualidade e regularidade da produção científica/tecnológica/artística, compativel com o projeto de pesquisa/Trabalho de Conclusão de Curso)

- Satisfatória.

4- Parecer conclusivo, recomendações e/ou sugestões:

- Recomenda-se adequação do TCLE e adaptação do cronograma.

5 - Pendências: (Enumerar sucintamente as pendências a serem sanadas pelo Coordenador do Projeto de Pesquisa/Trabalho de Conclusão de Curso

- Não se aplica.

6 - Parecer Consubstanciado

Aprovado $\square \quad$ Aprovado com recomendaçōes $\square \quad$ Pendências $\square \quad$ Não aprovado

\begin{tabular}{|l|l|}
\hline Assinatura do Coordenador do CEP: & Data da reunião: \\
&
\end{tabular}

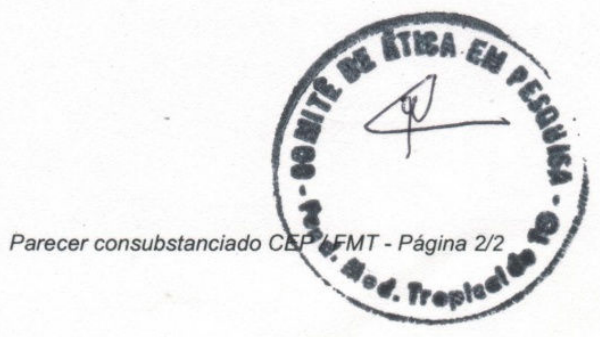


ANEXO 4: PLANILHA DE DADOS

\section{Legenda:}

Sexo: 0 - fem; 1 - masc

Tipo Alta: 0 - óbito; 1 - melhorado; 2 - outros

Infecção: 0 - sem; 1 - com

Proteína C: $0<6 ; 1>6$

Grupo de Paciente com Zinco plasmático menor que $70 \mu \mathrm{g} \cdot \mathrm{dL}^{-1}$

\begin{tabular}{|c|c|c|c|c|c|c|c|c|c|c|c|}
\hline NOME & IDADE & SEXO & TINTER & IPO DE & ECÇÃO & $\mathrm{Hb}$ & .INFÓCITO & ! PROTEINA C & ALBUMINA & ZINCO & IMC \\
\hline OPM & 78 & 0 & 10 & 0 & 0 & 8,30 & 1.350 & - & & 40 & \\
\hline BSF & 82 & 1 & 14 & 1 & 1 & 12,90 & 1.344 & - & & 41,8 & \\
\hline$A B F$ & 85 & 0 & 16 & 1 & 0 & 13,40 & 950 & - & & 43 & \\
\hline PAN & 80 & 1 & 16 & 1 & 1 & 12,30 & 936 & 0 & 3,60 & 44,9 & \\
\hline AMB & 65 & 1 & 10 & 0 & 0 & 11,80 & 1.339 & 0 & 2,70 & 45,2 & \\
\hline AVS & 76 & 1 & 5 & 1 & 0 & 9,70 & 1.962 & - & & 45,2 & \\
\hline MJA & 85 & 0 & 11 & 1 & 0 & 13,50 & 1.634 & 1 & 2,90 & 52,1 & 18,6 \\
\hline SV & 67 & 1 & 4 & 1 & 0 & 13,30 & 882 & 1 & 4,00 & 53,2 & 21,5 \\
\hline ASM & 84 & 1 & 15 & 1 & 1 & 13,10 & 888 & - & & 55,4 & \\
\hline FPS & 70 & 1 & 9 & 1 & 0 & 11,70 & 1.035 & 0 & 4,30 & 55,8 & 18,4 \\
\hline$A R$ & 79 & 1 & 9 & 1 & 0 & 13,30 & 1.572 & 1 & 4,10 & 57,9 & 18,9 \\
\hline SPM & 78 & 1 & 4 & 0 & 0 & 15,90 & 1.620 & 0 & 4,00 & 58,3 & 19,1 \\
\hline JPS & 68 & 1 & 11 & 1 & 0 & 14,00 & 1.620 & 1 & 3,60 & 58,9 & \\
\hline AAP & 84 & 0 & 9 & 1 & 0 & 7,10 & 1.220 & 0 & 2,40 & 61,5 & 19,53 \\
\hline RAS & 88 & 1 & 9 & 1 & 0 & 8,30 & 1.139 & 1 & 1,90 & 61,5 & \\
\hline CCA & 85 & 1 & 13 & 1 & 0 & 9,10 & 996 & 1 & 2,30 & 61,9 & \\
\hline CJS & 70 & 0 & 7 & 1 & 0 & 14,60 & 2.121 & 0 & 3,50 & 62,6 & 24,2 \\
\hline MFS & 74 & 1 & 15 & 0 & 0 & 13,10 & 1.366 & 1 & 3,70 & 64,2 & 22,1 \\
\hline OSM & 73 & 0 & 14 & 1 & 0 & 7,80 & 800 & 0 & 3,00 & 64,4 & \\
\hline FBM & 71 & 1 & 3 & 2 & 0 & 12,40 & 1.512 & - & 3,00 & 64,8 & \\
\hline DFM & 76 & 1 & 23 & 1 & 0 & 13,90 & 2.067 & 0 & 3,20 & 65,3 & 16,1 \\
\hline $\mathrm{JCL}$ & 80 & 0 & 9 & 1 & 0 & 12,30 & 2.500 & 1 & 3,10 & 65,6 & \\
\hline FJS & 93 & 1 & 14 & 1 & 1 & 10,10 & 1.131 & 0 & 2,70 & 65,9 & 18,7 \\
\hline MRN & 74 & 0 & 9 & 1 & 1 & 11,90 & 1.632 & 1 & 3,10 & 67,1 & 22,9 \\
\hline RAA & 76 & 0 & 10 & 1 & 0 & 15,40 & 1.914 & - & 3,70 & 67,6 & \\
\hline MPC & 69 & 0 & 5 & 2 & 0 & 11,00 & & 1 & 2,60 & 67,7 & 14,6 \\
\hline VMB & 71 & 1 & 7 & 1 & 0 & 13,40 & 798 & 0 & 3,50 & 67,9 & 19,5 \\
\hline ACC & 73 & 1 & 23 & 1 & 0 & 9,20 & 908 & 1 & 2,90 & 68,2 & \\
\hline CAS & 94 & 1 & 11 & 1 & 1 & 12,70 & 935 & 1 & 3,90 & 69 & \\
\hline STN & 79 & 1 & 1 & 1 & 0 & 14,00 & 1.736 & 1 & 2,90 & 69,1 & \\
\hline ABS & 74 & 0 & 13 & 1 & 1 & 9,00 & 2.900 & 1 & 3,10 & 69,9 & 20,1 \\
\hline
\end{tabular}


Grupo de pacientes com Zinco plasmático acima de $70 \mu \mathrm{g} \cdot \mathrm{dL}^{-1}$

\begin{tabular}{|c|c|c|c|c|c|c|c|c|c|c|c|}
\hline NOME & DADE & SEXO & T INTER | & IPO DE A & -TINFECÇÃO & $\mathrm{Hb}$ & INFÓCITO: & PROTEINA C & ALBUMINA & ZINCO & IMC \\
\hline JMC & 83 & 0 & 8 & 1 & 0 & 13,30 & 936 & 1 & 3,30 & 71,2 & \\
\hline MCS & 69 & 0 & 6 & 1 & 0 & 13,80 & & 0 & 4,40 & 72,2 & 21,8 \\
\hline JMSC & 76 & 0 & 10 & 1 & 0 & 10,90 & 800 & 0 & 3,90 & 72,3 & 26,8 \\
\hline PMS & 65 & 1 & 2 & 1 & 0 & 10,10 & 989 & & 3,50 & 72,4 & 25,9 \\
\hline MLS & 80 & 0 & 34 & 1 & 0 & 10,50 & 490 & 1 & 2,80 & 73 & \\
\hline MMR & 79 & 0 & 15 & 1 & 0 & 11,60 & 1.476 & 0 & 4,50 & 73,3 & 27,5 \\
\hline JAA & 85 & 1 & 9 & 2 & 1 & 14,00 & 1.353 & - & & 74,5 & \\
\hline JAA2 & 85 & 1 & 7 & 0 & 0 & 14,00 & 1.353 & 1 & 3,20 & 74,7 & \\
\hline ASA & 77 & 0 & 30 & 1 & 0 & 12,30 & 2.544 & 1 & 3,40 & 75,6 & \\
\hline $\mathrm{AF}$ & 80 & 1 & 22 & 1 & 0 & 11,20 & 1.449 & - & 4,60 & 76,3 & 27,64 \\
\hline SEM & 76 & 1 & 17 & 1 & 0 & 11,50 & 1.380 & 1 & 3,20 & 76,5 & \\
\hline JBM & 74 & 1 & 3 & 1 & 0 & 13,60 & 1.672 & 0 & 3,90 & 77,1 & 21,3 \\
\hline ASD & 68 & 0 & 3 & 2 & 0 & 12,30 & 1.183 & 0 & 4,10 & 78,7 & \\
\hline MNS & 74 & 1 & 7 & 1 & 0 & 15,00 & 1.020 & 0 & 3,30 & 79,2 & \\
\hline RPS & 67 & 0 & 32 & 2 & 1 & 8,60 & 2.872 & 6 & 2,70 & 79,7 & \\
\hline AMG & 77 & 1 & 14 & 1 & 1 & 14,70 & 871 & 1 & 3,30 & 80,9 & 21,4 \\
\hline RAS & 74 & 0 & 5 & 0 & 0 & 17,60 & 817 & 1 & 3,30 & 82 & \\
\hline KA & 87 & 1 & 5 & 1 & 1 & 10,10 & 700 & 1 & 3,40 & 84,5 & 19,23 \\
\hline JCV & 76 & 1 & 2 & 2 & 0 & 11,00 & 1.309 & 1 & 3,60 & 85,1 & 17,7 \\
\hline RPS & 79 & 1 & 7 & 1 & 1 & 9,20 & 1.210 & 0 & 3,20 & 85,3 & 24 \\
\hline OVP & 79 & 1 & 6 & 2 & 1 & 8,40 & 1.980 & 1 & 4,00 & 85,6 & 20,6 \\
\hline SCC & 82 & 1 & 6 & 1 & 0 & 11,10 & 1.800 & 0 & 4,09 & 86,5 & \\
\hline OR & 71 & 1 & 24 & 0 & 1 & 12,70 & 1.449 & & 3,60 & 87 & 20,76 \\
\hline TDM & 75 & 0 & 10 & 1 & 0 & 11,40 & 2.265 & 0 & 3,20 & 88 & \\
\hline JCS & 66 & 1 & 12 & 1 & 1 & 11,70 & 1.035 & 0 & 2,60 & 88,5 & 22.95 \\
\hline JAT & 88 & 1 & 8 & 1 & 0 & 12,90 & 880 & 1 & 3,80 & 89,7 & \\
\hline JAT2 & 88 & 1 & 3 & 0 & 1 & 11.80 & 592 & - & & 89,7 & \\
\hline FS & 83 & 1 & 13 & 1 & 0 & 14,90 & 2.535 & 1 & 3,10 & 90,2 & 19,6 \\
\hline VCC & 79 & 1 & 13 & 1 & 0 & 16,80 & 720 & 1 & & 91,3 & \\
\hline PEA & 70 & 1 & 6 & 1 & 0 & 13,00 & 1.045 & 1 & 3,00 & 91,4 & 23,14 \\
\hline TP & 81 & 1 & 27 & 1 & 0 & 6,60 & 816 & 1 & 2,80 & 92,3 & 18 \\
\hline $\mathrm{CF}$ & 78 & 0 & 6 & 1 & 1 & 13,00 & 2.244 & - & 4,00 & 92,9 & 23,61 \\
\hline JPC & 79 & 1 & 8 & 1 & 0 & 12,90 & 936 & 1 & 4,30 & 93 & 27,25 \\
\hline FRS & 65 & 1 & 7 & 1 & 0 & 12,20 & 990 & 6 & 3,90 & 94 & \\
\hline PMS & 65 & 1 & 9 & 1 & 0 & 10,10 & 989 & 0 & 3,50 & 94 & \\
\hline MM & 81 & 1 & 11 & 1 & 0 & 15,60 & 2.640 & 1 & 3,70 & 97,6 & \\
\hline MAS & 75 & 0 & 4 & 0 & 1 & 14,50 & 2.665 & 1 & 3,00 & 97,8 & 15,5 \\
\hline OPA & 75 & 0 & 4 & 1 & 0 & 12,50 & 1.089 & 0 & 4,40 & 97,8 & \\
\hline$A J B$ & 73 & 1 & 2 & 1 & 0 & 13,90 & 968 & 0 & 3,80 & 98 & \\
\hline CSM & 66 & 0 & 3 & 1 & 0 & 15,40 & 1.870 & 0 & 4,10 & 98,4 & 23,1 \\
\hline EPS & 69 & 1 & 14 & 1 & 0 & 12,10 & 1.178 & 1 & 3,30 & 101,4 & 23,6 \\
\hline ACS & 71 & 1 & 18 & 1 & 1 & 14,40 & 1.800 & 1 & 2,60 & 101,9 & \\
\hline PAS & 83 & 1 & 11 & 1 & 0 & 15,00 & 1.863 & 0 & 4,20 & 103,8 & \\
\hline AGS & 84 & 1 & 38 & 1 & 0 & 7,80 & 1.480 & 0 & 3,60 & 104,6 & 22,3 \\
\hline RCS & 79 & 0 & 7 & 2 & 1 & 13,80 & 2.376 & 0 & 3,70 & 105 & \\
\hline JBS & 77 & 1 & 7 & 1 & 0 & 12,40 & 1.009 & 1 & 4,80 & 106,5 & 26,9 \\
\hline JNG & 69 & 1 & 15 & 1 & 1 & 13,00 & 2.291 & 0 & 4,10 & 110,4 & 31,9 \\
\hline JAS & 73 & 0 & 11 & 1 & 0 & 11,00 & 3.200 & 0 & 3,70 & 112,8 & 21,8 \\
\hline BSF & 88 & 1 & 3 & 0 & 1 & 10,80 & 1.254 & 1 & 2,30 & 114,9 & \\
\hline$A F$ & 85 & 0 & 12 & 1 & 0 & 12,30 & 1.710 & 1 & 3,70 & 122 & 19,98 \\
\hline MDA & 88 & 1 & 5 & 1 & 0 & 14,40 & 2.475 & 1 & 3,30 & 124 & \\
\hline AS & 87 & 0 & 13 & 1 & 0 & 13,80 & 1.520 & 1 & 4,00 & 128,5 & \\
\hline ASN & 70 & 1 & 7 & 1 & 0 & 16,60 & 1.495 & 0 & 4,70 & 129,5 & \\
\hline JAV & 75 & 1 & 4 & 1 & 0 & 11,00 & 901 & 1 & 4,20 & 134 & 32,83 \\
\hline $\mathrm{AL}$ & 67 & 0 & 12 & 1 & 0 & 13,00 & 1.100 & 1 & 3,10 & 100.5 & 37.39 \\
\hline GAS & 75 & 1 & 9 & 1 & 1 & 11,90 & 1.970 & 1 & 2,60 & 89.6 & 31,56 \\
\hline ADA & 78 & 1 & 3 & 1 & 1 & 9,50 & 2.250 & 1 & 2,20 & 97.4 & \\
\hline
\end{tabular}

